\title{
SPECTRAL ANALYSIS OF THE
}

ENERGY EXCHANGE AT OWS NOVEMBER

Kevin Merle Rabe 



\section{NAVAL POSTGRAUUATE SCHOOL Monterey, Galifornia}

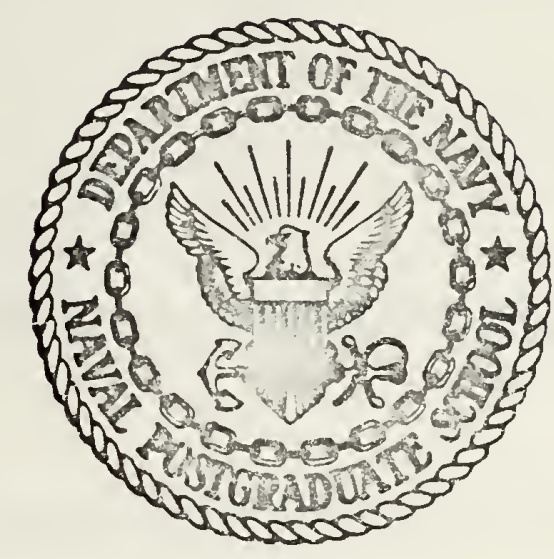

\section{THESIS}

Spectral Analysis of the

Energy Exchange at OWS NOVEMBER

by

Kevin Merle Rabe

March 1975

Thesis Advisor:

R. H. Bourke

Approved for public release; distribution unlimited. 



\begin{tabular}{|c|c|}
\hline REPORT DOCIJMENTATION PAGE & $\begin{array}{c}\text { I:EAD INSTRUCTIONS } \\
\text { BEFORE COMPLET:NG FORM }\end{array}$ \\
\hline $\begin{array}{l}\text { 4. TITLE (and Subitio) } \\
\text { Spectral Analysis of the Energy. } \\
\text { Exchange at OWS NOVEMBER }\end{array}$ & $\begin{array}{l}\text { 5. TYPE OF REPORT A PERIOD COVERED } \\
\text { Master's Thes is } \\
\text { March } 1975\end{array}$ \\
\hline $\begin{array}{l}\text { 7. AUTHOR(a) } \\
\text { Kevin Merle Rabe }\end{array}$ & 8. CONTRACT OR GRANT NUMBER(०) \\
\hline \multirow{2}{*}{$\begin{array}{l}\text { 11. CONTROLLING OFFICE NAME AND ADDRESS } \\
\text { Naval Postgraduate School } \\
\text { Monterey, CA } 93940\end{array}$} & $\begin{array}{l}\text { 12. REPORT DATE } \\
\text { March } 7975\end{array}$ \\
\hline & $\begin{array}{l}\text { 13. NUMBER OF PAGES } \\
108\end{array}$ \\
\hline \multirow[t]{2}{*}{ 14. MONITORING AGENCY NAME A ADDRESS(If dilforent (rom Controlline OUllce) } & $\begin{array}{l}\text { 15. SECURITY CLASS. (ol thie roport) } \\
\text { UNCLASSIFIED }\end{array}$ \\
\hline & $\begin{array}{l}\text { 15.. DECLASSIFICATION/DOWNGRADING } \\
\text { SCHEDULE }\end{array}$ \\
\hline
\end{tabular}

16. DISTRIBUTION STATEMENT (OF thl ROPOPI)

Approved for public release; distribution unlimited.

17. DISTRIBUTION STATEMENT (of the ebeteact entered in Block 20, If different fiom Report)

18. SUPPLEMENTARY NOTES

19. KEY WOROS (Continue on revoree elde If neceecery and ldentlty by block number)

Spectral Analysis

OWS November

Heat Budget

Sea-Surface Temperature

20. ABSTRACT (Conilnue on reverae elde Il neceesery and ldentlty by block number)

Oceanographic and meteorological data from Ocean Weather Station (OWS) NOVEMBER were analyzed by statistical and spectral methods in order to describe the nature and periodicities of the air-ocean energy exchange. Salinity data from 1968 through 1970 were compared with daily observed parameters commonly associated with changes in the salinity. Regression analysis showed surface salinity to be highly

DD I FORM 1473 EDITION OF I NOV BS IS OESOLETE (Page 1)
$S / N 0102-014-66011$

\section{UNCLASSIFIED}

SECURITY CLASSIFICATION OF THISPAGE (WhEn DAIA Entured) 

20. Abstract (continued)

correlated with surface pressure which is interpreted as the surface salinity responding to a baroclinic transport. At this location none of the classical parameters usually associated with fluctuations in the surface salinity were highly correlated.

Twenty-four years (1947-1970) of daily averaged, observed climatological values, as well as heat exchange terms computed from them, were compared with the sea-surface temperature time series and spectrally analyzed. The spectral analysis yielded spectral density, phase and coherence functions indicating the response of surface temperature to the heat exchange terms. From these it was evident that at the yearly cycle the net heat exchange, which is shown to be equal to the horizontal heat advection, is of the same order of importance as solar radiation in its effect on the fluctuation of sea-surface temperature. 



\title{
Spectral Anaiysis of the Energy Exchange at OWS NOVEMBER
}

\author{
by \\ Kevin Merle Rabe \\ Environmental Prediction Research Facility \\ B.A., University of Washington, 1970 \\ B.S., University of Washington, 1970
}

Submitted in partial fulfillment of the requirements for the degree of

MASTER OF SCIENCE IN OCEANOGRAPHY

from the

NAVAL POSTGRADUATE SCHOOL

March 1975 

Oceanographic and meteorological data from 0 cean Weather Station (OWS) NOVEMBER were analyzed by statistical and spectral methods in order to describe the nature and periodicities of the air-ocean energy exchange. Salinity data from 1968 through 1970 were compared with daily observed parameters commonly associated with changes in the salinity. Regression analysis showed surface salinity to be highly correlated with surface pressure which is interpreted as the surface salinity responding to a baroclinic transport. At this location none of the classical parameters usually associated with fluctuations in the surface salinity were highly correlated.

Twenty-four years (1947-1970) of daily averaged, observed climatological values, as well as heat exchange terms computed from them, were compared with the sea-surface temperature time series and spectrally analyzed. The spectral analysis yielded spectral density, phase and coherence functions indicating the response of surface temperature to the heat exchange terms. From these it was evident that at the yearly cycle the net heat exchange, which is shown to be equal to the horizontal heat advection, is of the same order of importance as solar radiation in its effect on the fluctuation of sea-surface temperature. 

TABLE OF CONTENTS

I. INTRODUCTION

A. OBJECTIVE

B. REVIEW OF THE LITERATURE

1. The Subtropic Region

2. Surface Circulation

3. The Subarctic Transition Zone -.....-.-16

4. Average Annual Heat Balance -......-.-20

5. Surface and Subsurface

Temperature Anomalies _................. 21

6. Recent Studies of Pacific Air-Sea

Interactions -............. 23

I I. TREATMENT OF THE DATA

A. SOURCES -

B. TREATMENT OF THE DATA TIME SERIES -......... 26

C. THE HEAT BUDGET EQUATIONS $\ldots \ldots \ldots$

D. COMPUTATION OF PRECIPITATION

E. COMPUTATION OF THE ENERGY SPECTRUM -....... 33

F. COMPUTATION OF THE CROSS-SPECTRAL DENSIY -... 34

G. COMPUTATION OF THE COHERENCE FUNCTION $\ldots \ldots$

H. COMPUTATION OF THE PHASE ANGLE _........... 36

III. RESULTS

A. REGRESSION ANALYSIS $\ldots \ldots$

B. SPECTRAL ANALYSIS -......... 46

IV. CONCLUSIONS 

APPENDIX A - THE AUTOCORRELATION FUNCTIONS -....... 77 APPENDIX B - FIFTEEN-YEAR TIME SERIES SEGMENTS _..... 95 LIST OF REFERENCES INITIAL DISTRIBUTION LIST 



\section{LIST OF TABLES}

I. Correlation coefficients by season, resulting from a linear regression analysis of surface temperature, surface salinity, and 50 meter temperature data, 1968 through $1970 \ldots 44$

II. Correlation coefficients, all parameters vs surface salinity

III. Contribution of the yearly cycle to the total variance

IV. Spectral results for the solar radiation, sea-surface temperature, and cloud cover

at the yearly cycle

v. Months of maximum and minimum value for the surface temperature and the heat budget terms -..- 52

VI. Spectral results for the back radiation and related parameters at the yearly cycle ........ 53

VII. Spectral results for the heat of evaporation and related parameters at the yearly cycle -.... 60

VIII. Spectral results for the convective heat vs the SST at the yearly cycle

IX. Spectral results for the net radiation and related parameters at the yearly cycle 



\section{LIST OF FIGURES.}

1. Oceanographic climatic regions of the North Pacific ocean showing the location of 0cean Weather Station November at $30^{\circ}$ north, $140^{\circ}$ west - 15

2. Winter surface circulation patterns for the



3. Summer surface circulation patterns for

the North Pacific Ocean

4. Monthly means of the observed surface temperatures, 1968 through 1970 and Robinson's

(1971) long-term monthly means

5. Total monthly meridional transport between $135^{\circ}$ and $145^{\circ}$ west at $30^{\circ}$ north during 1969 and 1970 .

Positive northward, negative southward ........ 40

6. Monthly means of observed surface salinity,

1968 through 1970

7. Monthly temperature and salinity modal points resulting from the bivariate analysis of the data, 1968 through $1970 \ldots$

8. Spectral density, coherence and phase for the SST vs the solar radiation

9. Spectral density, coherence and phase for the SST vS cloud cover

10. Spectral density, coherence and phase for

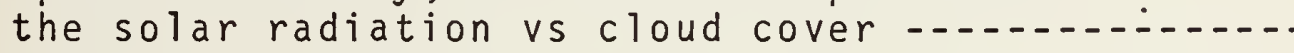

11. Spectral density, coherence and phase for

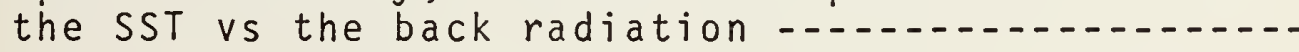

12. Spectral density, coherence and phase for

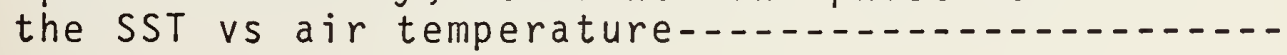

13. Spectral density, coherence and phase for the SST vs the air-sea temperature difference -...-

14. Spectral density, coherence and phase for the SST vs the vapor pressure of the air

15. Spectral density, coherence and phase for

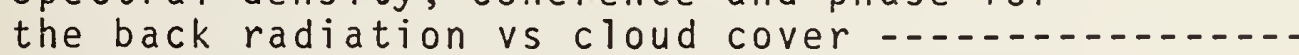



16. Spectral density, coherence and phase for the SST vs the heat of evaporation

17. Spectral density, coherence and phase for the SST vs the vapor pressure difference ....... 63

18. Spectral density, coherence and phase for the SST vs the wind speed

19. Spectral density, coherence and phase for the SST vs the wind speed squared

20. Spectral density, coherence and phase for the SST vs the evaporation

21. Spectral density, coherence and phase for the SST vs the convective heat

22. Spectral density, coherence and phase for the SST vs the net radiation

23. Spectral density, coherence and phase for the SST vs the surface pressure

24. Spectral density, coherence and phase for the net radiation vs the surface pressure -...-.- 74 



\section{LIST OF SYMBOLS}

SST

Sea-surface temperature $\left({ }^{\circ} \mathrm{C}\right)$

PS

Surface pressure (mb)

W

Wind speed $\left(\mathrm{m} \mathrm{sec}^{-1}\right)$

$w^{2}$

Wind speed squared

E

Evaporation $(\mathrm{cm})$

P

Precipitation $(\mathrm{cm})$

$T_{a}$

Air temperature $\left({ }^{\circ} \mathrm{C}\right)$

$T_{W}$

Water temperature $\left({ }^{\circ} \mathrm{C}\right)$

$C L$

cloud cover, in tenths of sky covered

$e_{w}$

Vapor pressure over water (mb)

e

Vapor pressure of the air (mb)

$C_{D}$

The drag coefficient

$S$

Salinity $(\% \circ)$

QS

Solar radiation (cal $\mathrm{cm}^{-2} \mathrm{day}^{-1}$ )

QB

Back radiation (cal $\mathrm{cm}^{-2} \mathrm{day}^{-1}$ )

QE

Heat of evaporation (cal $\mathrm{cm}^{-2} \mathrm{day}^{-1}$ )

QC

Convective heat $\left(\mathrm{cal} \mathrm{cm}^{-2} \mathrm{day}^{-1}\right)$

QN

Net radiation (cal $\mathrm{cm}^{-2} \mathrm{day}^{-1}$ ) 



\section{ACKNOWLEDGMENTS}

The author wishes to thank Dr. Robert Bourke for his assistance and guidance, both during the course of this research and the preparation of this thesis, and also, Dr. Dale Leipper and Dr. Edward Thornton for their constructive review of the text. Thanks are also extended to various personnel at both the Environmental Prediction Research Facility and Fleet Numerical weather Central through whose assistance the opportunity to conduct this research was made possible. They are: Captain G. D. Hamilton, past Commanding Officer at EPRF, Captain R. C. Sherar, present Commanding Officer, Dr. Taivo Laevastu, my immediate supervisor, and Captain C. Barteau, formerly Chief of Development at FNWC. 



\section{INTRODUCTION}

A. OBJECTIVE

Sea-surface temperature is one of the most important parameters in any study of air-sea interaction. Anomalies of this parameter, measured over periods of a week to several months, have been linked to gross atmospheric effects. However, few studies have investigated the time response of the sea-surface temperature over long periods to those factors which govern its fluctuations.

Until the more recent decades such a study would have been limited by both instrumentation and general paucity of data. This resulted in reliance upon monthly or annual means to describe the state of the ocean. The advent of the ocean weather station program in the $1940^{\prime} s$, and recently, the use of satellites has greatly increased the amount and frequency of data available to the researcher. Also, the advent of high speed computers has made the use of time series analysis routines relatively easy and inexpensive to use.

The past limitations made statistical studies of changes of surface temperature on time scales of a day or less, difficult. However, daily fluctuations can be quite informative. If advection is ignored, the sea-surface temperature at OWS NOVEMBER was found to fluctuate primarily in response to the day to day changes in air temperature, the amount of 

insolation, wind-wave mixing, and the amount of cloud cover as well as the elevation of the sun. The magnitude of these diurnal fluctuations can be as large as the monthly fluctuations.

Sea-surface temperature fluctuations are important in many oceanographic parameters, such as the stability of the water column. This, in turn, is of great consequence in sound propagation. Anomalies of sea-surface temperature, likewise, have been linked to climatic variations over the ocean .

The salinity is important in that it affects the density of sea water. Thus, it affects both vertical stability and sound propagation. Together with the water temperature, one can infer transport characteristics of a region based on water mass analysis.

This study examines changes occurring at the surface of the ocean over time scales varying from one day to several years. The two parameters of primary interest are the sea-surface temperature and surface salinity. The area of study is Ocean weather Station (OWS) NOVEMBER located at $30^{\circ}$ North and $140^{\circ}$ West. The data used are synoptic data collected by the United States Coast Guard at this position. The data are of two types: hydrographic Nansen cast data and shipboard meteorological observations.

The thesis is organized to first present correlations of the primary parameters versus various meteorological parameters. These correlations provide an indication of 

those parameters which can be used as predictors for the sea-surface temperature and salinity.

Secondly, a spectral analysis of the data is made. From this, the synoptic atmospheric mechanisms which cause the fluctuations of the sea-surface temperature are identified. Periods of high spectral energy, along with their corresponding phase and coherence relationships are examined to gain insight into the time scales associated with each mechanism.

\section{B. REVIEW OF THE LITERATURE}

1. The Subtropic Region

Ocean weather Station NOVEMBER, located at $30^{\circ}$

North and $140^{\circ}$ West, lies within what Tully (1964) defines as the Pacific Subtropical Region. Figure 1 shows its location in comparison to other major features of the North Pacific 0cean. The region is characterized by three dominant conditions: an excess of evaporation over precipitation throughout the year, the occurrence of convective mixing, and seasonal heating and cooling patterns which result in a pronounced seasonal thermocline.

The excess of evaporation over precipitation (E-P), has a distinct effect on the other two traits. Tully (1964) estimated E-P to be approximately $80 \mathrm{~cm}^{-1} \mathrm{yr}$ in the vicinity of OWS NOVEMBER. This leads to a removal of fresh water from the surface and acts as a driving force for the convective mixing. This mixing then contributes to the erosion of the seasonal thermocline. 



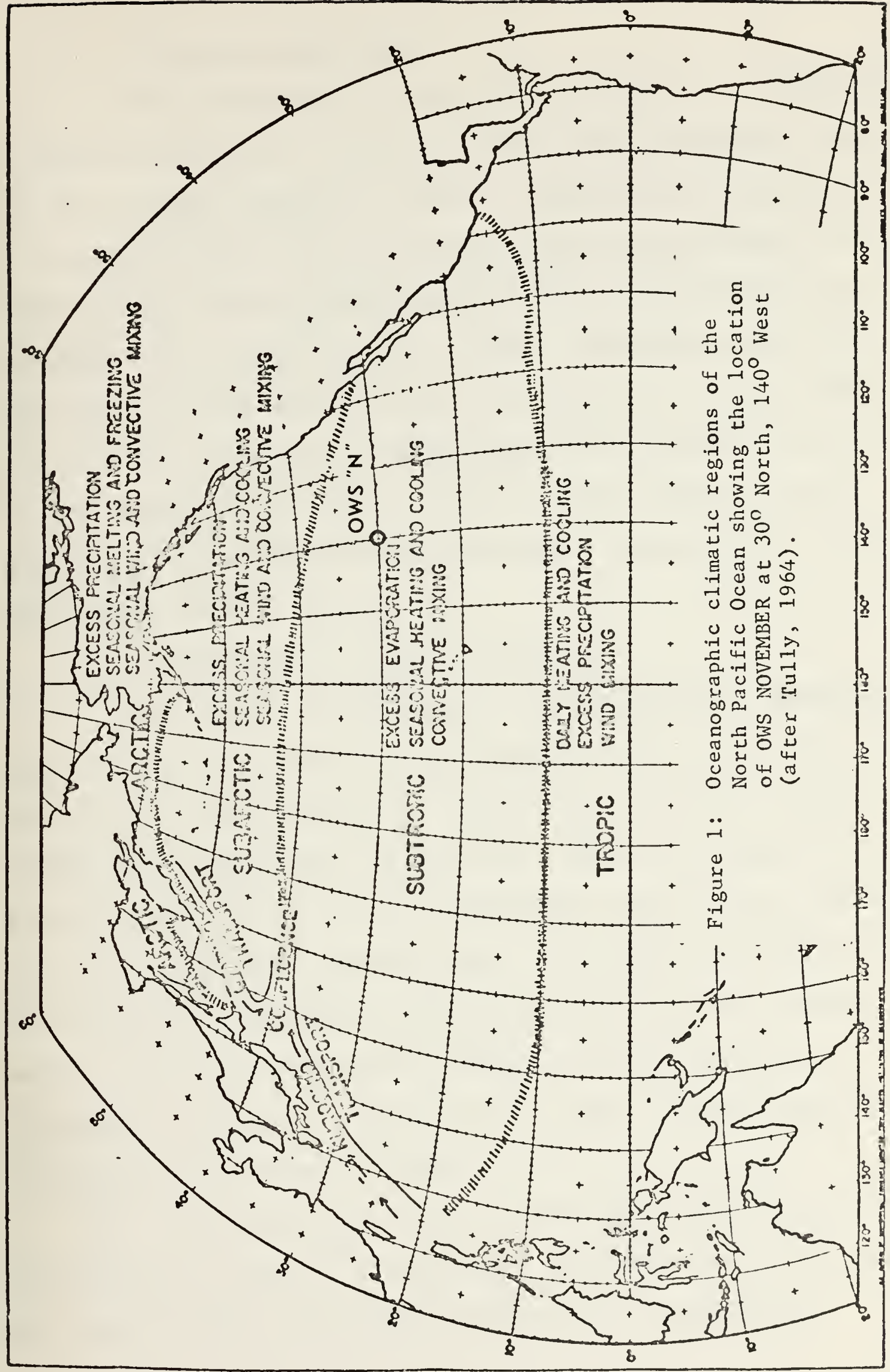




\section{Surface Circulation}

The subtropical region of the Pacific is dominated by the Pacific Gyre. Figures 2 and 3 show graphically how the gyre varies seasonally both in location and intensity. In the winter the gyre's axis is displaced northward; in summer it is shifted approximately $100 \mathrm{n} \mathrm{mi}$ southward and intensifies by approximately $0.2 \mathrm{kt}$. Throughout the year the current speed ranges from 0.1 to $0.3 \mathrm{kt}$. Hansen (1973) hypothesized that this intensification occasionally results in the advection of large volumes of cold subarctic water into the area surrounding OWS NOVEMBER, specifically during the period of 1968 through 1970.

\section{The Subarctic Transition Zone}

The North Pacific Gyre, linked with the Subarctic Gyre, is also involved in the formation of a transition zone which bounds the subtropical region to the north. Roden (1970) first described the subarctic transition zone as an area characterized by large temperature and salinity gradients and low hydrostatic stabilities. This oceanic front defines the boundary between the subtropical and subarctic water masses, varying in location between $30^{\circ}$ and $40^{\circ}$ North. Subsequent articles by Roden $(1971,1972)$ further described this zone in the North Pacific.

The transition zone is largely maintained by the surface wind stress. Its northern boundary is characterized by the subarctic water mass, resulting in temperature 


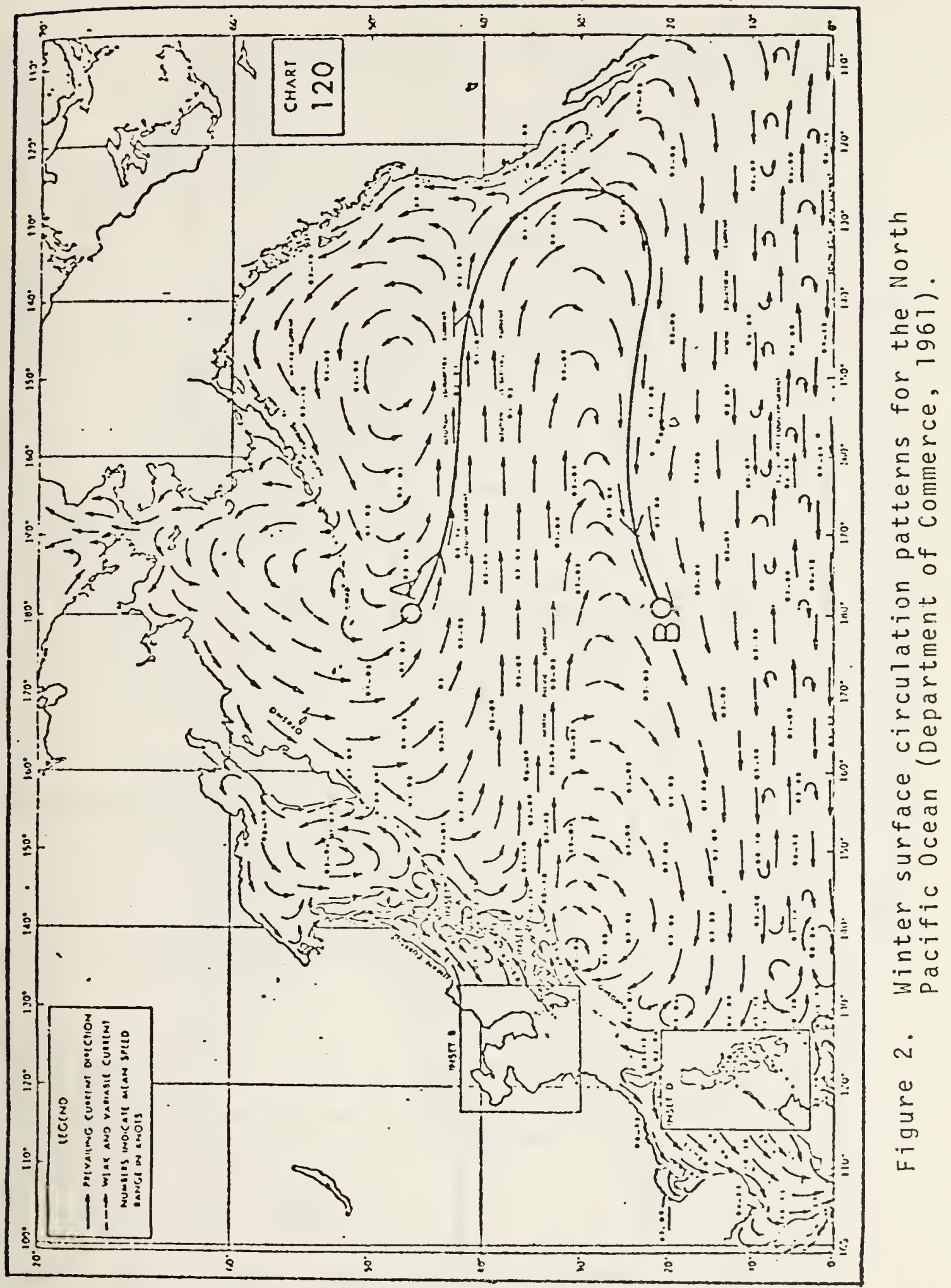




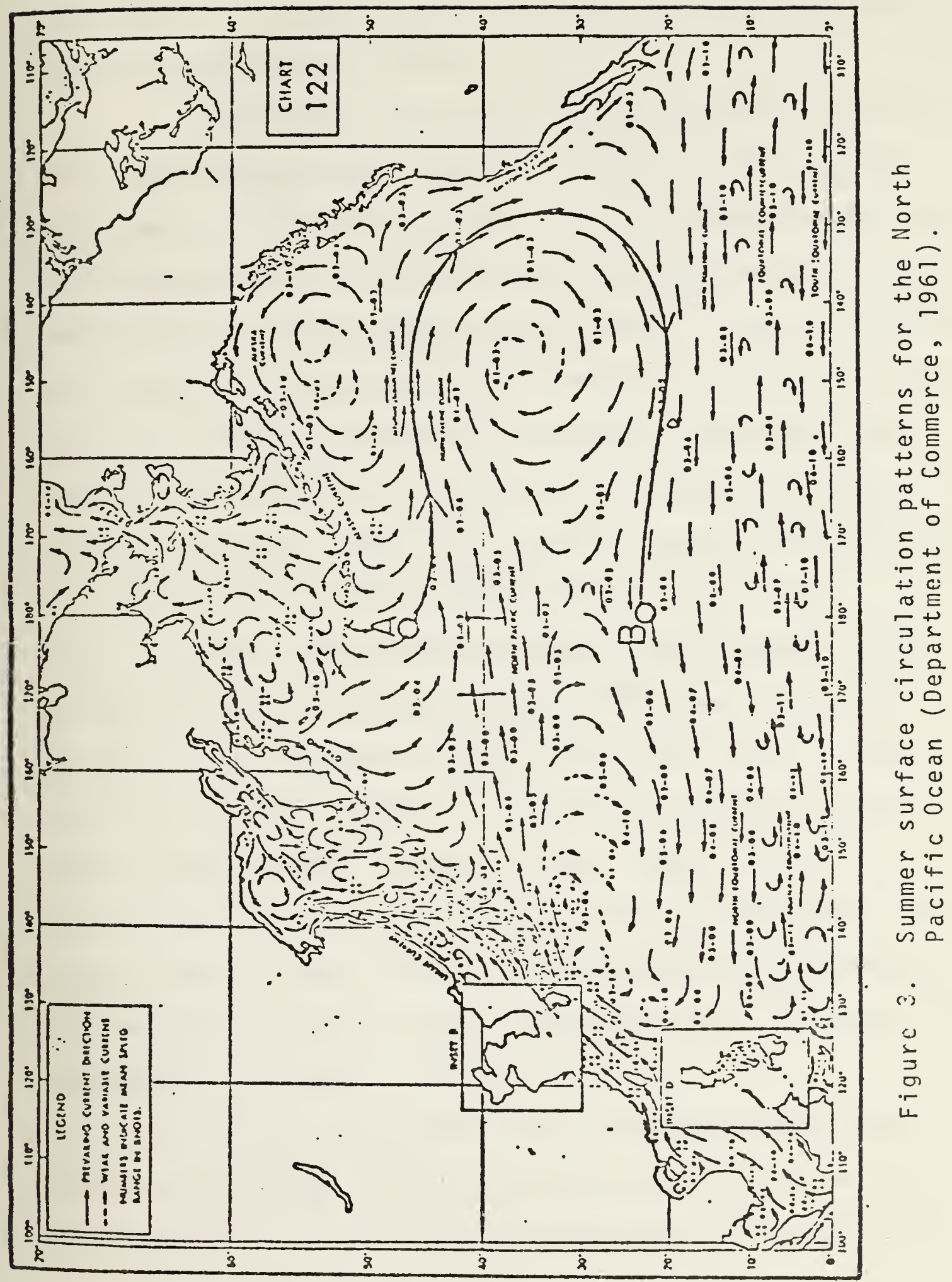


inversions, gravitational instabilities, a complicated sound velocity structure, and a disappearance of the subarctic halocline. It appears to lie in the area of $40 \mathrm{~N}$ to $45 \mathrm{~N}$ latitude throughout the year.

The southern boundary lies in the area of $30 \mathrm{~N}$ to $32 N$, depending upon the season, and is displaced to the north more in the winter months. It is characterized by sharp temperature gradients in the thermocline and vertical instabilities in the mixed, upper layers. A salinity minimum is a common occurrence at this boundary. Also, around $30 \mathrm{~N}$ there is a transition toward the higher salinities and higher temperatures of the subtropical water mass with salinities greater than $35 \%$ and a strong halocline located at a depth between $50 \mathrm{~m}$ and $100 \mathrm{~m}$.

Thus, the transition zone is defined by a deep salinity minimum, at approximately $500 \mathrm{~m}$ and a concurrent sound velocity minimum of less than $1480 \mathrm{~m} \mathrm{sec}^{-1}$. There is apparently both a seasonal and yearly variation in the position of the boundary (Seckel, 1968). Both the salinity minimum and sound velocity minimum rise as one goes further to the north. Roden (1970) also examined both barotropic and baroclinic motion in the transition zone and found that they rarely exceeded $5 \mathrm{~cm} \mathrm{sec}^{-1}$.

As the transition zone approaches North America, it turns to the southeast and becomes associated with the heat and salt flux divergence zones noted by Roden (1971) 
in the area of OWS NOVEMBER. These are related to flux divergencies which are linked to the presence of horizontal advection of salinity as has been noted by Hansen (1973).

\section{Average Annual Heat Balance}

Based upon an examination of the annual heat balance of the North Pacific Ocean and the prevalent circulation patterns, Wyrtki (1965) determined that there is a small amount of heat gain in the vicinity of OWS NOVEMBER. On the average, he estimated this gain to be approximately $251 \mathrm{y} \mathrm{day}^{-1}$ (where a langley, ly, $=1 \mathrm{cal} \mathrm{cm}^{-2}$ ).

Seckel (1970) computed the heat balance for the area of OWS NOVEMBER during the Trade Wind Zone Pilot Study. His studies showed that the average net radiation computed on a daily basis was approximately $37 y \mathrm{day}^{-1}$.

In a more recent study, Dorman (1974) studied 20 years of the heat balance at OWS NOVEMBER and separated it into two decades, 1951 through 1960 and 1961 through 1970. He found the two decades had distinctly separable heat balances, with the first decade having a deficit of $901 y \mathrm{day}^{-1}$ and the second a $401 \mathrm{y} \mathrm{day}^{-1}$ deficit. These results were based on three-hourly meteorological observations. Dorman ascribed this difference to the change in climatic regimes described by Namias (1970, 1971), which resulted in displacement of cooler waters in the North Central Pacific by warmer water, beginning approximately in 1961. 


\section{Surface and Subsurface Temperature Anomalies}

The sea-surface temperature and its anomalies have been widely studied in their relationships to both oceanographic and meteorological forecasting. Emphasis has also been placed on subsurface temperature anomalies. Beland (1971) illustrated their considerable importance to the flow of energy between the sea and the atmosphere. Bernstein (1974) used subsurface temperature measurements in the trade wind region northeast of Hawaij to identify mesoscale eddies drifting westward.

Namias (1971) in his study of an anomalous warming of the northeastern Pacific from May to June 1968, found the anomaly extended to a depth of $122 \mathrm{~m}$. The warming, as a whole, was attributed to increased insolation and horizontal convergence of surface waters with its associated downwelling. The warming was identified with the development and maintenance of a Pacific anticyclone in June of 1968. The depth of the anomaly was attributed to bulk heating and downward advection of the warmer surface waters.

Clark (1972) concluded that both advection and non-advective processes are vital in determining the nature of surface temperature anomalies. He hypothesized that advection is the more important process in the winter and spring seasons, while the non-advective processes dominate in the summer and fall. 

Beland (1971) in his study of the North Pacific, observed that about $50 \%$ of the near-surface temperature anomalies extended to at least $100 \mathrm{~m}$ depth. Most of these were negative anomalies in the months of March and April, apparently due to the distribution of heat throughout the upper layer by convective mixing. Positive anomalies were more common in December through February and were confined to the upper $30 \mathrm{~m}$. Whereas the negative anomalies were of a magnitude of $1.0^{\circ} \mathrm{C}$ or more, the positive anomalies were generally less than $1.0^{\circ} \mathrm{C}$.

Finally, Favorite and McClain (1973) reported that they could observe an orderly trans-Pacific movement of areas of anomalously warm and cold surface waters. These features were found to be quasi-permanent and apparently move around the North Pacific gyre, approximately 180 degrees out of phase and with periods of 5 to 6 years. These anomalies have been shown to have a great influence on the weather conditions off the west coasts of Canada and the United States, as shown by Namias and Born (1970).

From the above it can be noted that temperature anomalies, both surface and subsurface, and whether temporary or periodic, inhabit the region around OWS NOVEMBER, and in all probability, affect the location of the subarctic transition zone and the heat balance through the process of advection. 

6. Recent Studies of Pacific Air-Sea Interactions

In recent years there have been three studies

of the air-sea relationships at or around OWS NOVEMBER by different researchers using three different methods. Taken as a whole, they provide a logical progression, resulting in the methods utilized in this study. The first of these studies was carried out by Seckel and Yong in 1970, using harmonic analysis to study temperature and salinity fluctuations at Koko Head, Hawai, and Christmas Island. Hansen (1973) used regression methods to study surface and subsurface temperatures and salinities at OWS NOVEMBER. Dorman (1974) used a spectral approach on time series of meteorological values at OWS NOVEMBER, dividing the time series into two ten-year decades. Since each of these studies utilized a different approach, each will be described in some detail here.

Seckel and Yong (1970) utilized temperatures and salinities measured at two points in the North Central Pacific; Koko Head, Hawai, beginning in 1956 and running through 1969, and Christmas Island, beginning in 1954 and continuing through 1969. Their hypothesis was that fluctuations in the temperature and salinity time series reflected air-sea interaction processes (heat exchange, E-P) and oceanographic processes (advection, diffusion, etc.). Their approach used a Fourier series to provide a least squares fit to the observed values, which was done for each year of the available data. This approach expressed the 

temperature and salinity as a function of time. Phase angles and coefficients for each year of salinity and temperature data from both locations were computed and tabulated.

The results at Koko Head showed seasonal variability in the salinity, but not the temperature series. At both locations the annual cycle $(n=1)$ was the dominant cycle. Also of note were the 60- and 52-day cycles, ascribed by the authors to the presence of large geostrophic eddies. The Christmas Island results were quite similar except that they lacked evidence of the eddy-induced seasonal variations.

The next major method was a regression analysis used by Hansen (1973) in his study of temperature and salinity fluctuations at the surface, $50 \mathrm{~m}$, and $200 \mathrm{~m}$ at OWS NOVEMBER. His data were for 1968 through ig70 and consisted of daily hydrographic records. Deterministic approaches showed that the temperature system was seasonal so the data were divided into four seasonal records, February to April, etc., in three month segments corresponding to spring, Summer, etc. Regressions were then computed with the surface salinity, and $50 \mathrm{~m}$ and $200 \mathrm{~m}$ temperatures being regressed against the surface temperatures.

Most of the results showed little correlation, except occasionally during the spring and fall transition periods. Only a very poor correlation was found between the surface salinity and the surface temperature. From this, it 

was concluded that these seasonal correlations were due to the advection of water by the shifting of the subarctic transition zone.

The final approach was that utilized by Dorman (1974) who computed spectra for surface wind speed, air pressure, sea temperature, air temperature and dew-point temperature for the 10-year period 1961 through 1970. Spectra were also computed for each of the four seasons. From this it was found that the energy peaked significantly at the annual, diurnal and semi-diurnal periods. Variances were largest in the winter season and smallest in the summer season, except for the sea-surface temperature which had its largest variance in the spring and the smallest in the winter. The maximum spectral density, for all variables, was at the annual period. From the annual period the spectral densities followed a decrease to the shorter periods, where significant spikes at the diurnal and semi-diurnal periods were noted in many of the spectra. 


\section{TREATMENT OF THE DATA}

\section{A. SOURCES}

The climatological data used in this study were taken from the NWRC, Asheville data file of ocean weather station observations. These observations were begun at OWS NOVEMBER in 1947 and have continued to the present. The observations were taken every three hours, except for some short periods when all or only some of the observations were not taken for some parameters. The data extracted included the sea-surface temperature, air temperature, wind speed, surface pressure, cloud amount and the present weather codes for 1947 through 1970 .

The salinity data used in this study came from the NODC hydrocast data. Since July 1966, the U.S. Coast Guard has conducted a continuing program of collecting Nansen cast data at OWS NOVEMBER. The surface salinity data for 1968 through 1970 was utilized in one segment of this study.

\section{B. TREATMENT OF THE DATA TIME SERIES}

Daily surface salinity values from 1968 though 1970 were extracted from the NODC data set and any gaps in the series were linearly interpolated. The daily salinity values were then included with surface pressure, evaporation, solar radiation, heat of evaporation, and wind speed, all taken directly from or computed from the Asheville data set. To this was added the calculated values of precipitation and 
the evaporation minus precipitation terms to form a threeyear time series which was then used in the regression analysis segment of this study.

The Asheville meteorological data were used primarily to create the 24-year (1947-1970) time series used in the spectral analysis segment of this study. The values of SST, air temperature, cloud amount, air-sea temperature difference, the saturated vapor pressure of the air, the vapor pressure over the water, wind speed, surface pressure and wind speed squared were extracted or computed for every three hours and then converted into daily average values and these were the values utilized in all the spectral analyses. For the cloud amount parameter, only daylight observations were used. From these data sets the heat budget terms were computed on a daily basis. For the occasional gaps in the data, linear interpolations were made.

\section{THE HEAT BUDGET EQUATIONS}

Empirically derived formulas were used to create the heat flux data for this study. The heat budget equation utilized excludes the effects of heat gained or lost by ocean currents:

\footnotetext{
HEAT CHANGE = HEAT INCOMING - HEAT LOSSES$$
Q N=Q S-Q E-Q B-Q C
$$ 
where $Q N$ is the measured heat change, i.e., the heat gained or lost by the water due to the exchange processes. On the right-hand side of the equation, $Q S$ is the incident solar radiation, $Q B$ is the effective back radiation, $Q E$ is the heat of evaporation and $Q C$ is the conduction of sensible heat. Each of these terms will be described in detail below as to their formulation.

The equation used for $Q S$ is an improved version of that described by seckel (1970). The basic form is:

$$
Q S=Q_{0} K
$$

where

$$
Q_{0}=A_{0}+A_{1} \cos \phi+B_{1} \sin \phi+A_{2} \cos 2 \phi+B_{2} \sin 2 \phi
$$

From the Smithsonian Tables (List, 1951), utilizing a transmission coefficient of 0.7 , the above terms can be computed as follows for latitude $30 \mathrm{~N}$ :

$$
\begin{aligned}
& A_{0}=-32.65+674.76 \cos \ell=551.7 \\
& A_{1}=19.88+397.26 \cos (\ell+90)=-178.7 \\
& B_{1}=-6.75+224.38 \sin \ell=105.4 \\
& A_{2}=-1.32+16.10 \sin 2(\ell-45)=-9.4 \\
& B_{2}=-1.04+29.76 \cos 2(\ell-5)=18.1
\end{aligned}
$$

where:
$\ell$ is the latitude
$t$ is the time of the year in days
$C$ is the cloudiness in tenths, ranging from 0 to 1 , and 



$$
\phi=\frac{2 \pi}{365}(t-21)
$$

The cloud factor correction utilized was one for cumulus type clouds (Seckel, personal communication):

$$
K=1.0-0.012 C-0.363 c^{2}
$$

An albedo factor of 0.95 was utilized.

The new equation results in values approximately onefourth to one-third greater than previously estimated.

The effective back radiation, $Q B$, is a Berlyand expression utilized by Seckel (1970):

$$
\begin{aligned}
Q B= & 1.14(10)^{-7}\left(273.16+T_{W}\right)^{4} \\
& \left(0.39-0.05 \sqrt{e_{a}}\right)\left(1-0.6 C^{2}\right) \\
& +4.58(10)^{-7}\left(273.16+T_{W}\right)^{3} \\
& \left(T_{W}-T_{a}\right)
\end{aligned}
$$

where $T_{W}$ is the sea-surface temperature in degrees $C$. It utilizes a cloud coefficient of 0.6 and neglects latitudinal variation.

QE, the heat of evaporation depends upon the difference between the saturation vapor pressure over the sea at the sea-surface temperature and the vapor pressure of the air above the sea surface:

$$
Q E=3767 C_{D}\left(0.98 e_{W}-e_{a}\right) W
$$


where:

$$
\begin{aligned}
& e_{a} \text { is the vapor pressure of the air (mb) } \\
& e_{w} \text { is the saturation vapor pressure over water } \\
& \text { at sea-surface temperature (mb) } \\
& C_{D} \text { is the drag coefficient } \\
& W \text { is the wind speed }\left(\mathrm{m} \mathrm{sec}^{-1}\right)
\end{aligned}
$$

Whereas Seckel utilized a varying drag coefficient, this study utilized a constant drag coefficient of $1.3 \times 10^{-3}$. As in Seckel's study, the vapor pressure difference was multiplied by 0.98 to account for the salt effect.

The final heat balance term is the conduction of sensible heat, $Q C$ :

$$
Q C=4\left(T_{w}-T_{a}\right) W
$$

where:

$$
\begin{aligned}
& T_{W} \text { is the sea-surface temperature }(C) \\
& T_{a} \text { is the air temperature }(C) \\
& W \text { is the wind speed }\left(\mathrm{m} \mathrm{sec}^{-1}\right)
\end{aligned}
$$

It can be seen readily that $Q C$ is dependent upon two factors, the air-sea temperature difference and the wind speed. It is usually the smallest of all the heat exchange terms. As with Seckel's study, a conduction factor of 4.0 is used.

The above equations were those used to create the five heat flux time series used in this study. QS was computed using only the daylight cloudiness observations, night 

values being ignored. A daily value for each day was calculated for the span of 1947 through 1970. They were compared with seckel's (1970) results to guarantee their accuracy, where possible. The utilization of the newer QS formula resulted in higher values for this term than he reported and correspondingly more positive values of $Q N$.

\section{COMPUTATION OF PRECIPITATION}

In relation to the study of the surface salinity at OWS NOVEMBER, it was vital to have some measurement of E-P, the evaporation-precipitation term. The evaporation was readily available, having been calculated from the data a Tready available. However, no direct measurement of precipitation is made routinely at ocean weather stations. To gain a measure of the precipitation, Tucker's (1961) method was used. Elliot and Reed (1973) applied this method along the Pacific Northwest Coast with good results. This approach is based on the current weather code which gives a numerical value to the type of weather being observed at three hour intervals; this yields an estimation of the amount of rainfall. The amount of rainfall was based on the amount of precipitation observed for a similar weather code at a land station where actual rainfall measurements were available. Based on a frequency analysis for all the codes and the measured rainfall, Tucker was able to fit a numerical system of equations to the prediction of precipitation, using only the weather code as an input. 
In Tucker's system all codes less than 50 are rejected since they contribute no appreciable amount of precipitation. The codes used had values ranging from 50 to 99. Each of these codes is associated with a term made up of some combination of three rainfall parameters. These are $x$, associated with light, continuous rainfall; y, associated with moderate, continuous rainfall; and $z$, which is a measure of heavy, continuous rain. These three parameters satisfy the following criteria:

$$
\begin{aligned}
& y=n x \mathrm{~mm} \text { where } 1<n<5 \\
& z=m y \mathrm{~mm} \text { where } 1<m<3 \\
& z=10 \mathrm{~mm} \text { (in } 3 \mathrm{hr} \text { ) }
\end{aligned}
$$

For this study $x$ was set equal to $1.85, y=5.66$, and $z=8.13$, the same values as derived by Tucker from his frequency distributions of the codes recorded and the actual rainfall at land stations. Thus, the amount of rainfall, in millimeters, associated with each current weather code can be determined from one of the above, or a combination or ratio of these terms. For example, weather code 64 , which is "rain, not freezing, intermittent, but heavy at the time of observation", is described by the term $z / 2$. Likewise, code 84 , "showers of rain and snow mixed, moderate to heavy", is represented by the formula, $\frac{y+z}{4}$. 
For the purposes of this study, the precipitation was calculated every three hours and then summed to obtain the total precipitation for that particular day. This was then subracted from the evaporation term for that day to yield the E-P time series for 1968 through 1970.

E. COMPUTATION OF THE ENERGY SPECTRUM

The covariance function, $R_{x x}(\tau)$, of a time series of random data is a measure of the general dependence of the values of the data at one time, $t$, with the values at another time, $t+\tau$. The covariance equation in integral form is :

$$
R_{x x}(\tau)=\lim _{T \rightarrow \infty} \int_{0}^{T} x(t) x(t+\tau) d t
$$

This yields the average of the product of the value of a data point, $x(t)$, with that of $x(t+\tau)$, a point at some lagged time increment, $\tau$. As $T$ approaches infinity, the resulting average product approaches the exact autocovariance function.

Since this data forms a finite data set, a lag window is applied to the covariance function. The Parzen window used in this analysis is defined as:

$$
\begin{array}{rlrl}
P(\tau) & =1-6\left(\tau / T_{m}\right)^{2}+6\left(\tau / T_{m}\right)^{3} & \tau=0,1,2 \ldots T_{m} / 2 \\
& =\left(1-\left(\tau / T_{m}\right)\right)^{3} & \tau & =T_{m} / 2+1, \ldots-T_{m} \\
& =0 & \tau & =T_{m}
\end{array}
$$



where $\tau$ is the $1 \mathrm{ag}$ and $T_{m}$ is the total lag time. This window has the desirabre effect of minimizing any numerical instability due to side lobe resonance (Bendat and Piersol, $1971)$.

The energy-density spectrum is obtained by Fourier transforming the covariance function. The form of the energy-density spectrum, corrected by the Parzen window is:

$$
S_{x x}(f)=\int_{-\infty}^{\infty} P(\tau) R_{x x}(\tau) e^{-i 2 \pi f \tau} d \tau
$$

with $f$ being a specific frequency. The energy-density spectrum is the statistical estimate of the energy-density distribution for the frequency bands forming the total spectrum.

\section{F. COMPUTATION OF THE CROSS-SPECTRAL DENSITY}

When comparing two-time series of the same length and time interval, the cross-covariance function similar to the covariance function, is used. For a given lag time interval, $\tau$, it has the form:

$$
R_{x y}(\tau)=\lim _{T \rightarrow \infty} \frac{1}{T} \int_{0}^{T} x(t) y(t+\tau) d t
$$

Because the data sets are records of finite length, the Parzen lag window is applied. Thus, similar to the covariance function and the spectral density, the cross-spectral density is the Fourier transform of the Parzen window lagged, crosscovariance function. 

The cross-spectral density is a non-zero function, having real and imaginary parts of the form:

$$
S_{x y}(f)=\int_{-\infty}^{\infty} P(\tau) S_{x y}(\tau) e^{-i 2 \pi f \tau} d \tau
$$

which can be expressed in terms of its real and imaginary parts:

$$
S_{x y}(f)=C_{x y}(f)-i Q_{x y}(f)
$$

where $c_{x y}(f)$, the real co-spectrum, is given by:

$$
c_{x y}(f)=2 \int_{0}^{\infty}\left[S_{x y}(\tau)+S_{x y}(-\tau)\right] \cos (2 \pi f \tau) d \tau
$$

and the imaginary quadrature spectrum, $Q_{x y}(f)$ :

$$
Q_{x y}(f)=2 \int_{0}^{\infty}\left[S_{x y}(\tau)-S_{x y}(-\tau)\right] \sin (2 \pi f \tau) d \tau
$$

G. COMPUTATION OF THE COHERENCE FUNCTION

The coherence function, for two records $x$ and $y$, is a measure of the statistical dependence of two series. The coherence is defined as:

$$
\gamma_{x y}^{2}(f)=\frac{\left[s_{x y}(f)\right]^{2}}{s_{x x}(f) s_{y y}(f)}
$$

where:

$$
0 \leq r_{x y}^{2}(f) \leq 1
$$



If $\gamma_{x y}^{2}(f)=1$, for all frequencies, then the two records are totally coherent and statistically dependent. If $\gamma^{2}(f)=0$ for all frequencies, then the $x$ and $y$ records $x y$ are totally independent. For intermediate range coherences three conclusions may be inferred concerning the two records (Bendat and Piersol, 1966); (1) the systems are non-linear, (2) noise is present in the measurements, or (3) the output response is due to more than one input function. It should be noted that this is the coherence squared, but will hereafter be referred to as the coherence.

H. COMPUTATION OF THE PHASE ANGLE

The average angular difference by which the crosscorrelated points in $y(t)$ lead their corresponding components of $x(t)$ is called the cross-spectral phase angle, $\varepsilon_{x y}(f)$. It is computed from the co- and quad-spectra by:

$$
\varepsilon_{x y}(f)=\arctan \left[Q_{x y}(f) / C_{x y}(f)\right]
$$

Since this study deals with a time step of one day, the phase angles can be converted to a lag in days from:

$$
L(\text { days })=\frac{\varepsilon_{x y}(f) * 0.01745}{f * 2 \pi}
$$

When either the value of the phase angle (measured in degrees) or the lag time (in days) is positive, then $y(t)$ lags behind $x(t)$ by that amount; if the value is negative, then $x(t)$ lags behind $y(t)$. 

In the computations involved in this study there were 8766 data points. A standard 1 ag of $876,10 \%$ of the total time series,was used. The $90 \%$ confidence interval for the energy densities was computed by the formula:

$$
r=\frac{N}{M} 3.7
$$

when $N=8716, M=876$.

The limits were found from tables to be:

$$
\begin{aligned}
& a=24.075 \\
& b=52.192
\end{aligned}
$$

where $a$ and $b$ are the values which when subtracted and added, respectively, to the value of the spectral energy density result in the lower and upper $90 \%$ confidence limits. 



\section{RESULTS}

\section{A. REGRESSION ANALYSIS}

The regression analysis phase of this study was limited to the three-year time series of the NODC hydrocast data due to the desire to utilize the salinity data present in this data set alone. The period covered was from 1968 through 1970, the same time span of data analyzed by Hansen (1973). At this point it is appropriate to visually inspect the surface temperature and salinity data sets in a deterministic approach.

Figure 4 shows the monthly means of the sea-surface temperature for 1968 through 1970 compared to Robinson's (1971) twenty-year long-term monthly means. A characteristic annual cycle is evident in all three years as well as the long-term mean. The only major difference from the longterm mean is a persistent cold anomaly which is present in the spring of all three years.

The year 1968 was the most anomalous, being both colder in March and April and warmer for the balance of the year. Namias (1971) attributed this to bulk heating, advection and mixing. The year 1969 was more normal, except for an anomalous cooling in the summer, attributed by Roden (1970) to a southward displacement of the transition zone. This has been supported by Wickett and Thompson (1971a, 1971b) whose meridional transport data, Figure 5, shows a transport 



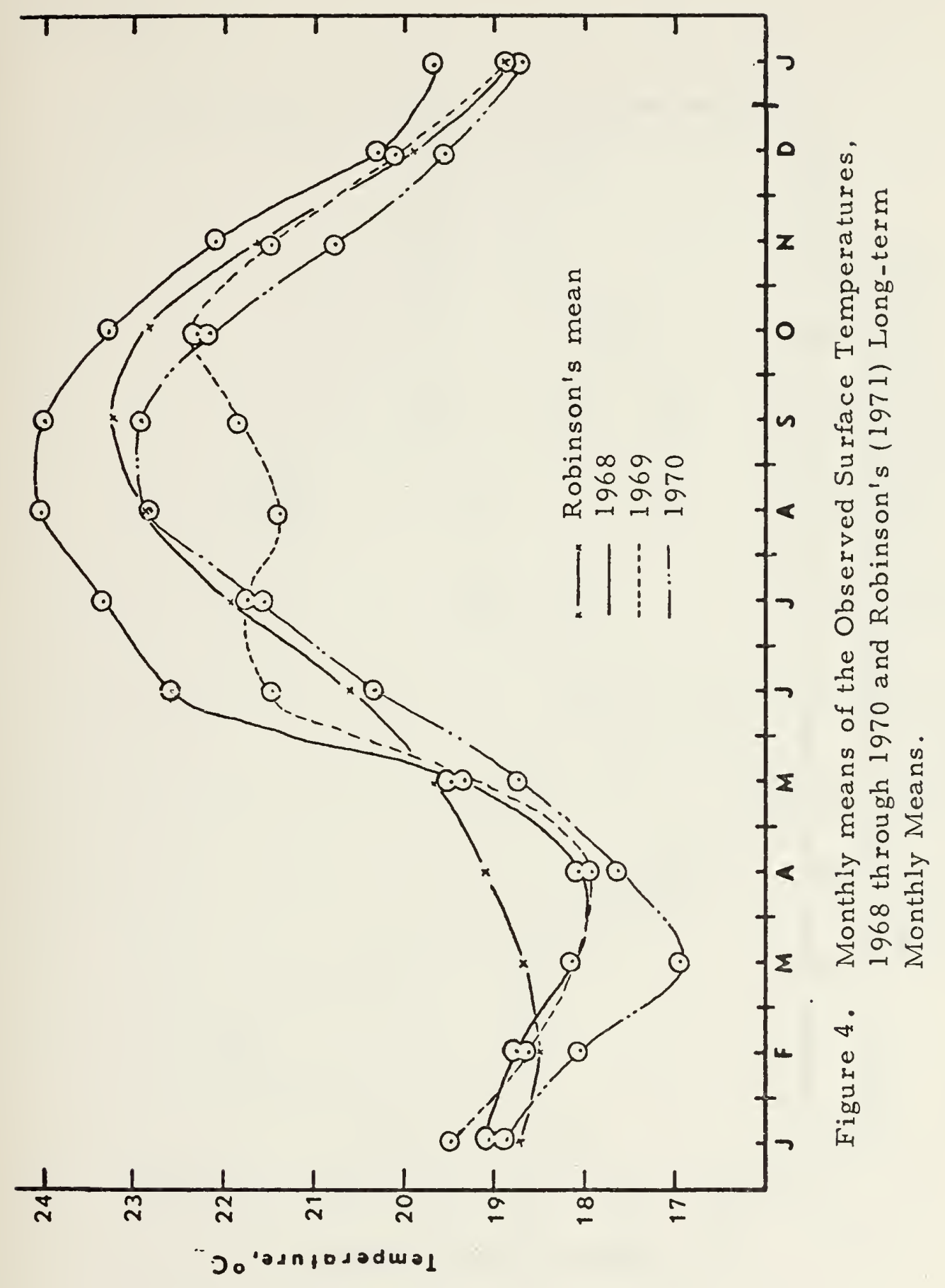





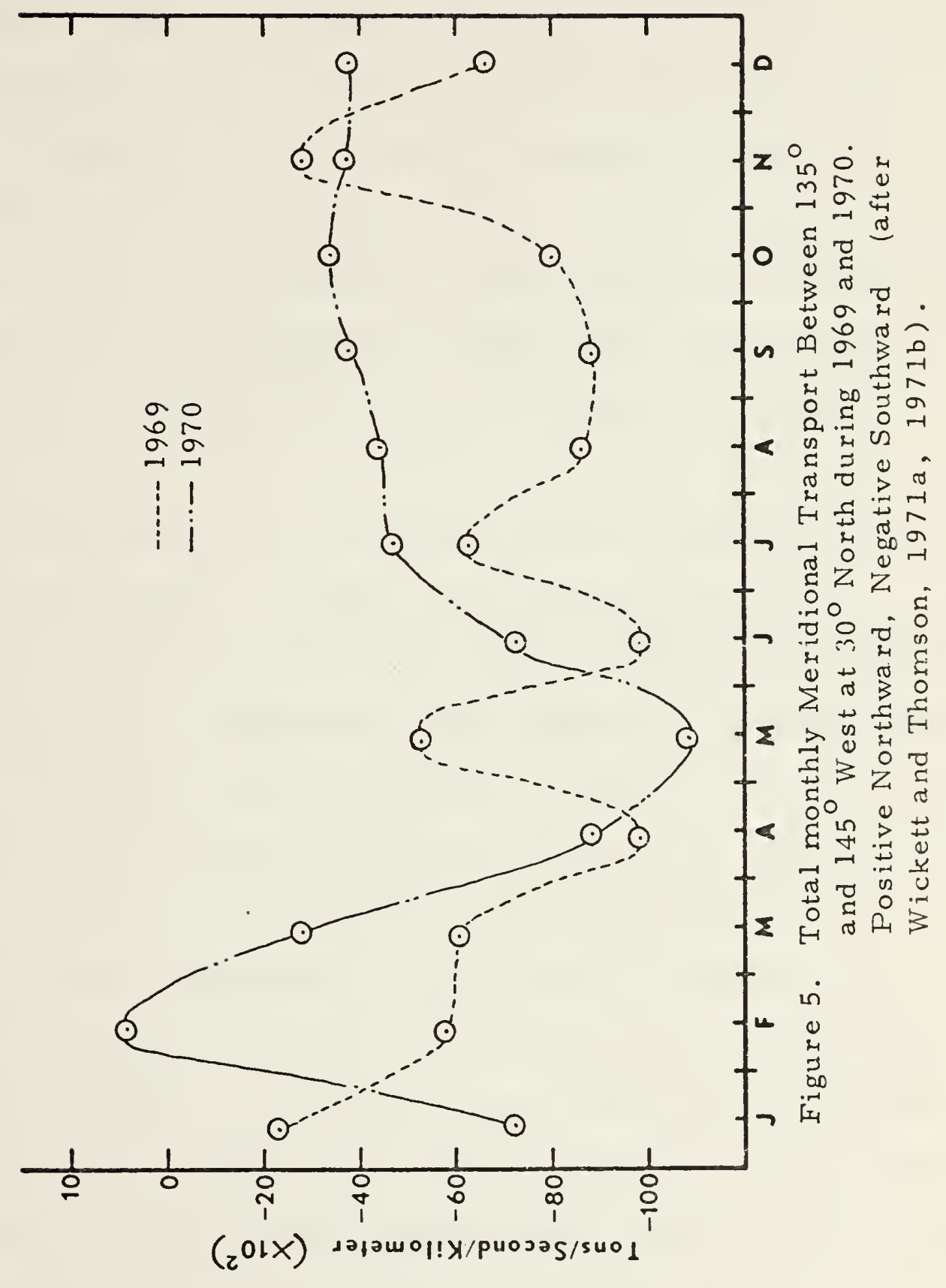



of cooler water equatorward during April through October, 1969. Except for the spring months, 1970 was more typical to the long-term mean than the preceding two years.

Figure 6 shows the monthly means of surface salinity for 1968 through 1970. The most obvious fact from this figure is that the salinity shows evidence of having a semi-annual periodicity. In addition to this, there is the feature in 1970 of a reduction in the salinity, possibly due to the advection of abnormally fresh, cool subarctic water, indicating an equatorward shift in the subarctic transition zone.

As stated previously, Hansen (1973) did much work on the same data series. Figure 7 is the result of his bivariate analysis of the monthly mean surface temperatures and salinities. It shows that the temperature follows four phases, namely the seasonal phases of summer, autumn, winter and spring, with autumn and spring appearing as transitional phases. Hansen also performed a regression test. of the seasonal surface temperature versus the surface salinity and also the temperature at $50 \mathrm{~m}$. The correlation coefficients are given in Table I. For most cases the correlations were poor, especially between the surface salinity and the surface temperature. The only good correlations occurred during the transition periods when both the surface temperature and salinity were responding to the changes of the annual cycle. 



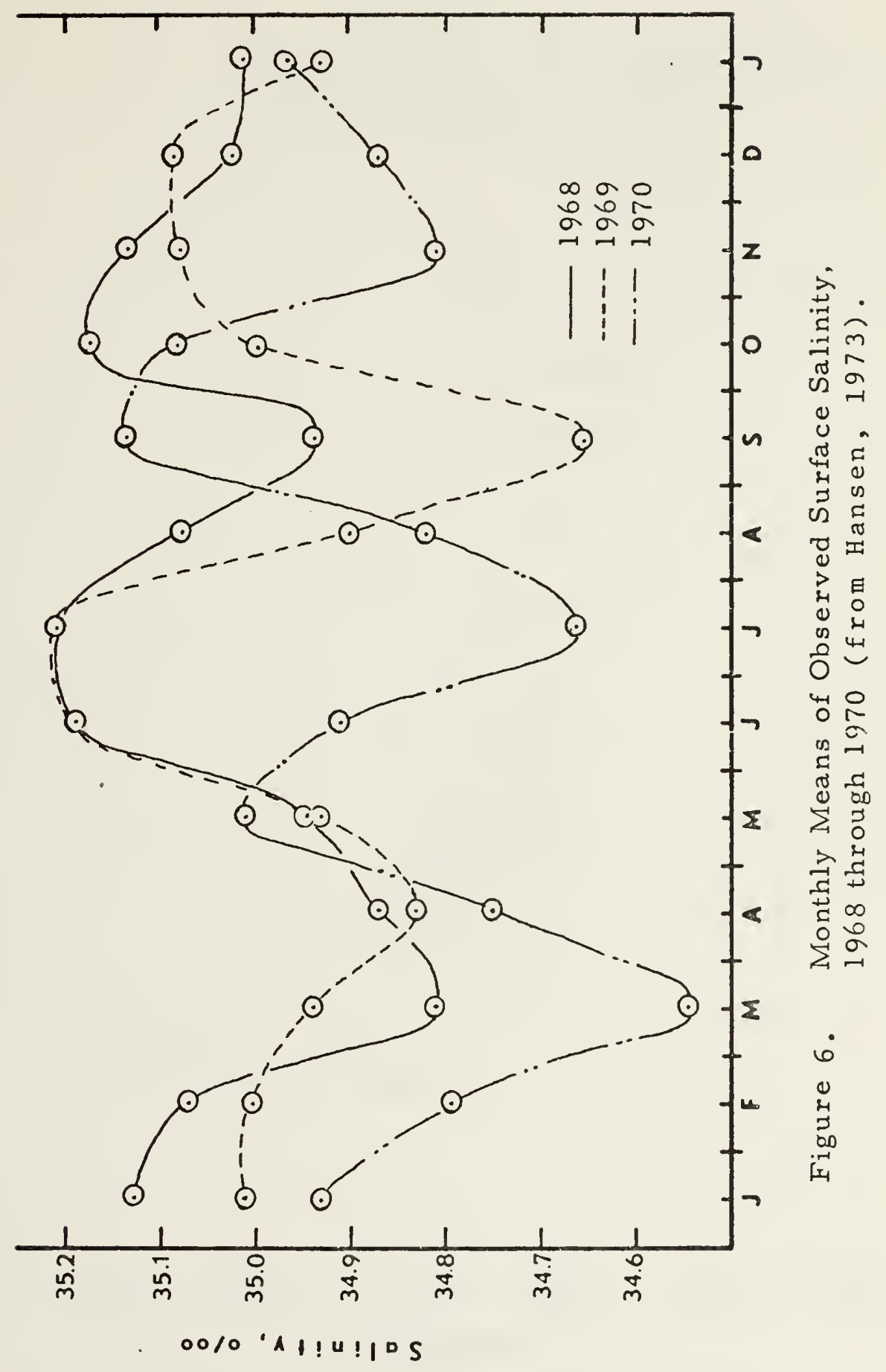





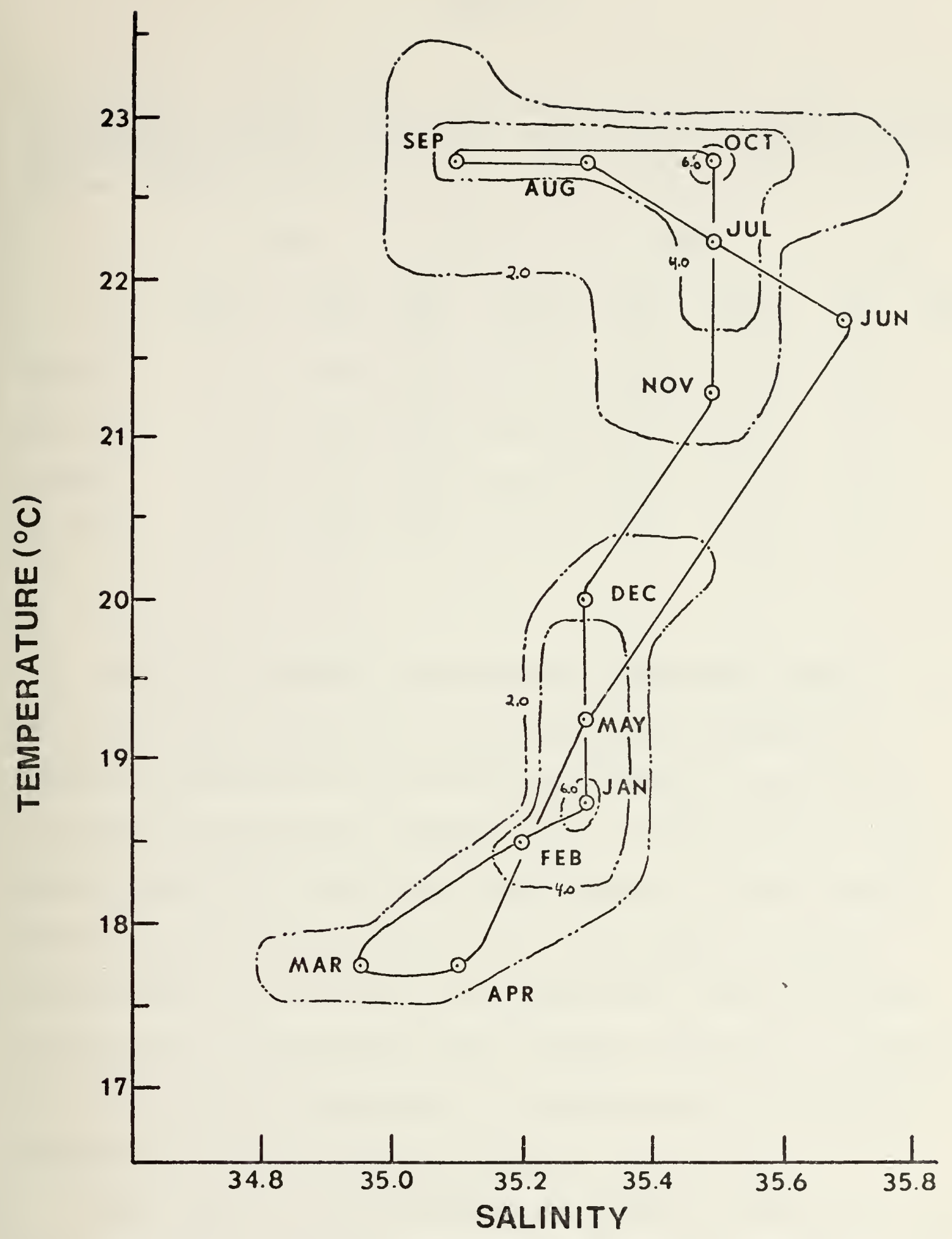

Figure 7. Monthly Temperature and Salinity Modal Points Resulting from the Bivariate Analysis of the Data, 1968 through 1970 (from Hansen, 1973). 

Correlation coefficients, by season, resulting from a linear regression analysis of surface temperature, surface salinity, and 50 meter temperature data, 1968 through 1970 (from Hansen, 1973).

$1968 \quad 1969 \quad 1970 \quad$ Mean

$\begin{array}{llllllll}\mathrm{SfC} & 50 \mathrm{~m} & \mathrm{SfC} & 50 \mathrm{~m} & \mathrm{SfC} & 50 \mathrm{~m} & \mathrm{Sfc} & 50 \mathrm{~m} \\ \mathrm{Sal} & \text { Temp } & \mathrm{Sal} & \text { Temp } & \mathrm{Sal} & \text { Temp } & \text { Sal } & \text { Temp }\end{array}$
Winter
0.61
0.58
0.61
0.56
0.77
0.42
0.66
0.52
Warming
0.59
0.90
0.77
$\begin{array}{ll}0.70 & -0.11\end{array}$
0.67
0.42
0.75
Summer $-0.28$
0.310 .16
$0.40 \quad-0.05$
$-0.29$
$-0.05$
0.14
Cooling
0.57
0.88
0.84
$\begin{array}{ll}0.98 & -0.01\end{array}$
0.96
$0.47 \quad 0.94$

Since the surface salinity and temperature were obviously responding to different causal parameters, a further regression analysis was performed. The surface salinity was regressed against many of the classical parameters associated with its fluctuations. In this instance, there were seven variables chosen; the vapor pressure difference, E-P, the heat of evaporation, the wind speed, evaporation, precipitation and surface pressure. No separation into seasons was made, all computations being made as a three-year series of daily average observations.

The results of the regression study are shown in Table II Two major observations are apparent from this study. First, the standard parameters often associated with a change in salinity, especially E-P, showed very little correlation with the surface salinity. However, this is quite reasonable 

Correlation coefficients, all parameters vs surface salinity.

$\begin{array}{lccc}\text { PARAMETER } & 1968 & 1969 & 1970 \\ \mathrm{e}_{\mathrm{W}}-\mathrm{e}_{\mathrm{a}} & .094 & .043 & .097 \\ \mathrm{E}-\mathrm{P} & .045 & .157 & -.016 \\ \mathrm{QE} & .028 & .167 & -.001 \\ \mathrm{~W} & -.030 & .163 & -.043 \\ \mathrm{PS} & .830 & .803 & .003 \\ \mathrm{E} & .034 & .166 & .004 \\ \mathrm{P} & -.030 & -.019 & .028\end{array}$

considering the location of OWS NOVEMBER with its year round excess of evaporation over precipitation. The other major observation is that only one parameter is consistently highly correlated, i.e., the surface pressure.

This latter fact could mean that the changes in the surface salinity are largely due to an advective process, as is supported by the fact that the other non-conservative terms associated with the air-sea interface have such poor correlation coefficients. This suggests that the changes in the surface salinity are related to some geostrophic process, most likely an advection of water from the subarctic region, corresponding to a southward shift of the transition zone. 



\section{B. SPECTRAL ANALYSIS}

The major thrust of this study was to use spectral analysis as a means of numerically describing the interactions at the air-sea interface at OWS NOVEMBER. Specifically, it was to identify those meteorological parameters most closely associated with fluctuations in the sea-surface temperature. Since this latter term has a dominant annual cycle and most of the other parameters were compared with this term, the results presented here will primarily be those for the yearly cycle. The logic of this is further demonstrated by comparing the percentages of the variance explained by the yearly cycle for the different terms. The percentages shown in Table III were calculated from the energy-density functions which were produced for each time series. This function is a measure of the variance contained at that frequency. To compute the variance contributed by the yearly cycle a bandwidth was specified by those frequencies for which the value of the energy-density function decreased to less than half the value at the yearly cycle.

From Table III it can be seen that $86 \%$ of the total variance of the sea-surface temperature is explained by the yearly cycle alone. For this reason, even though the spectral results were computed for frequencies as short as the monthly cycle, the emphasis of this study was placed on the yearly cycle. Also, since the major areas of interest were the correlations with the heat budget terms, each of 

these is discussed describing its influence on the seasurface temperature. In addition, the contributing effects of the parameters involved in the computation of that heat flux term will be discussed.

\section{Table III}

Contribution of the yearly cycle to the total variance explained

\section{Parameter}

SST

$T_{a}$

$T_{w}-T_{a}$

$e_{w}$

$e_{a}$

$e_{w}-e_{a}$

E (evaporation)

W

$w^{2}$

Cl (cloud cover)

PS

QS

QB

QE

QC

QN

\section{$\%$ of Total Variance}

86

80

20

86

46

14

34

8

9

7

8

70

87

11

17

42 

The first heat budget term to be examined is the solar radiation, QS, which like the surface temperature exhibits a strong annual periodicity. From Tabe III, it can be seen that $70 \%$ of the total variance of this term is explained by the annual cycle. The term which primarily controls the variation of $Q S$ is the cloud cover, $C 1$, and in Table IV the spectral results for the yearly cycle are given for the interactions of the SST and Cl with QS. Along with a correlation of the cloud cover with the SST, the complete spectral results are shown in Figures 8,9 , and 10 . Figures $A-1, A-2$, and A-3 of Appendix A show the respective autocorrelation functions and Figures B-1 and B-2 of Appendix B illustrate 15-year segments of the 24-year time series of the SST and QS.

As would be expected, Table IV shows that the solar radiation is strongly coherent with the SST at the yearly cycle. However, there is a lag of almost 60 days, which cannot be explained by the cloud cover correlation with its low coherence and therefore dubious lag time. Also, there is a strong coherence at the semi-annual cycle, which appears to reflect the effect of the cloud cover as seen in Figure 10.

\section{Table IV}

Spectral results for the solar radiation, SST and cloud cover at the yearly cycle.

$\begin{array}{cccc}\begin{array}{c}\text { Parameter } \\ \text { Codes }\end{array} & \text { Coherence } & \begin{array}{c}\text { Phase } \\ \text { (degrees) }\end{array} & \begin{array}{c}\text { Lag } \\ \text { (days) }\end{array} \\ \text { QS VS SST } & .94567 & -60.0 & -58.5 \\ \text { QS VS C1 } & .85236 & 126.2 & 122.0\end{array}$




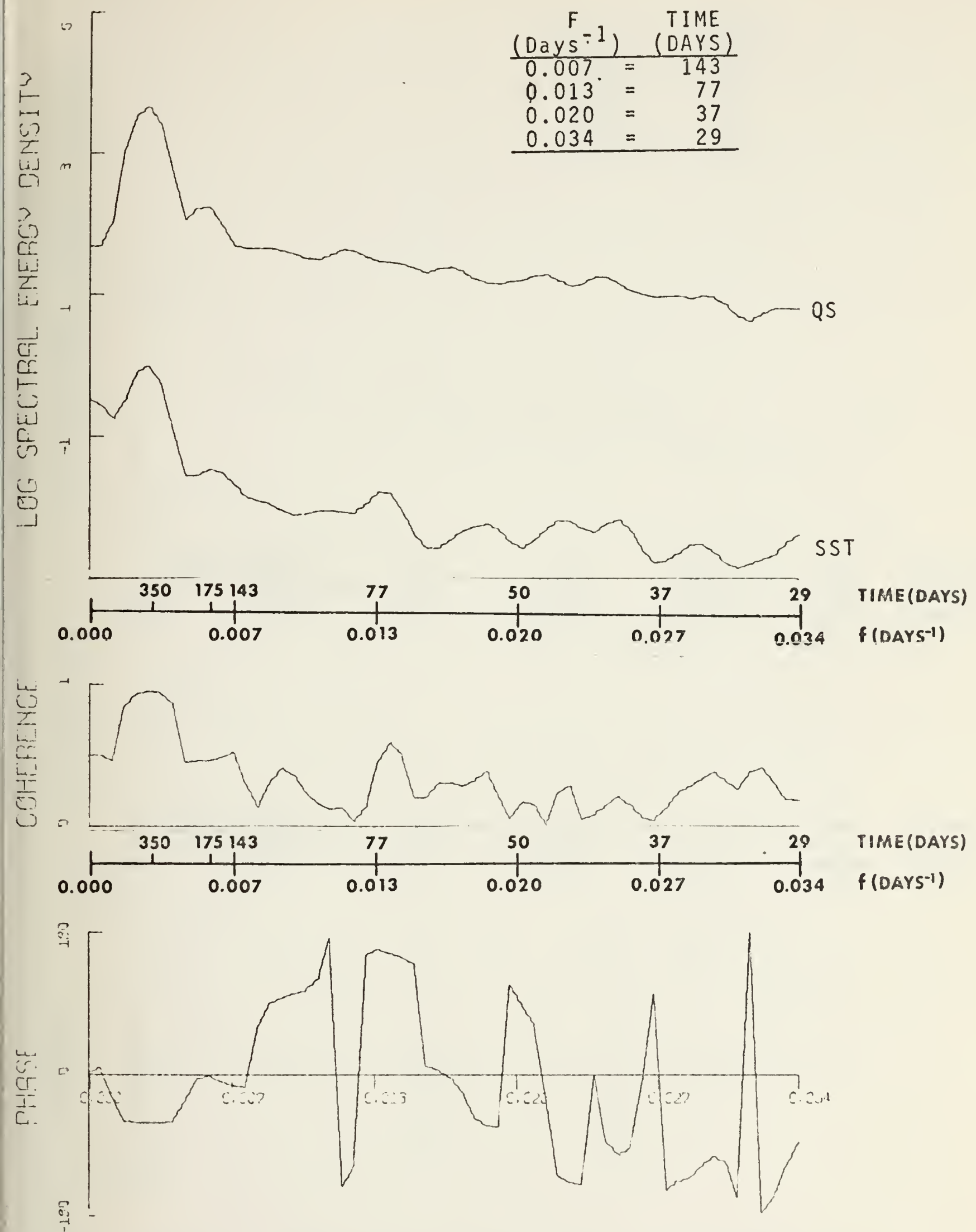

Figure 8. Spectral density, coherence and phase for the SST vs the solar radiation. 


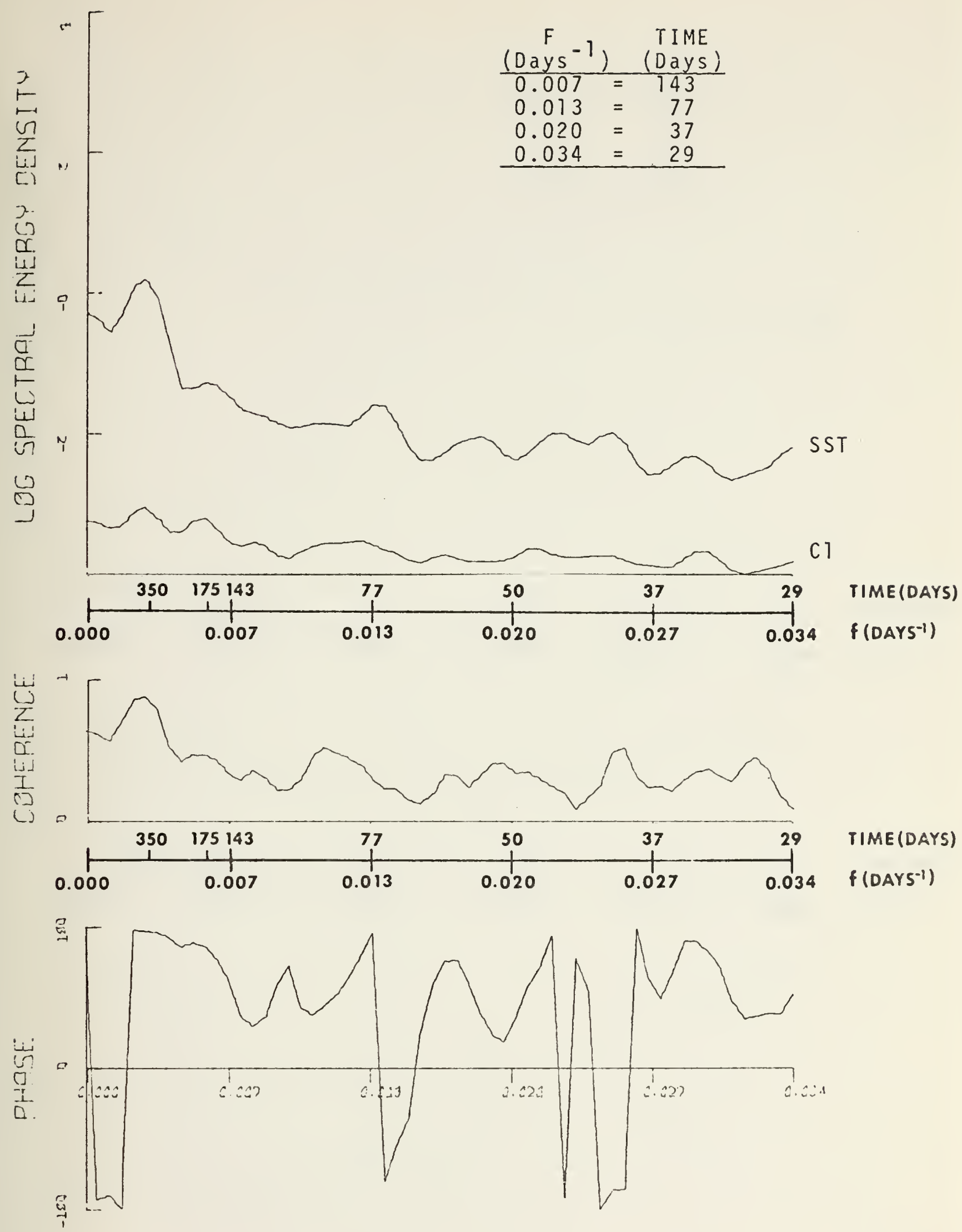

Figure 9. Spectral density, coherence and phase for the SST vS cloud cover. 



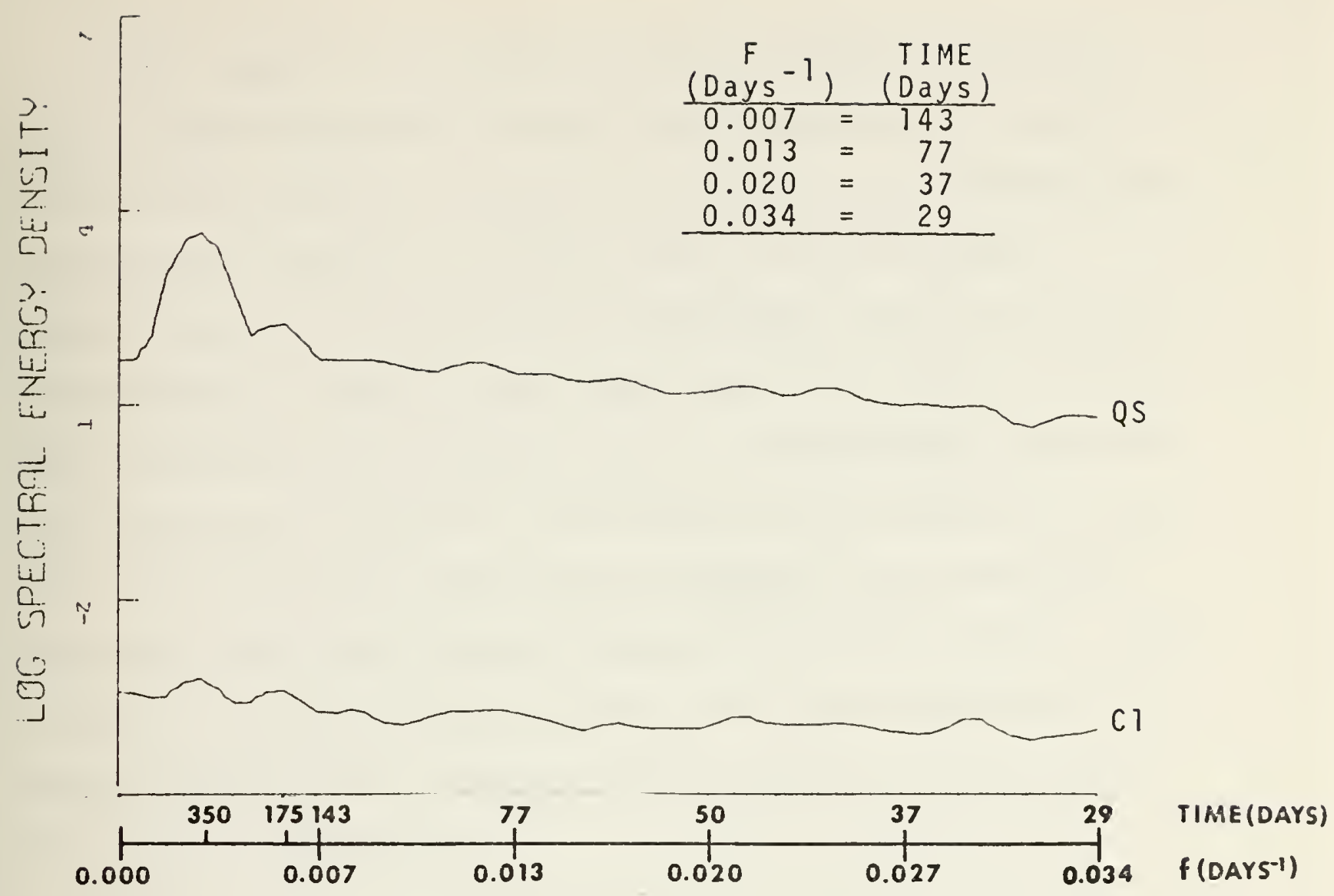

4
$y$
2
4
4
7
0
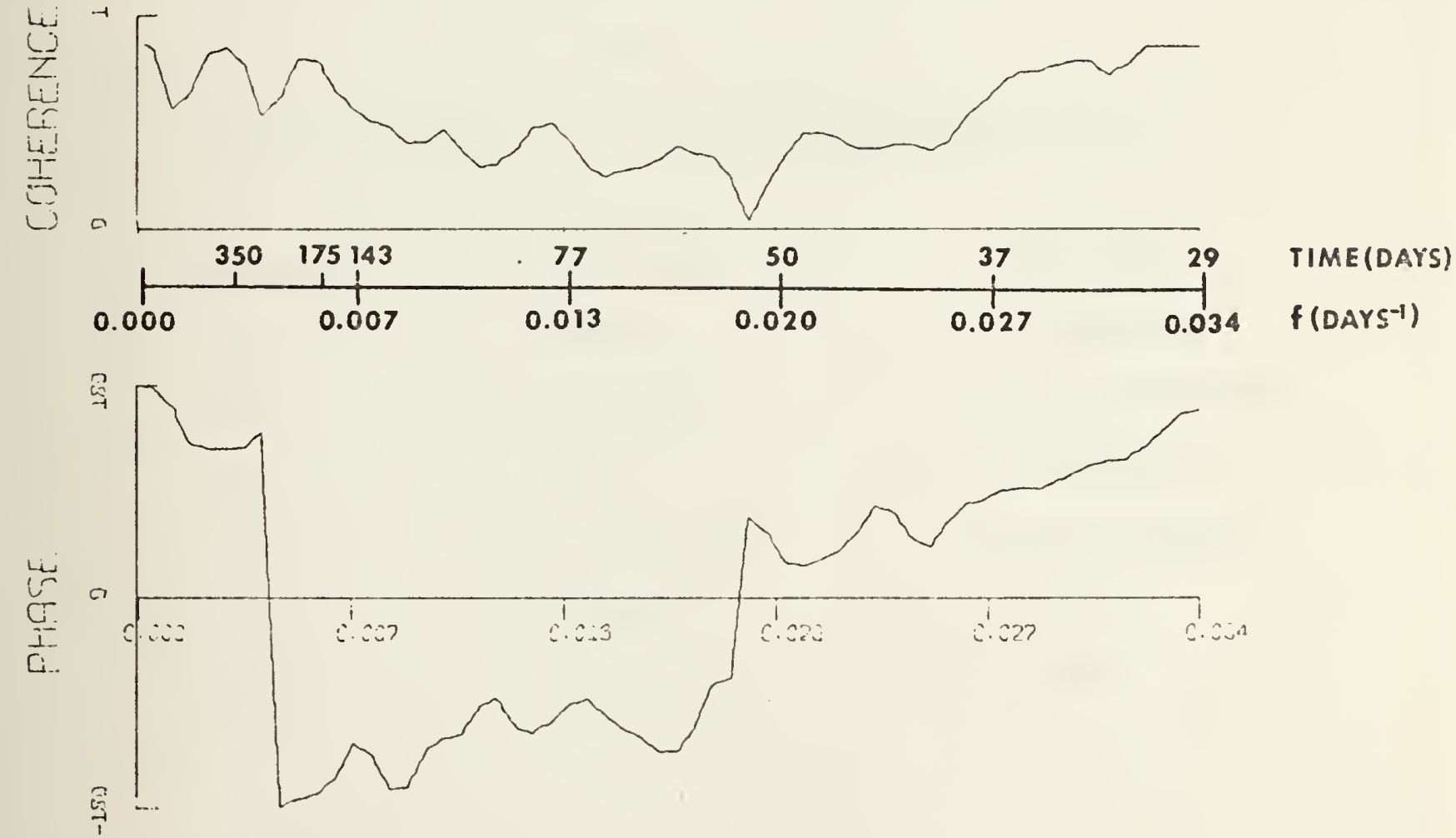

Figure 10. Spectral density, coherence and phase for the solar radiation vs cloud cover. 

This rather large lag is equally evident in Table $\mathrm{V}$ which shows the months in which SST and the heat transfer terms achieve their maximum and minimum values. Along with Figures $B-1$ and $B-2$, it can be seen that the surface temperature is a maximum during September and at a minimum during March. However, the solar radiation peaks in August and is a minimum in January. This is approximately the 58 day lag shown in Table IV. This lag can be explained by the fact that the solar radiation is absorbed and transferred throughout the upper mixed layers of the water column. Thus, a lag of two months exists before the total effects of the solar radiation are represented by a warming or cooling of the surface temperature.

\section{Table V}

Months of maximum and minimum value for the surface temperature and the heat budget term.

\begin{tabular}{ccc} 
Parameter & Minimum & Maximum \\
\hline SST & March & September \\
QS & January & August/September \\
QE & May & November \\
QB & July/January & March/November \\
QC & August & March \\
QN & December & June
\end{tabular}



In Figures 8,9 , and 10 there are also noticeable peaks at the six month cycle and three month cycle. These results are thought to be, for the most part, artifacts of the yearly cycle and are relatively small when compared to the yearly value; yet, as mentioned before, several show evidence of being real.

The major result of this portion of the study is that the use of the new formula for QS results in significantly, higher estimates of this term than previously calculated. Fluctuations in solar radiation precede those of the surface temperature by approximately two months and thus the solar radiation is a good predictor of the surface temperature, as would be expected.

The back radiation, $Q B$, represents the loss of heat energy as long-wave radiation. It is strongly dependent upon the surface temperature and the vapor pressure of the atmosphere. Table VI summarizes the results for the yearly cycle of $Q B$ and associated terms with the surface temperature.

\section{Table VI}

Spectral results for the back radiation and related parameters at the yearly cycle.

$\begin{array}{llll}Q B \text { vS SST } & .59755 & 121.8 & 119.0 \\ T_{a} \text { VS SST } & .98800 & -6.0 & -5.9 \\ T_{W}-T_{a} \text { VS SST } & .67194 & -49.1 & -47.9 \\ e_{a} \text { VS SST } & .98815 & -6.4 & -6.2 \\ Q B \text { vS CT } & .37565 & -82.9 & -78.1\end{array}$



From Table III it was found that about $87 \%$ of the total variance of the back radiation was contained in the yearly cycle; yet, Table VI shows only a slight coherence between the SST and QB for the yearly cycle and a large dubious lag value. This can be explained by examining the interactions involved. The back radiation term decreases as the SST increases due to the effect of the humidity in the atmosphere directly above the surface. Thus, over the yearly cycle, QB would ideally be 180 degrees out of phase with the surface temperature. However, the back radiation is also decreased by an increase in the cloud coverage. Thus, the condition illustrated by Figure $B-3$ and Table $V$ may be seen where $Q B$ is shown to have two maxima and minima on roughly a semiannual basis. From Figure A-4 it may be seen that this feature is superimposed over a larger annual cycle which explains the high percentage of the variance contained by the yearly cycle.

The complete spectral results for the above correlations are given in Figures 11 through 15. From Figure 11 it is seen that $Q B$ has two peaks, one at the yearly cycle and another lesser one at one-half the yearly cycle. Of the related parameters, only the air temperature and the vapor pressure of the air are highly correlated and then at only the yearly cycle. The air-sea temperature difference is only mildly correlated at the yearly cycle and its associated lag is highly suspect for that reason. The air-sea temperature 


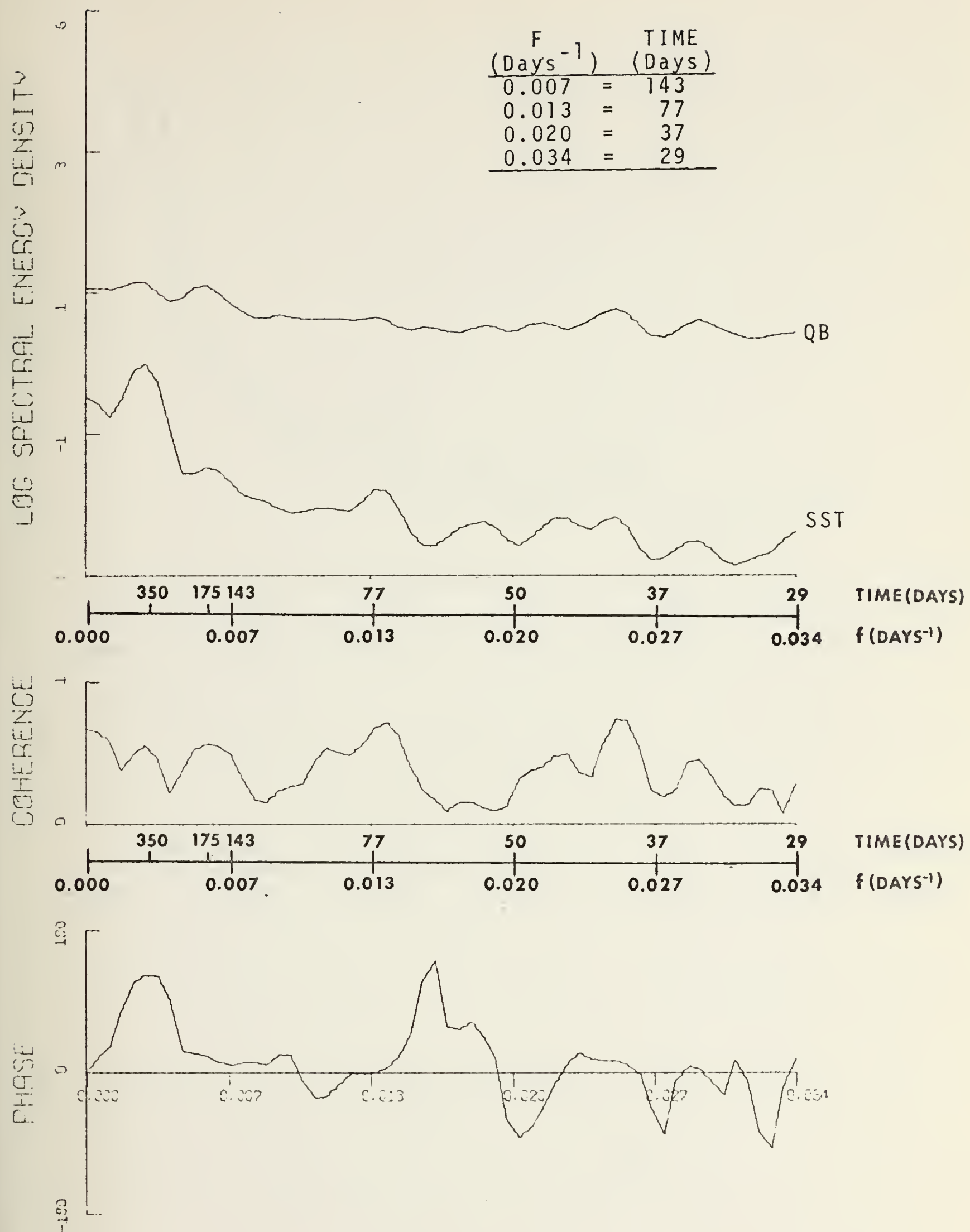

Figure 11. Spectral density, coherence and phase for the SST vs the back radiation. 


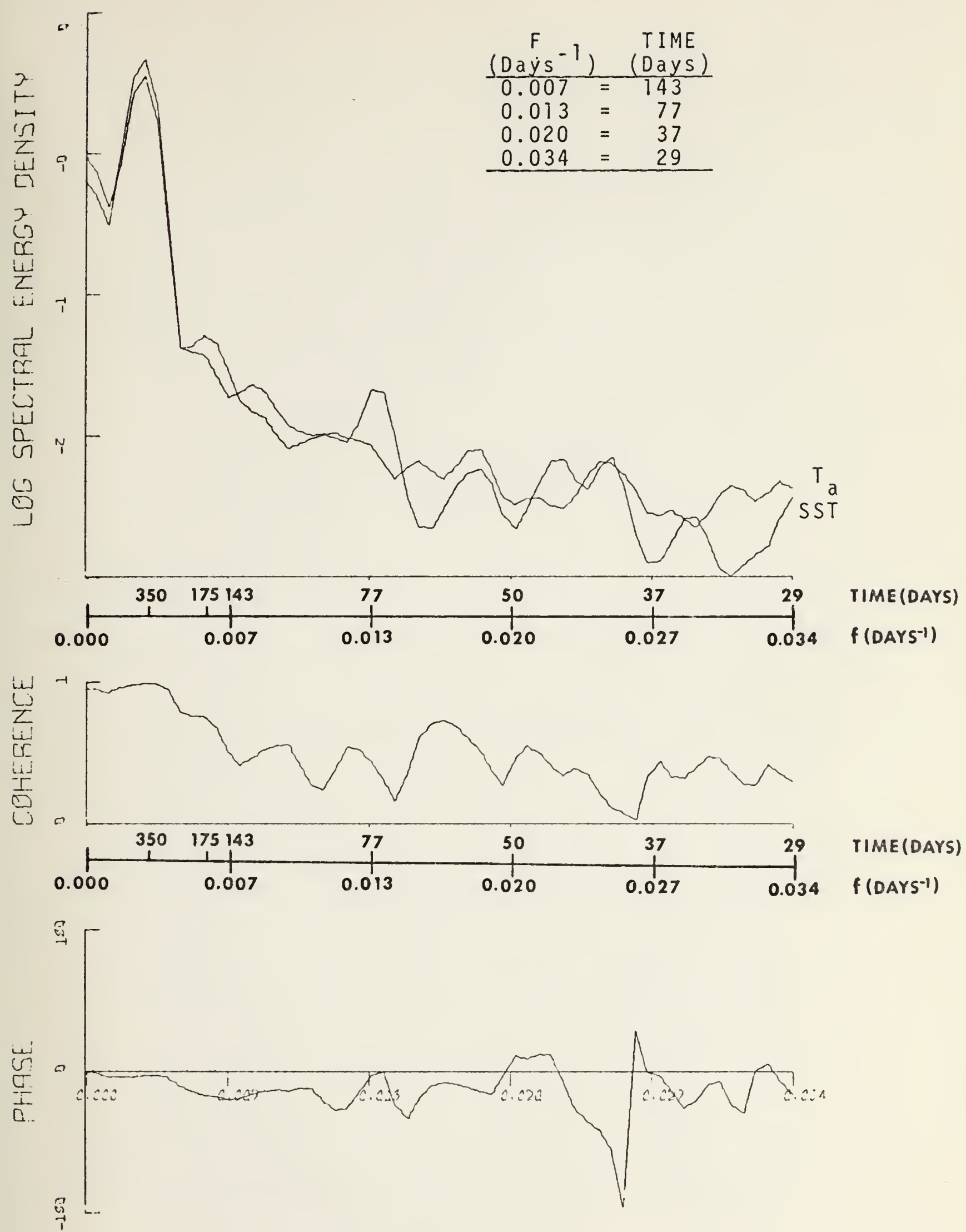

Figure 12. Spectral density, coherence and phase for the SST vs air temperature. 




Figure 13. Spectral density, coherence and phase for the SST vs the air-sea temperature difference. 



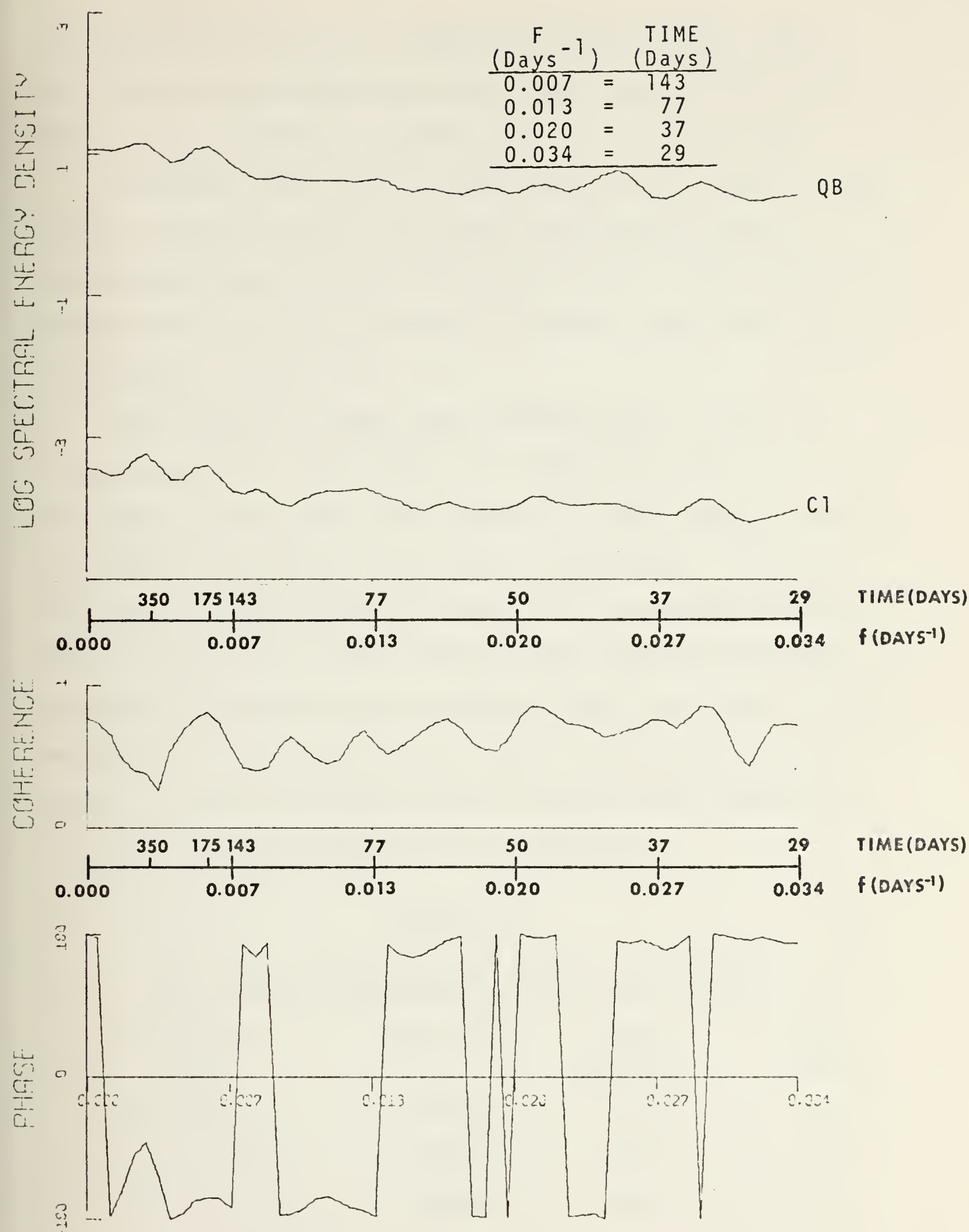

Figure 15. Spectral density, coherence and phase for the back radiation vs cloud cover. 

difference demonstrates a coherence at the 70-day cycle. Also the back radiation and cloud cover show evidence of this possible seasonal coherence.

The major conclusion to be drawn from this part of the study is that the back radiation is semi-annual with an underlying yearly cycle. As a predictor for the surface temperature, the back radiation is poorly associated with fluctuations in SST.

The next heat budget term examined was the heat of evaporation, QE. Only $11 \%$ of the total variance of $Q E$ is explained by the yearly cycle which in itself means that $Q E$ is a poor predictor of the surface temperature. This is verified by Table VII which shows only a moderate coherence for $Q E$ and the SST at the yearly cycie. This iessens the credibility of the large lag shown; also from Table $V$ it can be seen that the actual lag is more of the nature of two months. Additionally the lag is positive which means that fluctuations of QE follow those of the SST.

\section{Table VII}

Spectral results for the heat of evaporation and related parameters at the yearly cycle.

$\begin{array}{lccc}\begin{array}{c}\text { Parameter } \\ \text { Codes }\end{array} & \text { Coherence } & \begin{array}{c}\text { Phase } \\ \text { (degrees) }\end{array} & \begin{array}{c}\text { Lag } \\ \text { (days) }\end{array} \\ \text { QE VS SST } & .84783 & 97.5 & 95.0 \\ e_{W}-e_{a} \text { VS SST } & .86425 & 22.8 & 22.3 \\ W \text { VS SST } & .95593 & 138.7 & 135.4 \\ W^{2} \text { VS SST } & .95512 & 135.4 & 132.0 \\ \text { EVS SST } & .81722 & 76.9 & 74.9\end{array}$


Whereas QE is only weakly correlated with the SST at the annual cycle, the wind speed and wind speed squared are highly correlated to the SST with large positive lags (approximately 4 months). These would seem to explain much of the lag in QE when they are coupled with the vapor pressure difference. $Q E$ is a transfer mechanism of the form:

$$
Q E=-A_{e} \frac{\partial f}{\partial z}
$$

where:

$A_{e}$ is the eddy coefficient for water vapor

$\frac{\partial f}{\partial z}$ is the humidity gradient above the sea surface.

Both of these are highly dependent upon the wind speed.

Even though the vapor pressure difference and evaporation are weakly correlated to the SST, they combine with the wind speed to produce the low coherence and large lag for QE.

Figures 16 through 20 give the complete spectral results for the correlations shown. Being computed from the surface temperature, $e_{w}$ and SST are naturally perfectly correlated and is not included. The yearly cycle dominates in all except for QE, the vapor pressure difference and the evaporation, as would be expected. Both the wind speed and wind speed squared show a definite coherence at about the 80 -day cycle. The autocorrelation functions are found in Figures A-9 through A-13 and a 15-year plot of QE and its anomaly is shown in Figure $B-4$. 


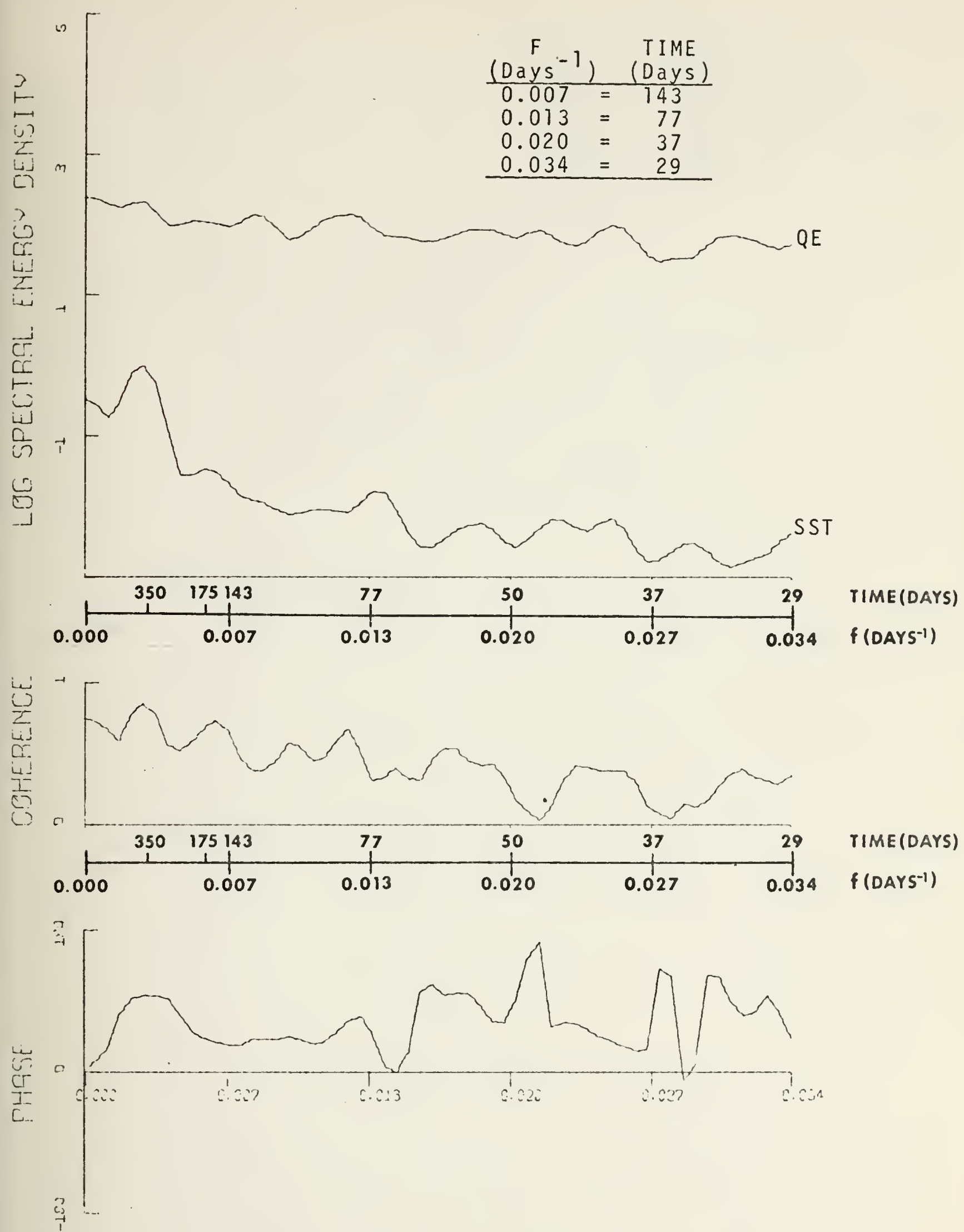

Figure 16. Spectral density, coherence and phase for the SST VS the heat of evaporation. 


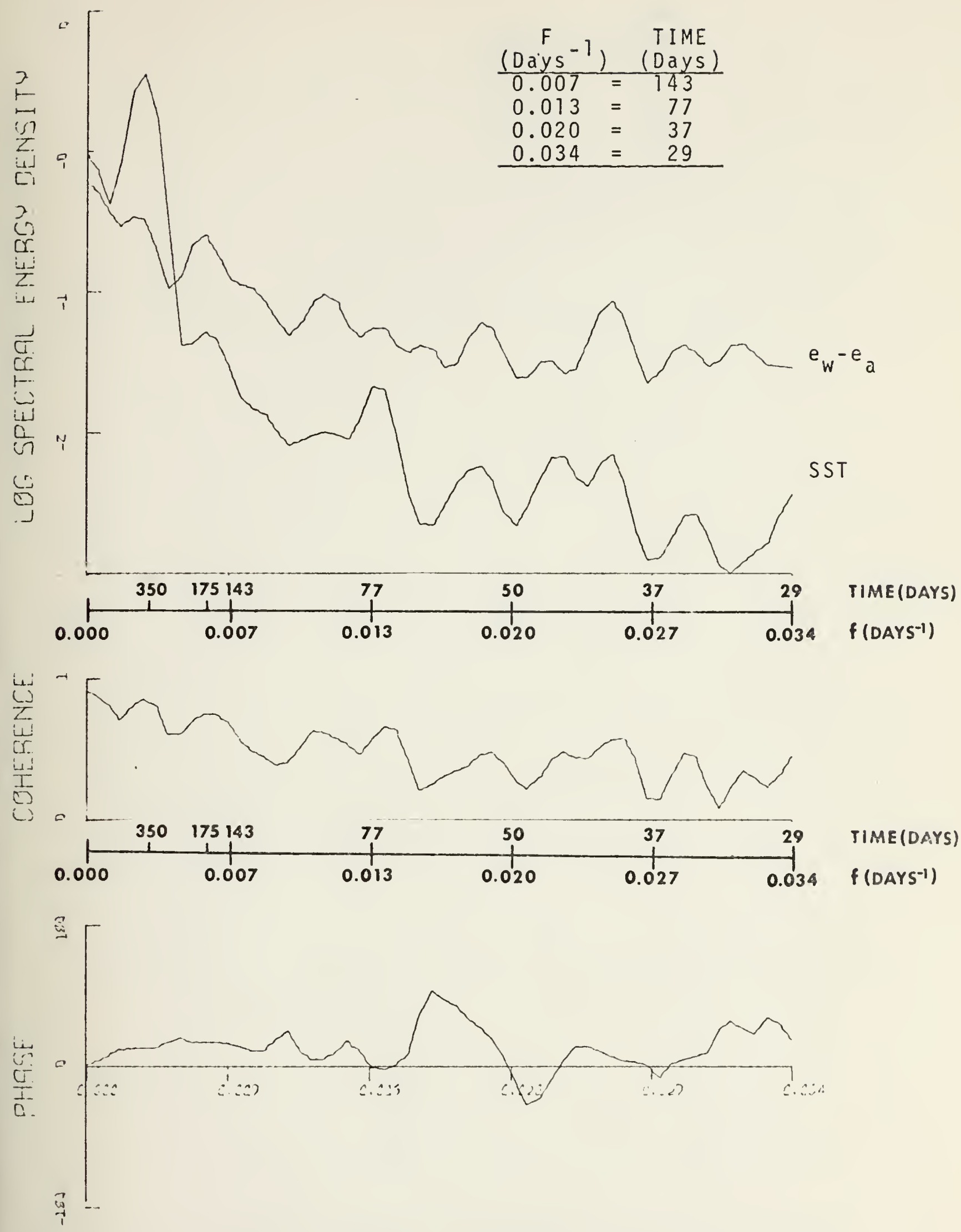

Figure 17. Spectral density, coherence and phase for the SST VS the vapor pressure difference. 




Figure 18. Spectral density, coherence and phase for the SST VS the wind speed. 


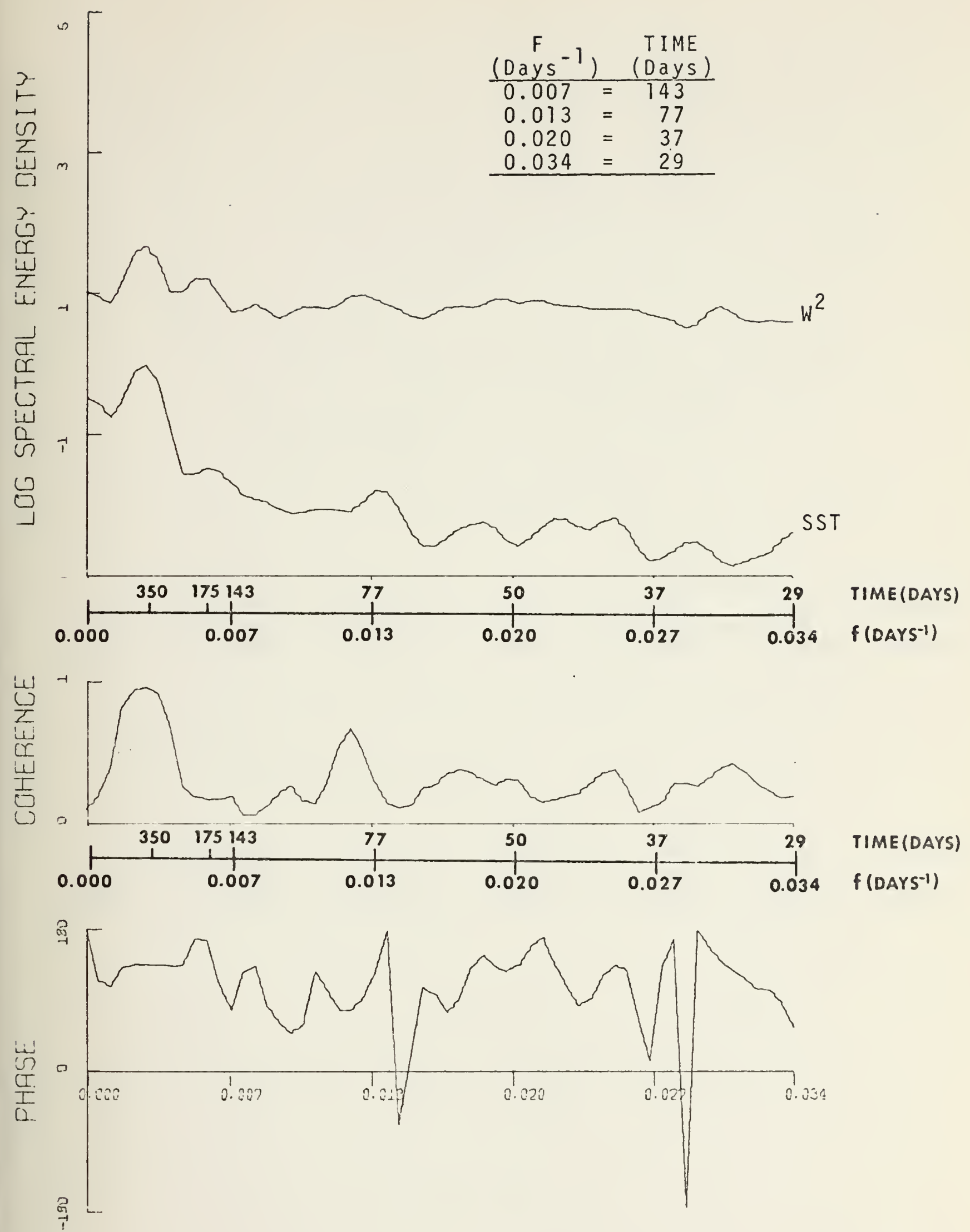

Figure 19. Spectral density, coherence and phase for the SST vs the wind speed squared. 


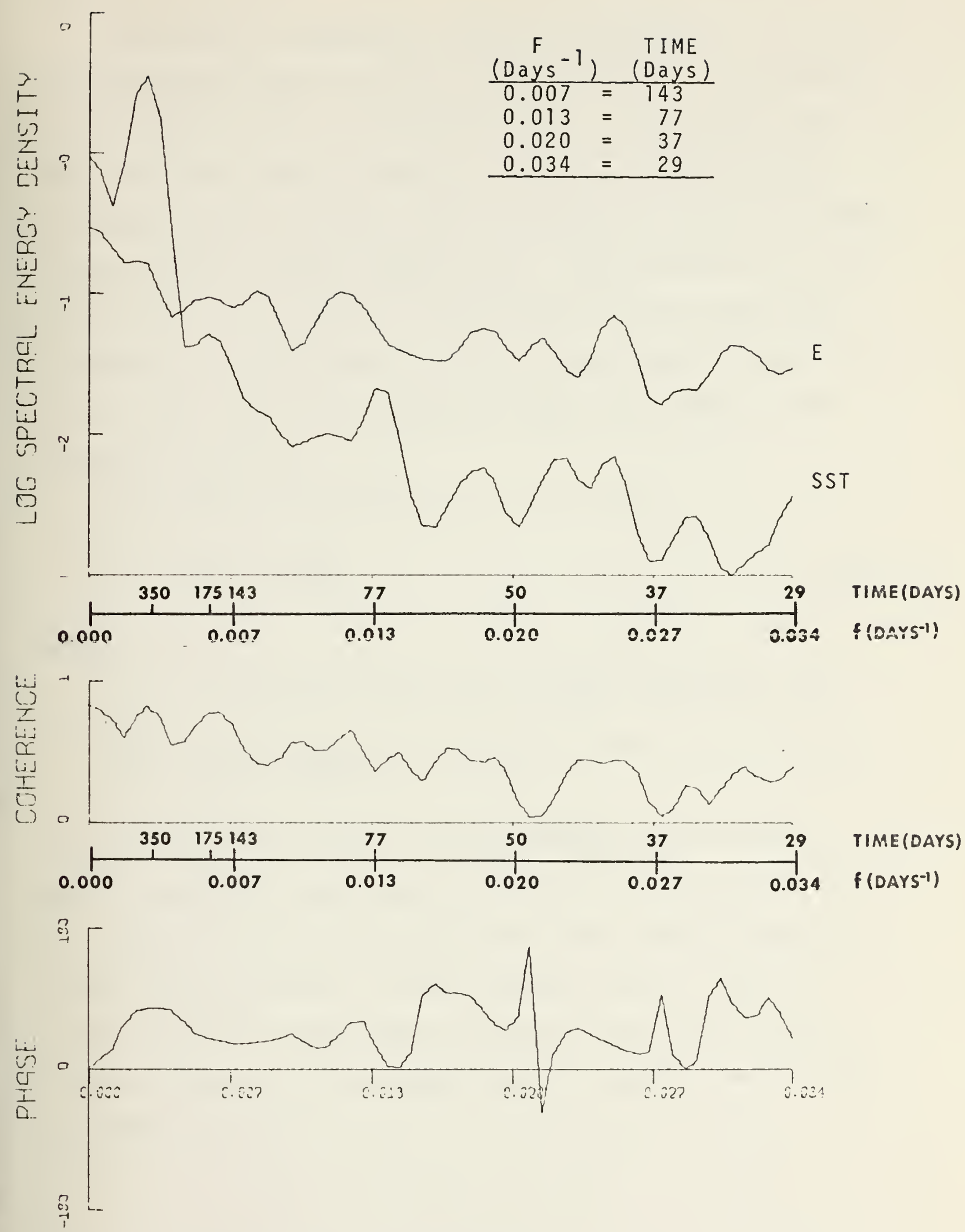

Figure 20. Spectral density, coherence and phase for the SST vs the evaporation. 
The heat of conduction, $Q C$, is the smallest of the heat flux terms and only $17 \%$ of its total variance is explained by the yearly cycle. From Table VIII it can be seen that this term also has an unusually large lag, approximately 130 days, and the lowest coherence of any of the heat budget terms with the surface temperature. From Figure 21 it can be seen that $Q C$ is nearly of the form of white noise with no distinct periodicities. This is confirmed by Figure B-5 which shows that $Q C$ is constantly small and contains few anomalies of note.

Like $Q E, Q C$ is a flux term of the form

$$
Q C=-A_{h} \frac{\partial T}{\partial z}
$$

where

$A_{h}$ is the eddy coefficient of heat conduction, and $\frac{\partial T}{\partial z}$ is the temperature gradient of the air overlying the sea surface.

For an area of the nature of OWS NOVEMBER, dominated by fairly constant temperature patterns for both the air and the ocean, it can be seen that this term would be expected to be fairly constant. It does contain quite a deal of energy in cycles other than the annual and shows evidence of good coherence at the semi-annual, seasonal and monthly periodicities. 


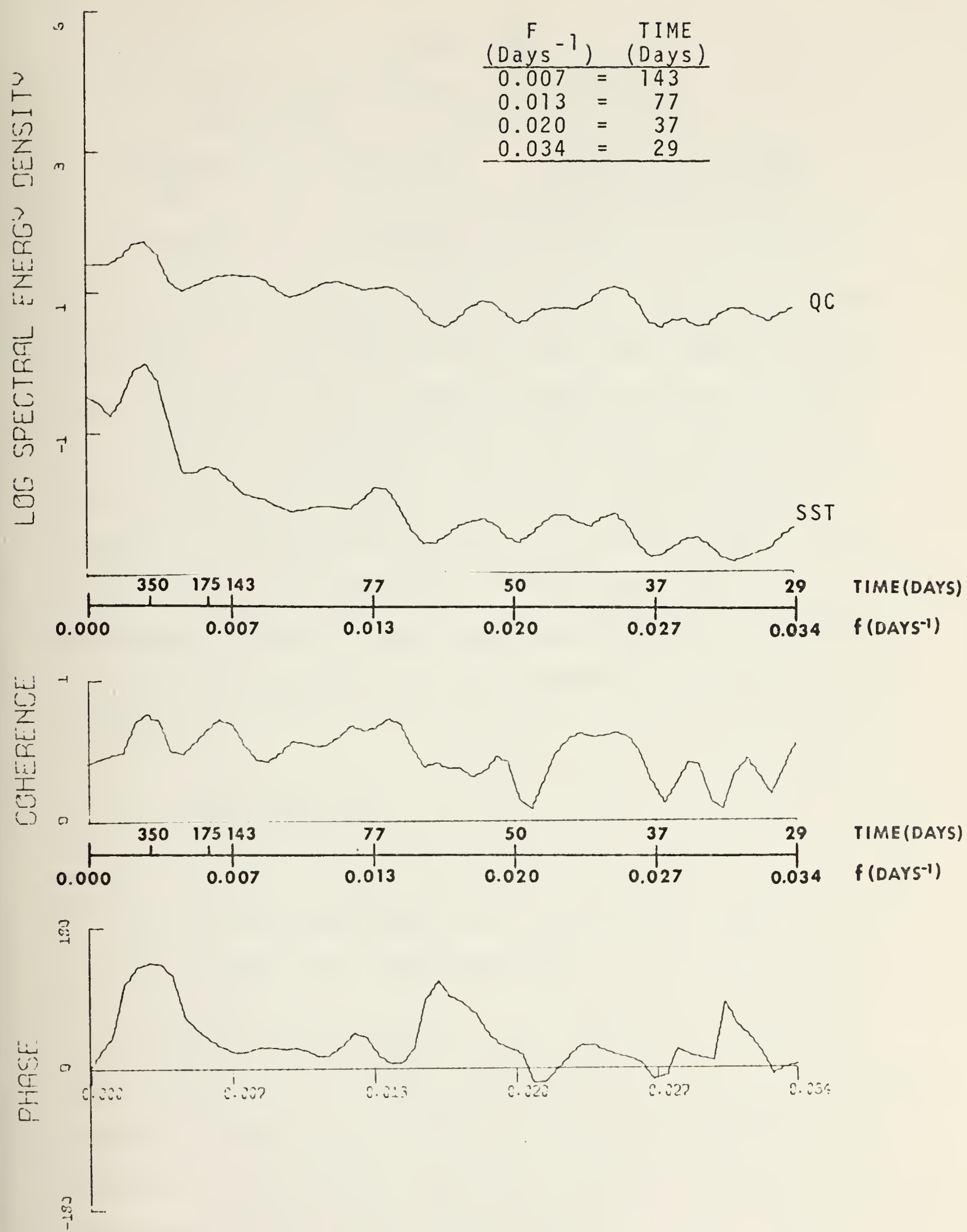

Figure 21. Spectral density, coherence and phase for the SST vs the convective heat. 

TABLE VIII.

Spectral results for the convective heat vs the SST at the yearly cycle

Parameter

Codes

QC VS SST
Coherence

.75694
Phase

(degrees)

134.1
Lag

(days)

130.7

The final heat budget term, the net heat transfer, QN, is perhaps the most interesting of the heat equation terms, representing the gain or loss of heat by the water column. To this point, the advective and local heat exchange terms have been ignored. However, since the values for the net radiation computed from Equation (1) did not result in zero values, then it is evident that these terms have to be considered. If $Q N$ is then viewed as a combination of the advective heat term and the local generation of heat it takes on the form:

$$
Q N=Q_{V}+Q_{\theta}
$$

where:

$Q_{V}$ is the advection of heat by currents, and

$Q_{\theta}$ is the local heat generated.

Over the annual cycle $Q_{\theta}=0$; therefore, $Q N$ must be representative of only the advection term. This is supported by the fact that for the entire 24-year period QN was found to have a slope of only 0.003 which signifies that no long term generation of heat has occurred. 

From Tables III and IX it can be seen that the net heat exchange is dominated by the annual cycle and is highly coherent with the surface temperature at this period.

Forty-two percent of the total variance is explained by the yearly cycle, which allows for some seasonal effects and Figure 22 shows some evidence of high coherence at the semi-annual and seasonal cycles. The lag is confirmed by both Table $V$ and Figure B-6. Much of this lag is undoubtedly due to the effect of the 58-day $1 \mathrm{ag}$ of the solar radiation and the balance by the other heat budget terms. In addition, the $\mathrm{lag}$ of $Q N$ and the surface pressure, considered here because of the previously noted high correlation of pressure with the surface salinity, may also contribute to the lag of QN and SST.

\section{TABLE IX}

Spectral results for the net radiation and related parameters at the yearly cycle

$\begin{array}{cccc}\begin{array}{c}\text { Parameter } \\ \text { Codes }\end{array} & \begin{array}{c}\text { Coherence } \\ \text { Squared }\end{array} & \begin{array}{c}\text { Phase } \\ \text { (degrees) }\end{array} & \begin{array}{c}\text { Lag } \\ \text { (days) }\end{array} \\ \text { QN vs SST } & .97954 & -76.7 & -74.8 \\ \text { PS VS SST } & .79993 & -120.6 & -118.6 \\ \text { QN VS PS } & .79250 & -46.9 & -45.3\end{array}$






Figure 22. Spectral density, coherence and phase for the SST vS the net radiation. 

Figures 22 through 24 give the complete spectral results for the net heat exchange, the surface temperature, and the surface pressure correlated versus each other. In all three instances the yearly peak dominates.

The major result of this segment is that the new solar radiation formula results in larger positive values of QN. Secondly, for the yearly cycle QN is a measure of heat advection and at OWS NOVEMBER this advection is of nearly equal importance as the solar radiation as an influence on the surface temperature. The negative lag makes QN a fairly good predictor of the surface temperature, even though much of the variance of the net heat exchange is contained in the seasonal cycles. The surface pressure seems to be less correlated with the surface temperature than it is with the salinity.

Very little has been mentioned about the autocorrelations; however, White (1974) has used this function in the study of SST and baroclinic transport anomalies. He found an apparent 5-year periodicity in the SST anomalies in the vicinity of OWS NOVEMBER. This cycle was attributed to deeper anomalous features in the baroclinic structure. 


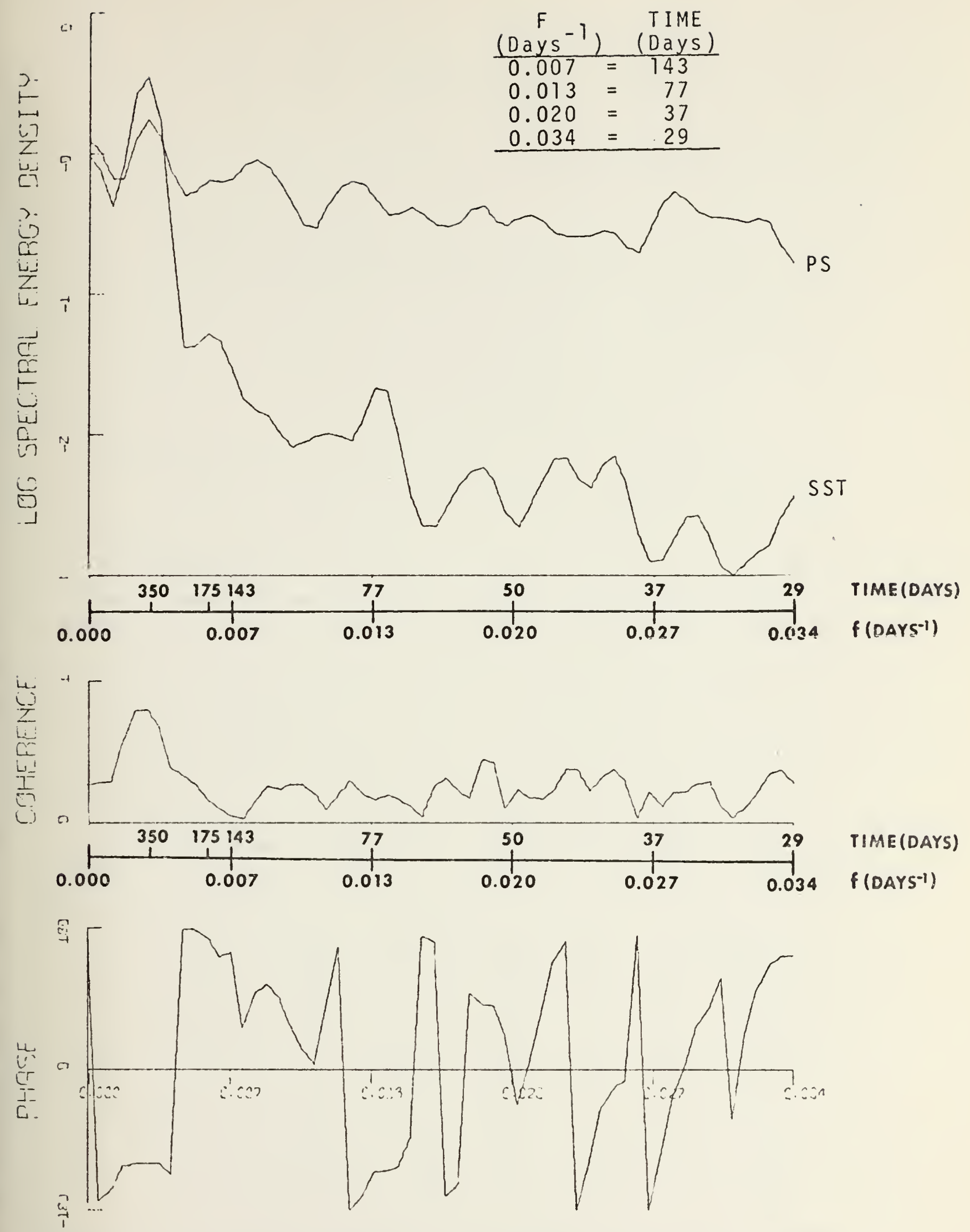

Figure 23. Spectral density, coherence and phase for the SST vs the surface pressure. 


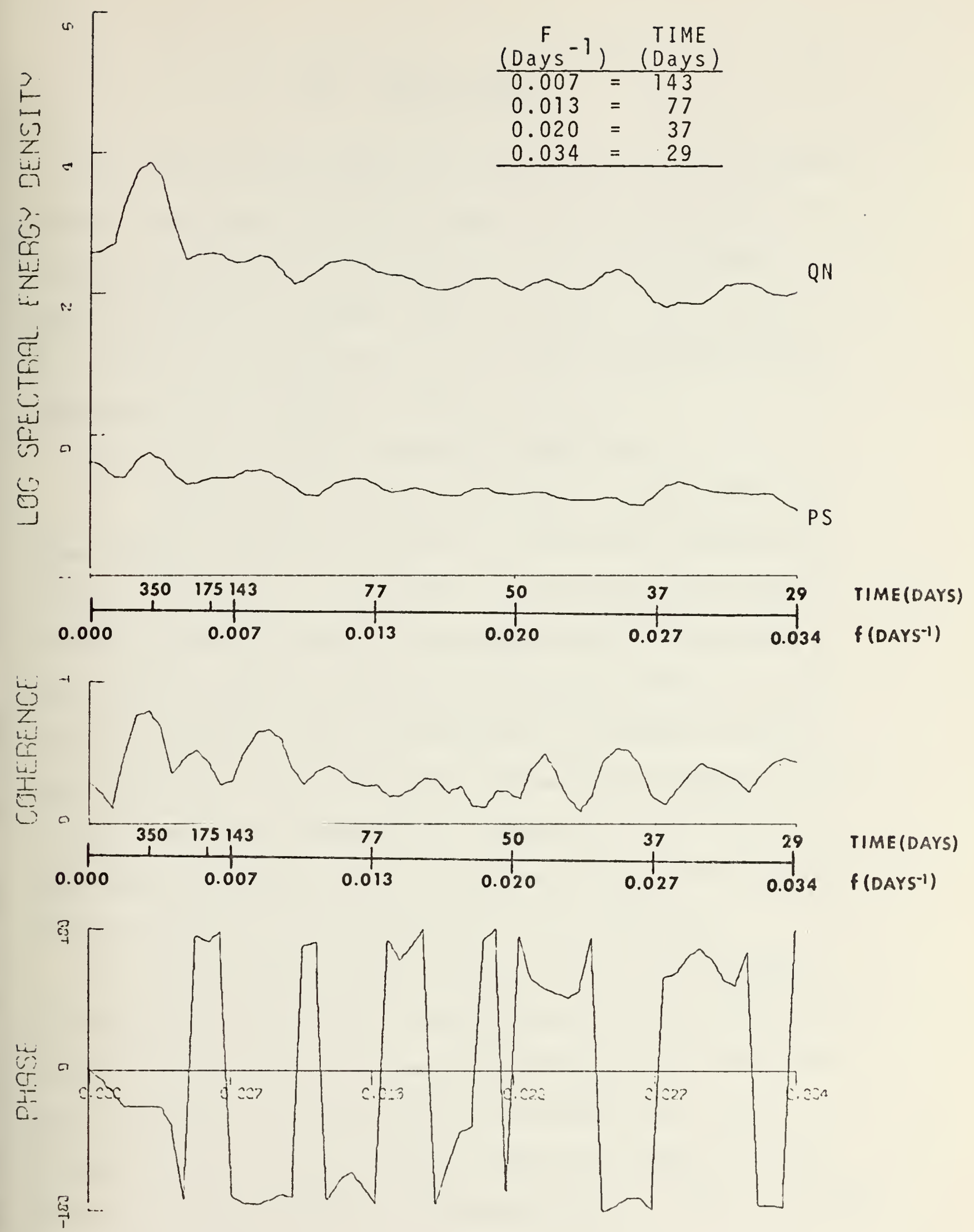

Figure 24. Spectral density, coherence and phase for the net radiation vs the surface pressure. 



\section{CONCLUSIONS}

The aim of this study was to use the tools of spectral analysis and other statistical approaches to describe the interactions of the air-sea interface at OWS NOVEMBER, specifically as to finding those parameters most closely associated with fluctuations of the daily average surface temperature and surface salinity.

The results of this research showed that:

1. The surface salinity from 1968 through 1970 was shown through regression analys is to be poorly correlated with the parameters traditionally associated with changes in the observed salinity. The evaporation, evaporation minus precipitation, and precipitation were found to have little correlation with fluctuations in surface salinity. These terms are non-conservative terms associated with the air-sea interface and their low correlation coefficients would appear to negate their importance in controlling the surface salinity at this location in the Pacific.

2. The surface pressure was found to be the most strongly correlated of all the parameters regressed against the surface salinity. It was therefore hypothesized that this represents the presence of a movement of a baroclinic system of cooler water from the subarctic region into the vicinity of OWS NOVEMBER, corresponding to a shift southward of the transition zone. 

3. For the yearly cycle, it was shown that the net radiation is a measure of the advection present and that this advection is of nearly equal magnitude as the solar radiation.

4. The new formula for the solar radiation leads to values for this term approximately 20 to 30 percent higher than previously computed. In turn, this leads to much larger positive values of the net heat exchange term and larger positive anomalies for both terms.

5. From the spectral analyses it was found that all the 24-year time series were dominated by the yearly cycle; except for the back radiation, cloud cover, wind speed and wind speed squared series which showed evidence of semiannual and seasonal cycles as well.

6. As predictors of the surface temperature, the solar radiation and advection in the form of the net heat exchange term were the only terms of suitable phase and coherence at the yearly cycle to be valid. The o.ther heat transfer terms seems to have less effect upon fluctuations of the surface temperature. Several of the observed parameters, such as the air temperature, were also highly coherent and, on the whole, had smaller lags associated with them. 



\section{APPENDIX A \\ THE AUTOCORRELATION FUNCTIONS}

Figure

Page

A-1 Autocorrelation curves for the SST

and the solar radiation, QS

A-2 Autocorrelation curves for the SST

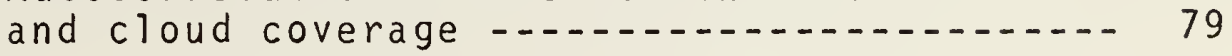

A-3 Autocorrelation curves for the cloud

coverage and the solar radiation

A-4 Autocorrelation curves for the SST

and the back radiation

A-5 Autocorrelation curves for the SST

and the air temperature

A-6 Autocorrelation curves for the SST

and the air-sea temperature difference _...-83

A-7 Autocorrelation curves for the SST

and the vapor pressure of the air

A-8 Autocorrelation curves for the

back radiation and cloud cover .......... 85

A-9 Autocorrelation curves for the SST

and the heat of evaporation

A-10 Autocorrelation curves for the SST

and the vapor pressure difference

A-11 Autocorrelation curves for the SST

and the wind speed

A-12 Autocorrelation curves for the SST

and the wind speed squared ............ 89

A-13 Autocorrelation curves for the SST

and evaporation _....................... 90

A-14 Autocorrelation curves for the SST

and the convective heat

A-15 Autocorrelation curves for the SST

and the net radiation

A-16 Autocorrelation curves for the SST

and surface pressure

A-17 Autocorrelation curves for the net

radiation and the surface pressure 



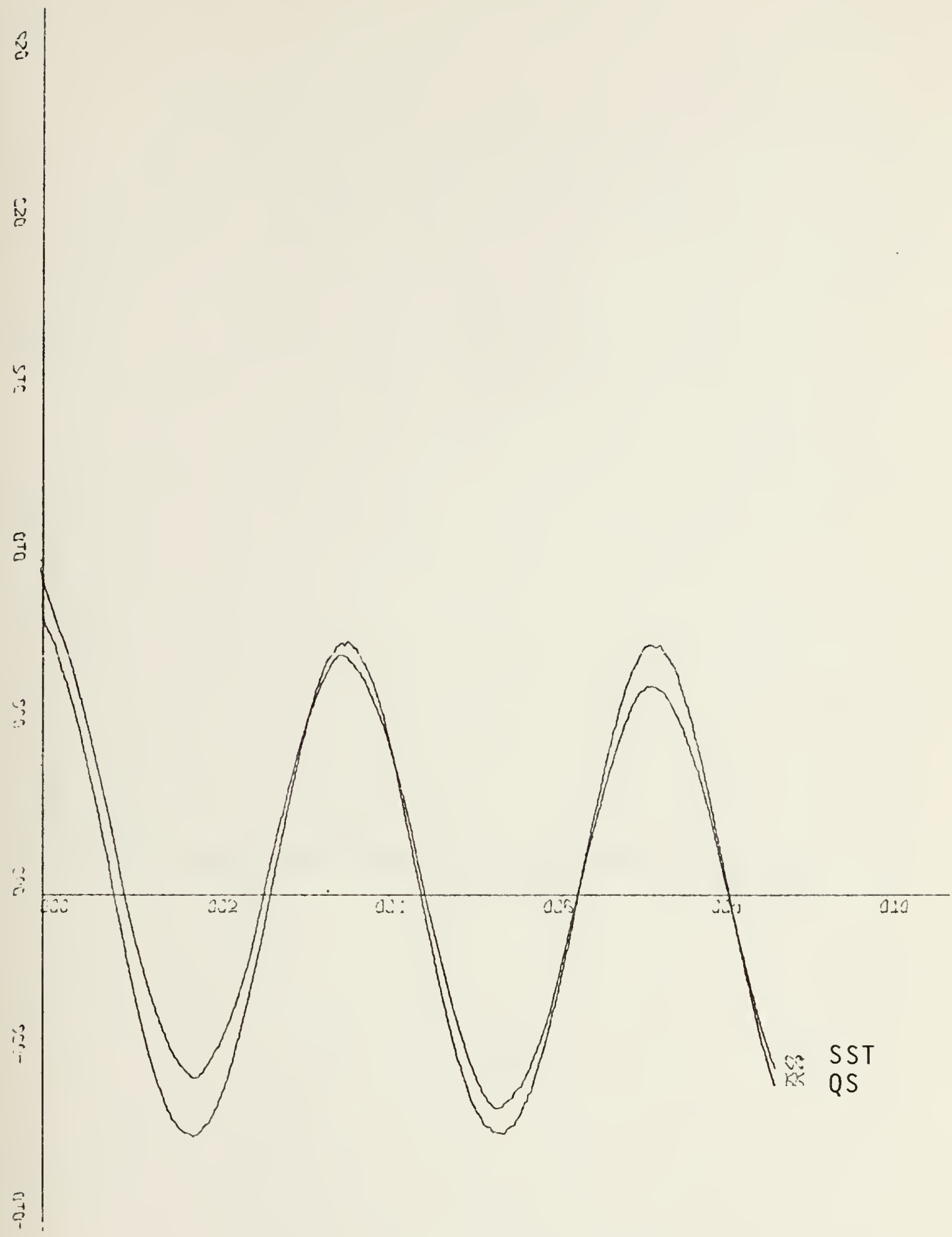

Figure A-1. Autocorrelation curves for the SST and the solar radiation, QS (abscissa is given in hundreds of days). 



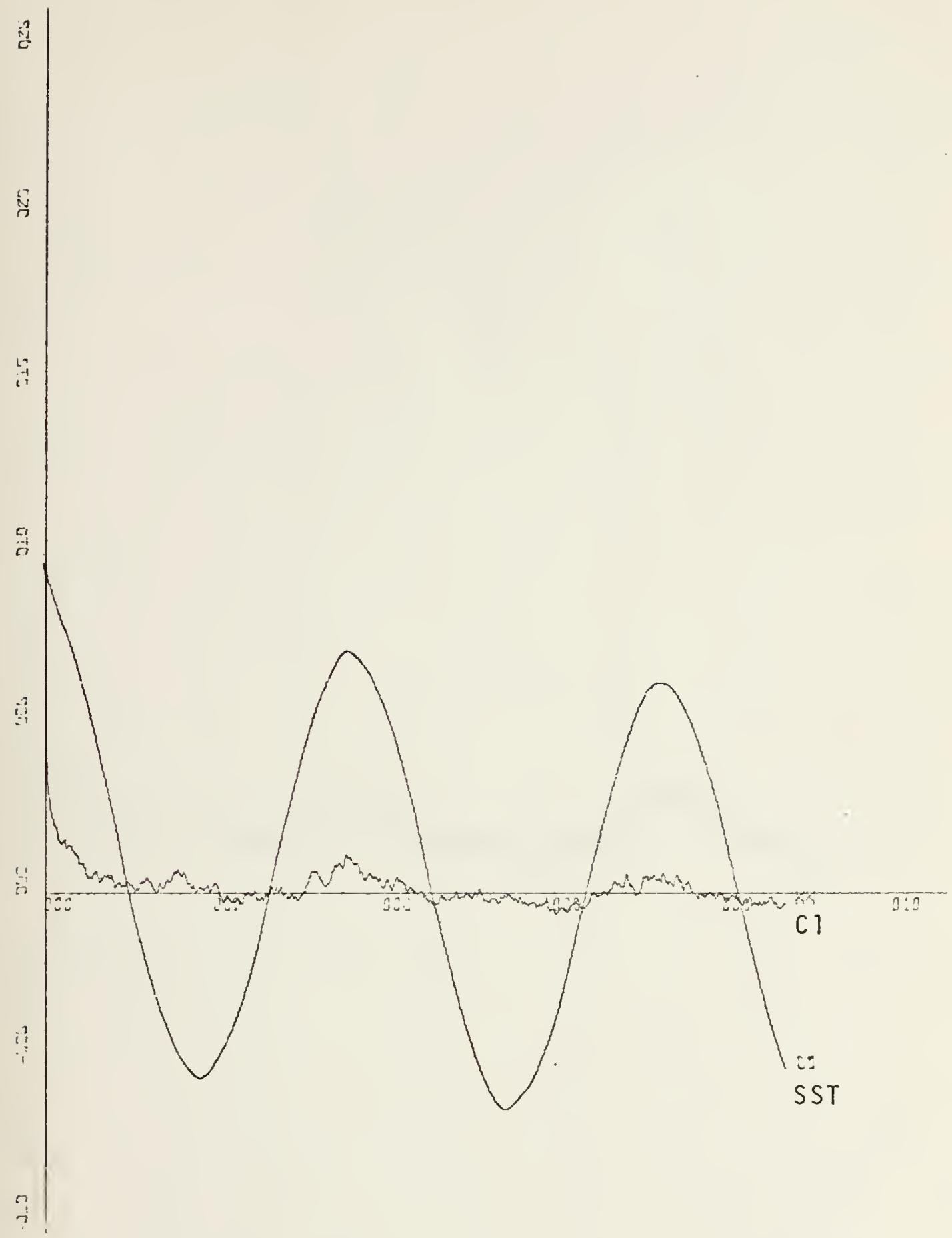

Figure A-2. Autocorrelation curves for the SST and cloud coverage (abscissa is given in hundreds of days). 



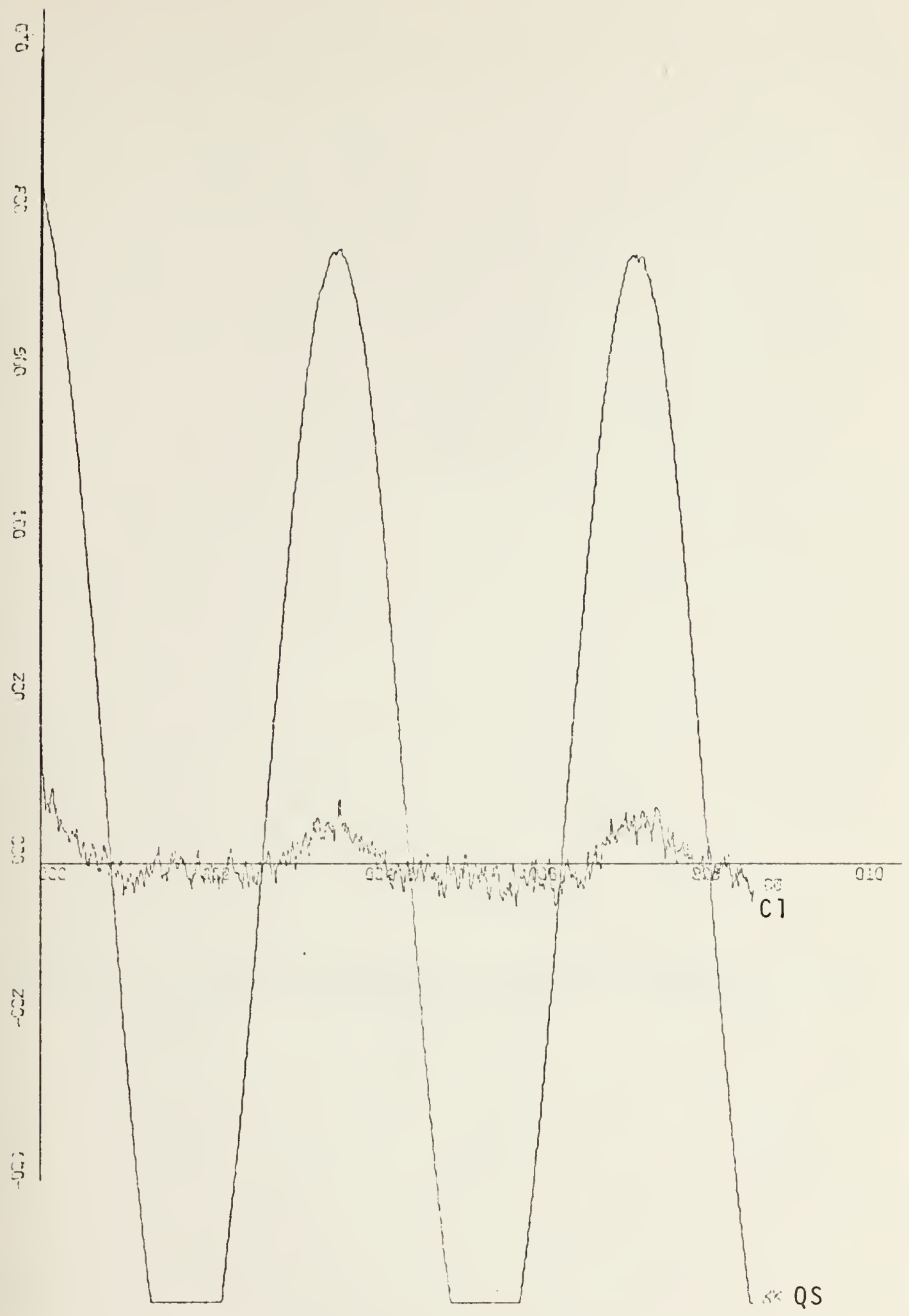

Figure A-3. Autocorrelation curves for the cloud coverage and the solar radiation (abscissa is given in hundreds of days). 



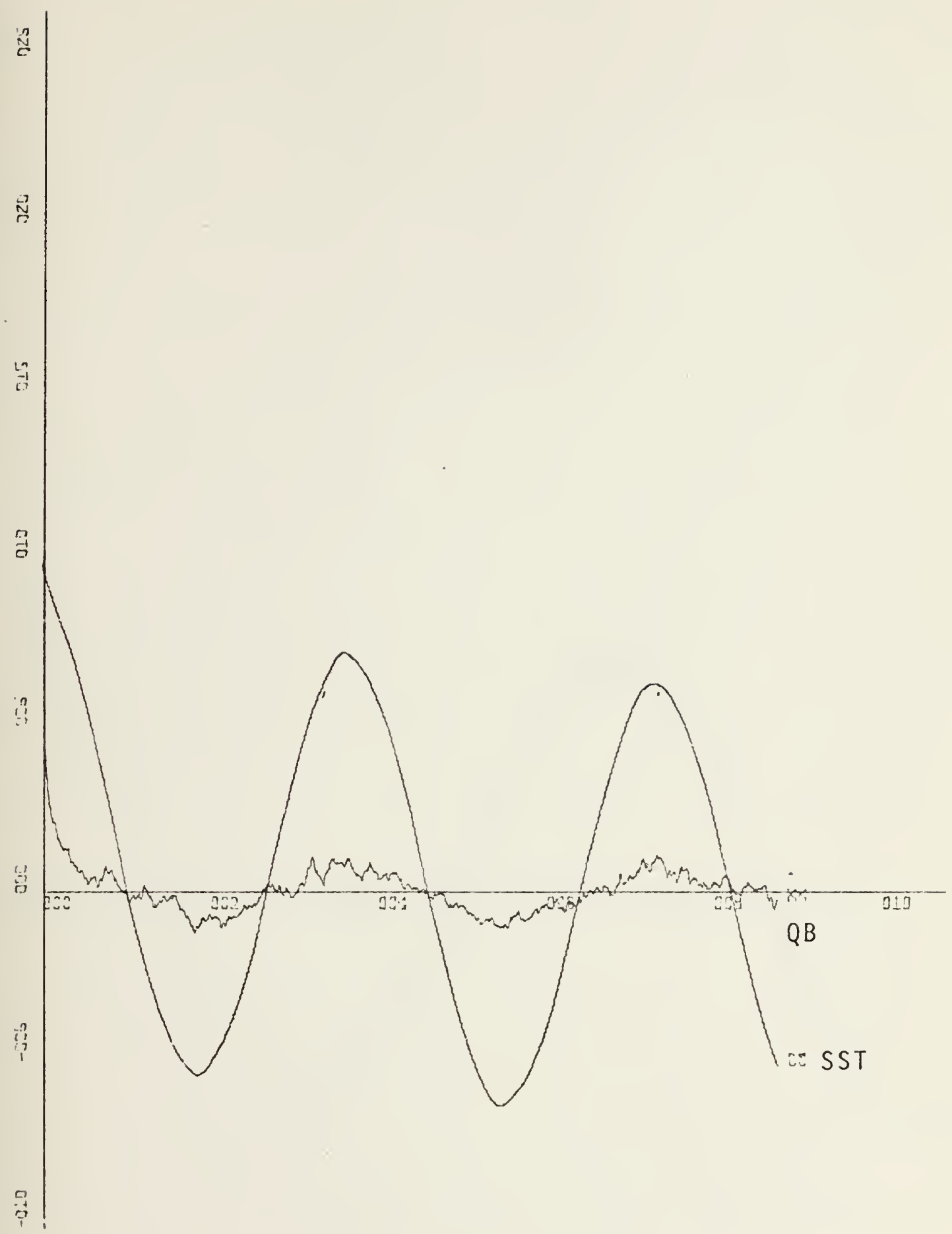

Figure A-4. Autocorrelation curves for the SST and the back radiation (abscissa is given in hundreds of days). 



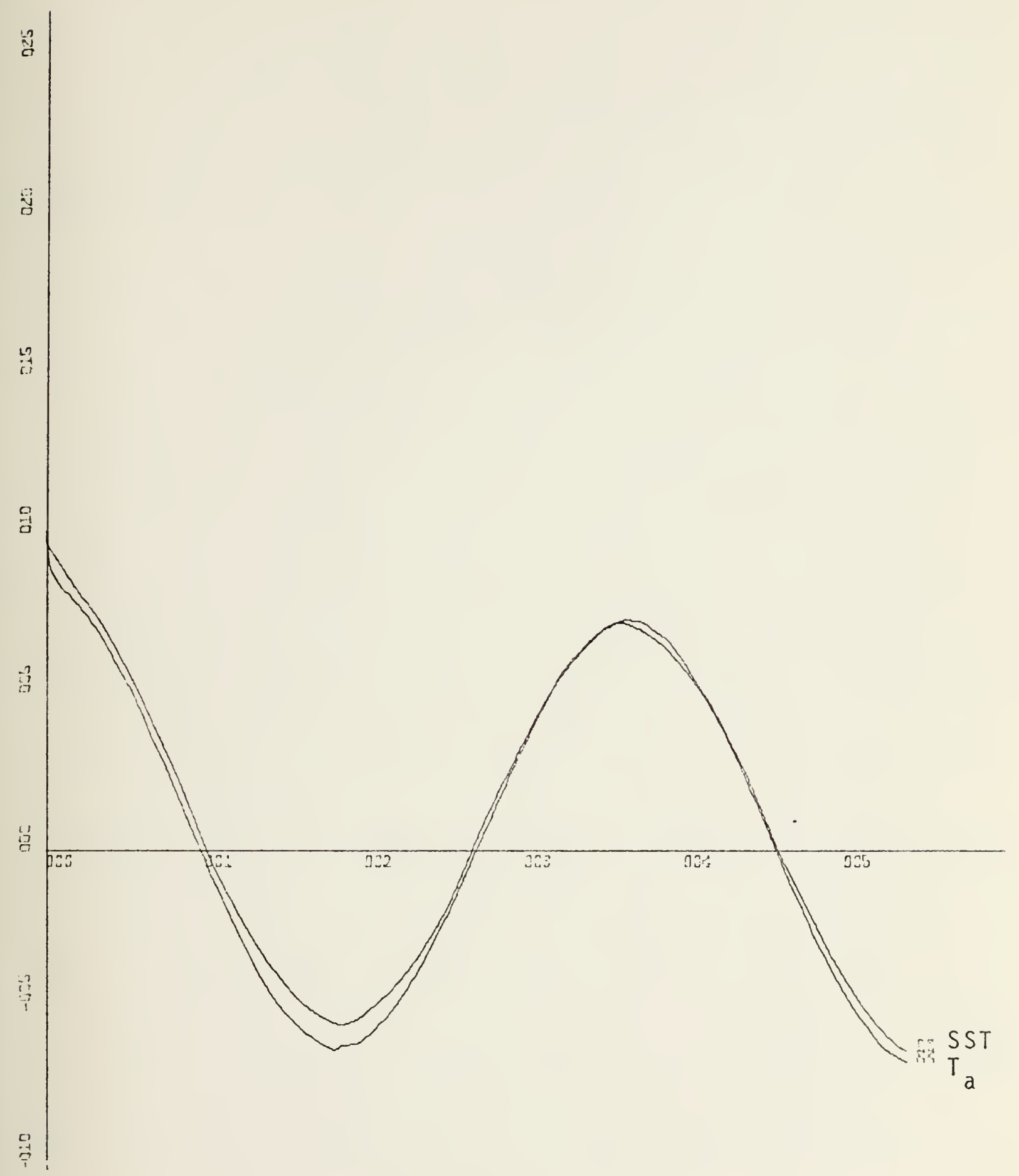

Figure A-5. Autocorrelation curves for the SST and the air temperature (abscissa is given in hundreds of days). 




Figure A-6. Autocorrelation curves for the SST and the a ir-sea temperature difference (abscissa is given in hundreds of days.). 





Figure A-7. Autocorrelation curves for the SST and the vapor pressure of the air (abscissa is given in hundreds of days). 



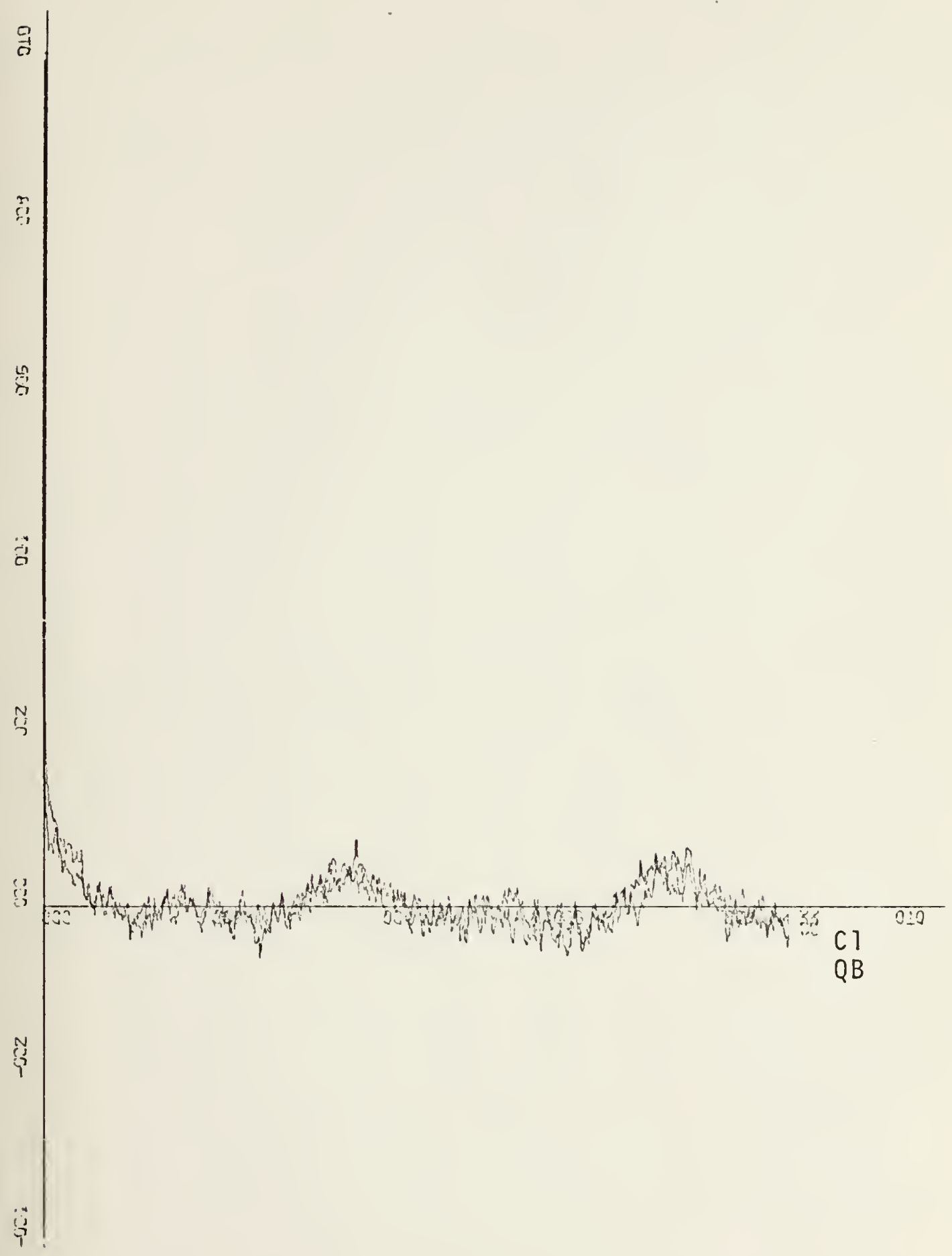

Figure A-8. Autocorrelation curves for the back radiation and cloud cover (abscissa is given in hundreds of days). 



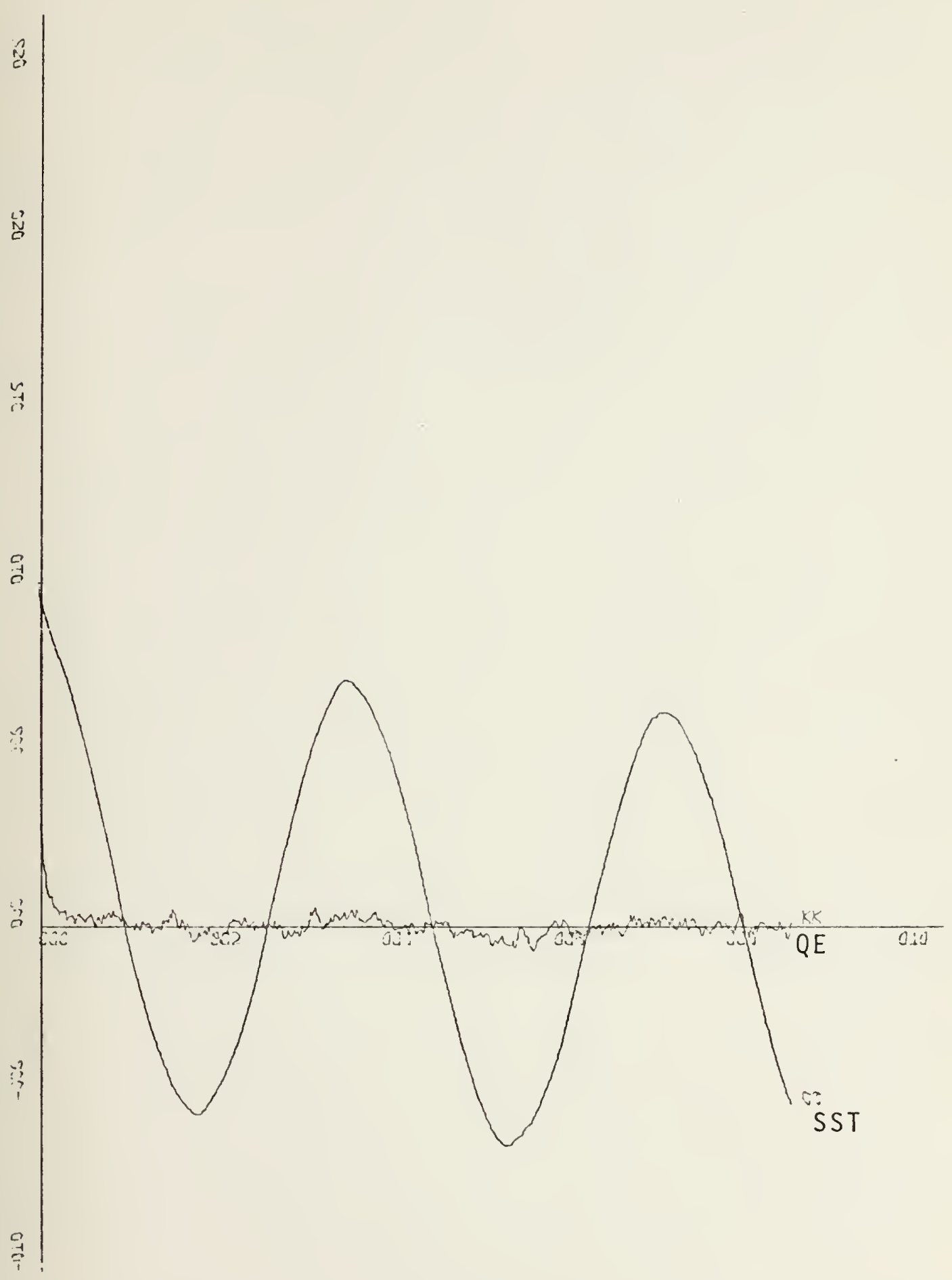

Figure A-9. Autocorrelation curves for the SST and the heat of evaporation (abscissa is given in hundreds of days). 





Figure A-10. Autocorrelation curves for the SST and the vapor pressure difference (abscissa is given in hundreds of days). 



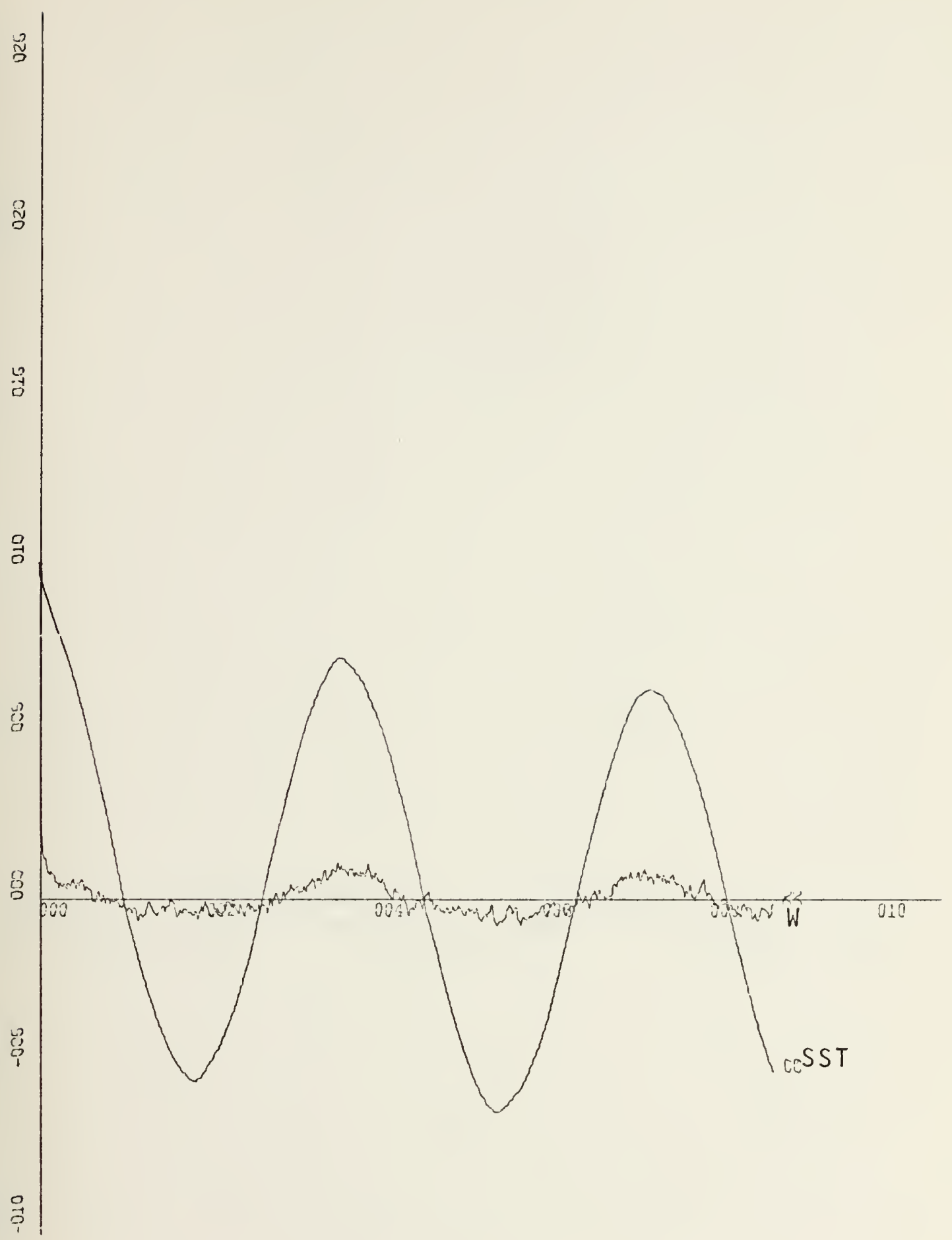

Figure A-11. Autocorrelation curves for the SST and the wind speed (abscissa is given in hundreds of days). 



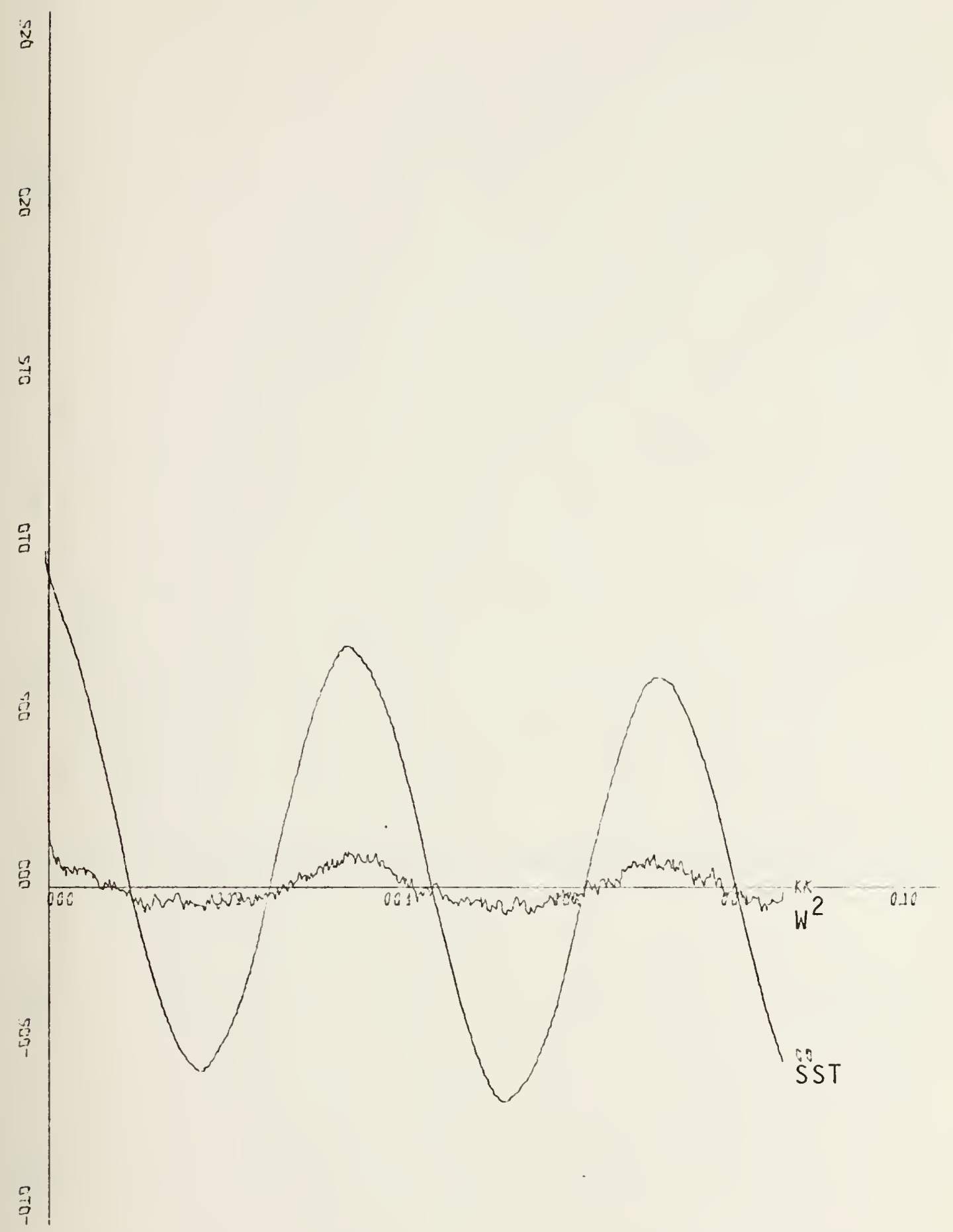

Figure A-12. Autocorrelation curves for the SST and the wind speed squared (abscissa is given in hundreds of days). 



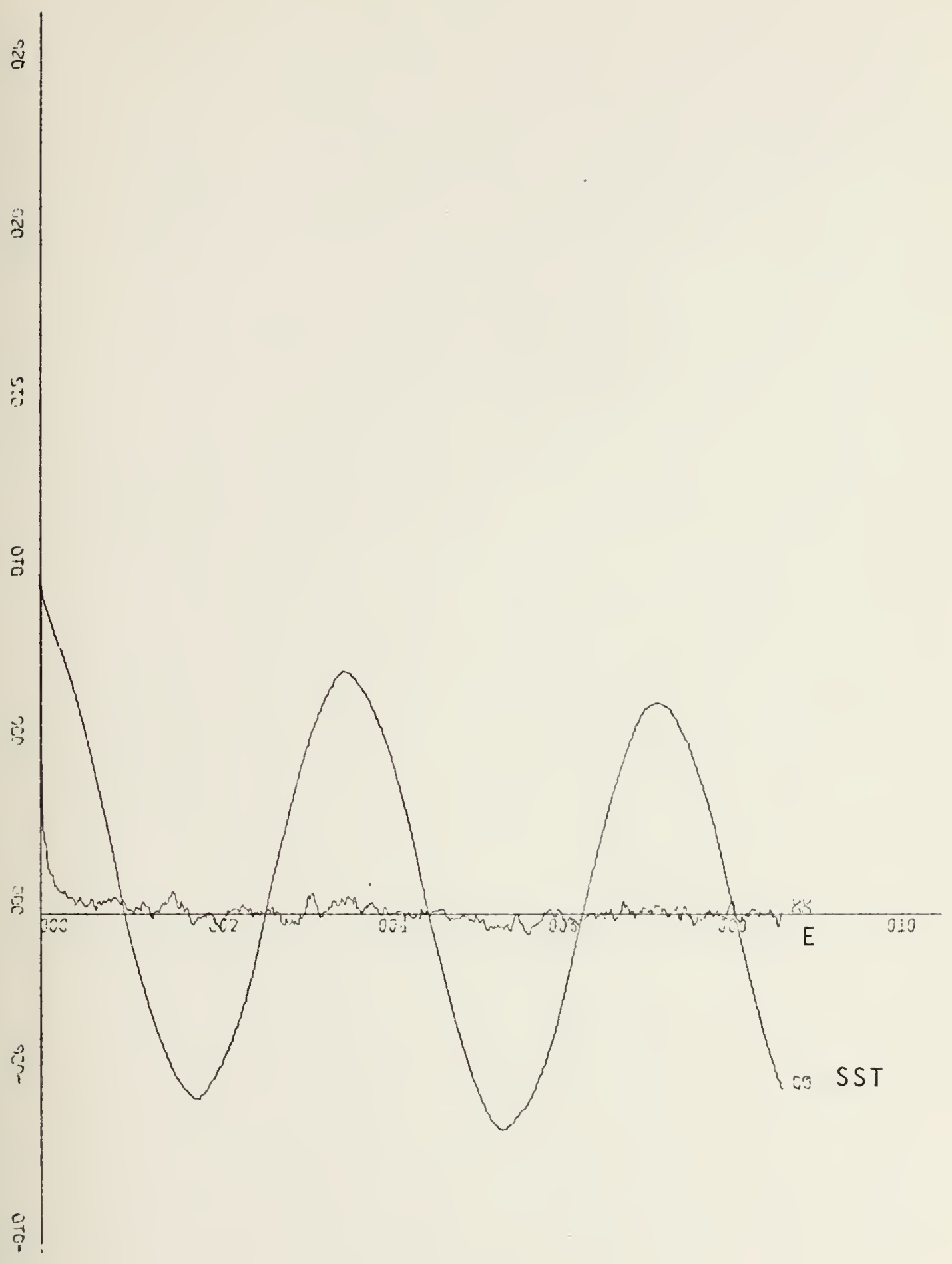

Figure A-13. Autocorrelation curves for the SST and evaporation (abscissa is given in hundreds of days). 



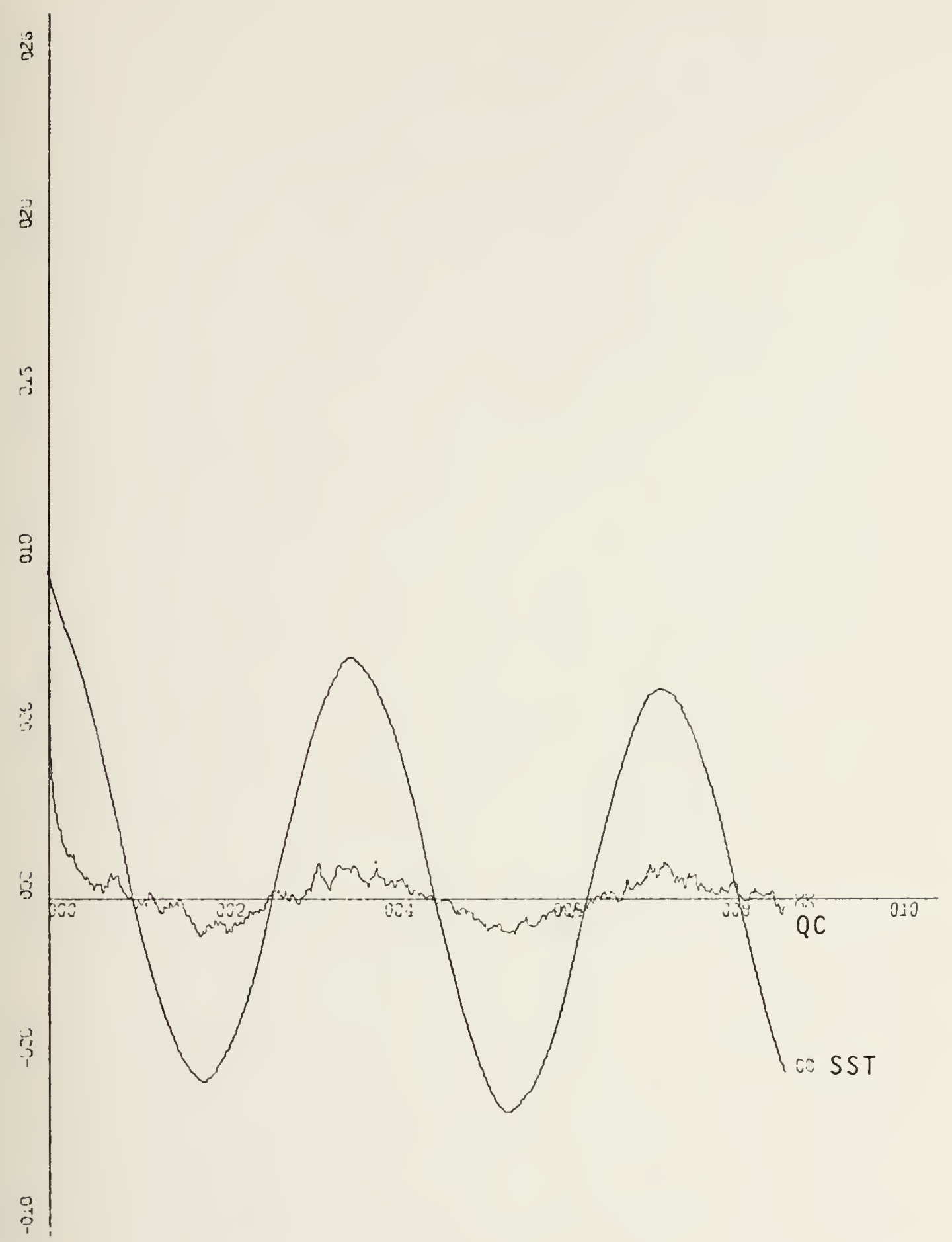

Figure A-14. Autocorrelation curves for the SST and the convective heat (abscissa is given in hundreds of days). 



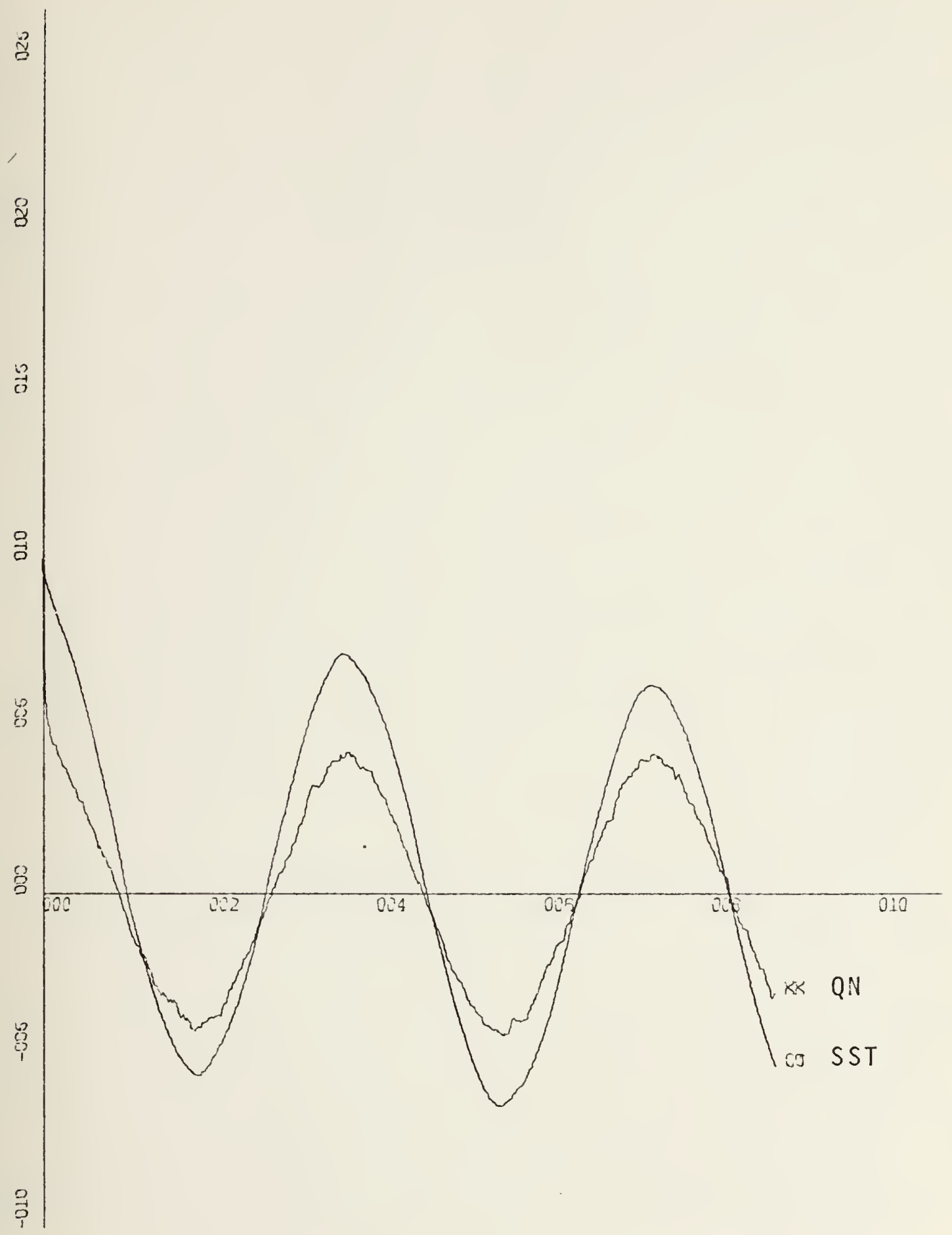

Figure A-15. Autocorrelation curves for the SST and the net radiation (abscissa is given in hundreds of days). 



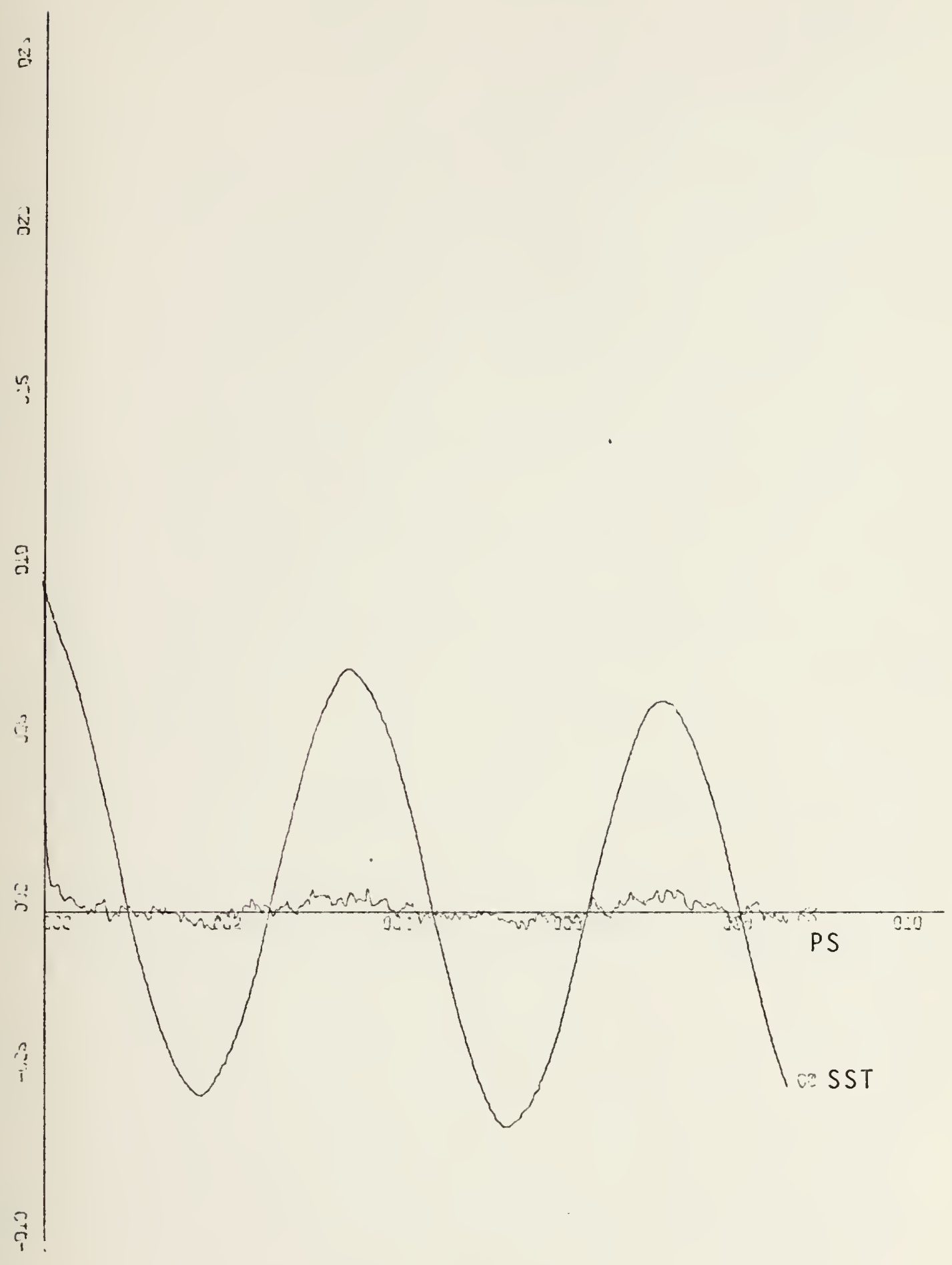

Figure A-16. Autocorrelation curves for the SST and surface pressure (abscissa is given in hundreds of days). 



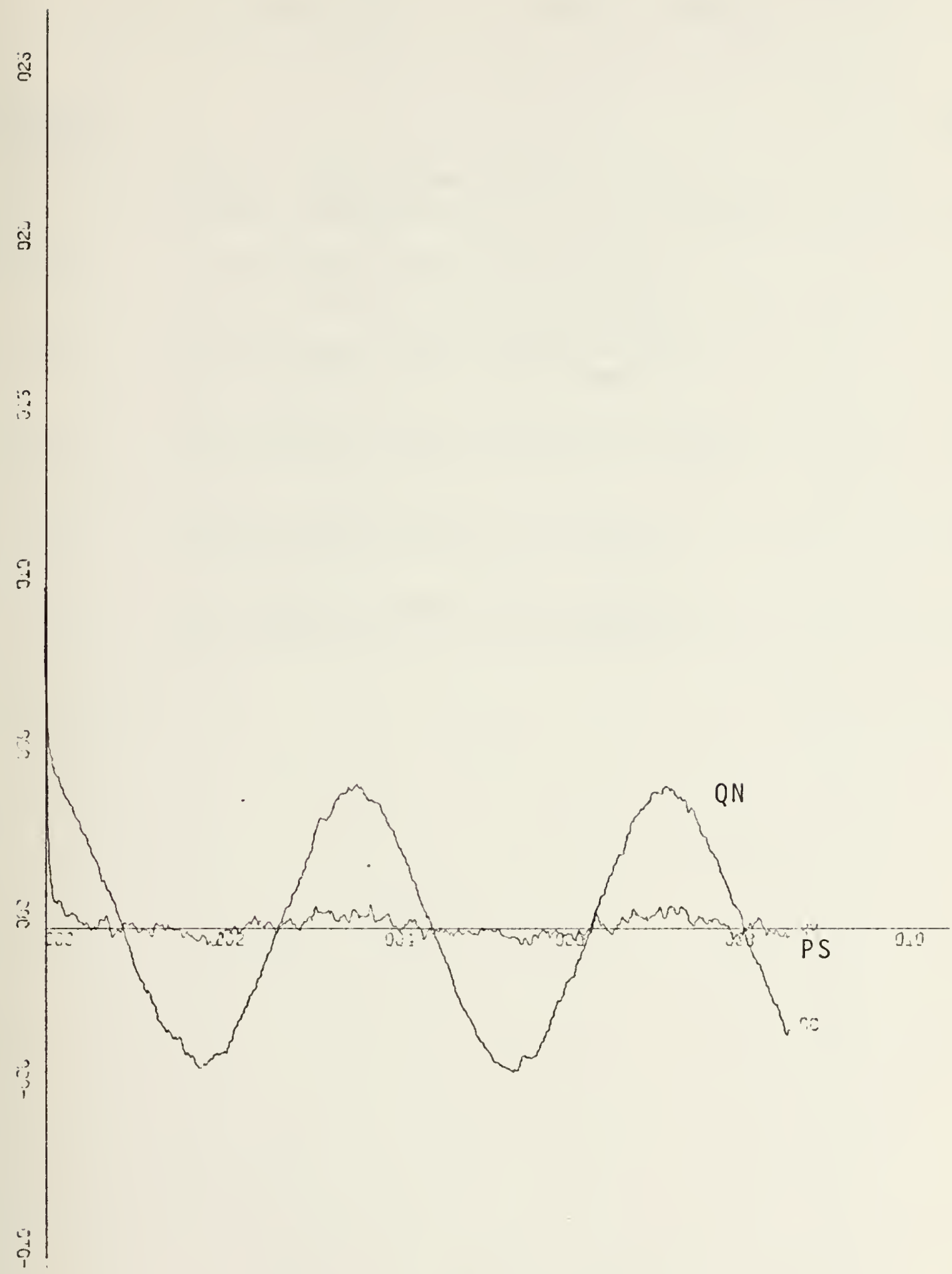

Figure A-17. Autocorrelation curves for the net radiation and the surface pressure (abscissa is given in hundreds of days). 



\section{APPENDIX B \\ FIFTEEN-YEAR TIME SERIES SEGMENTS}

Figure

Page

B-1 Fifteen-year time series of the

surface temperature and its anomaly -...-. 96

B-2 Fifteen-year time series of the solar radiation and its anomaly

B-3 Fifteen-year time series of the back radiation and its anomaly -.......- 98

B-4 Fifteen-year time series of the heat of evaporation and its anomaly -....- 99

B-5 Fifteen-year time series of the convective heat and its anomaly

B-6 Fifteen-year time series of the net radiation and its anomaly 


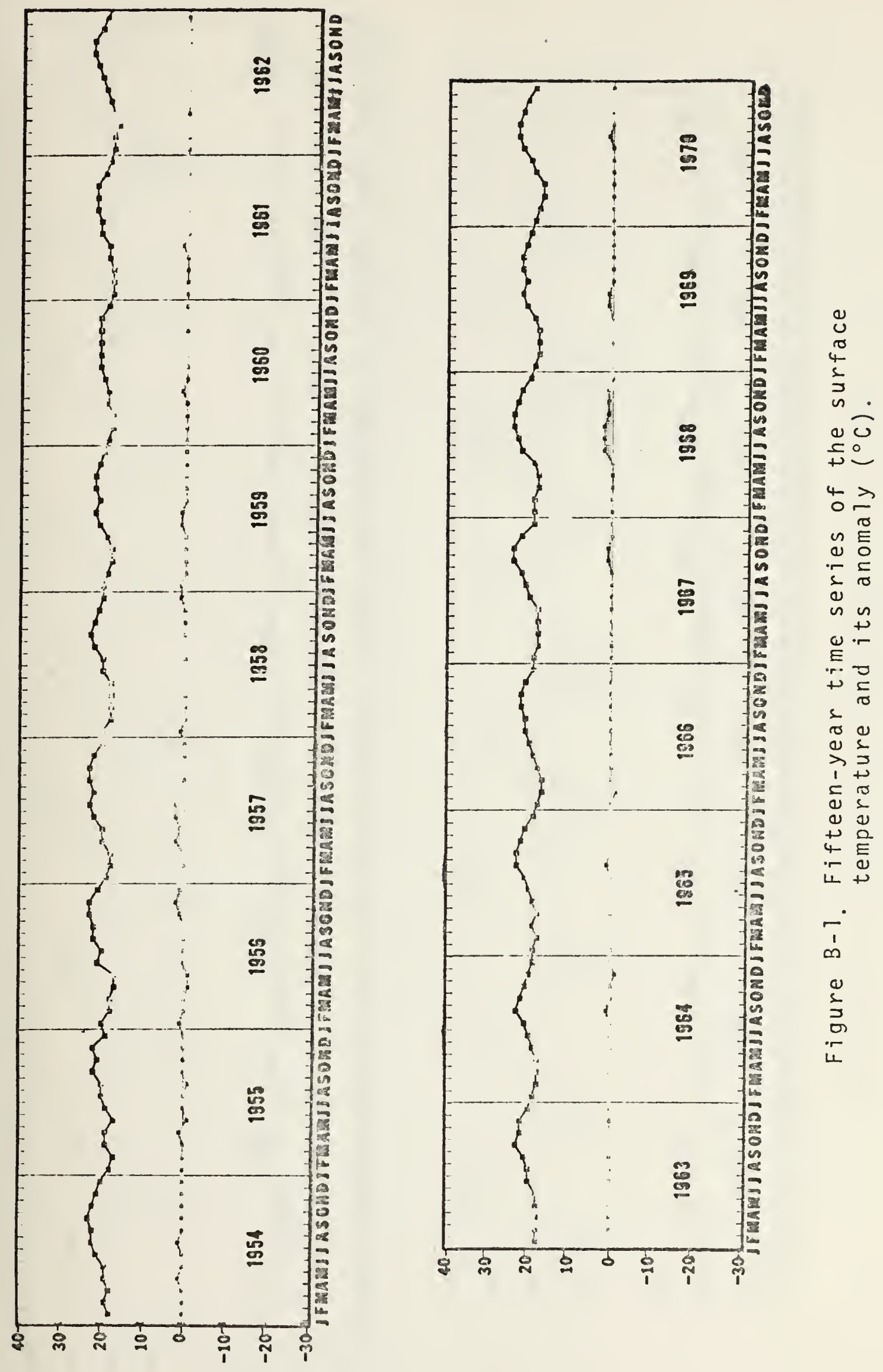



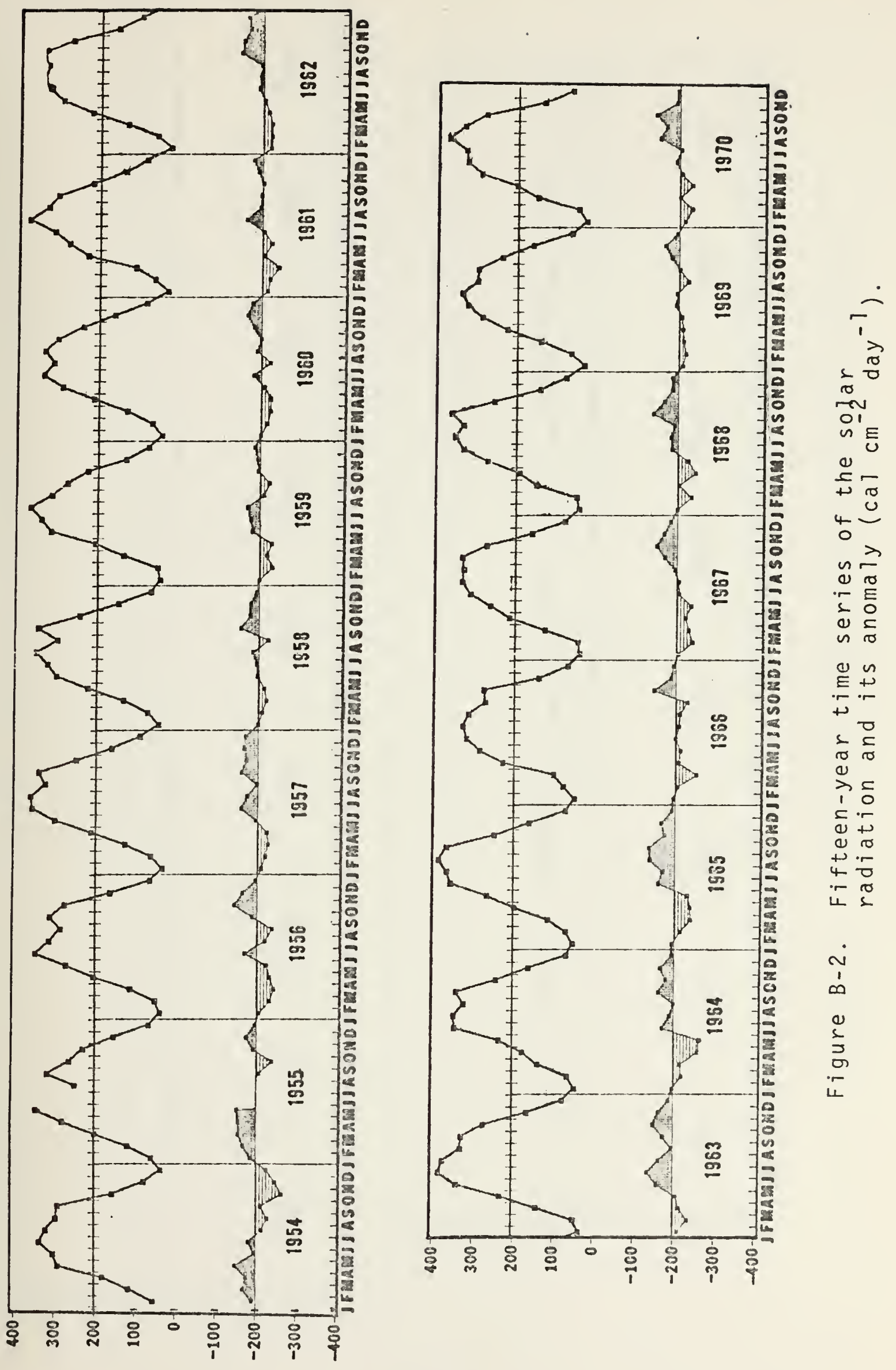










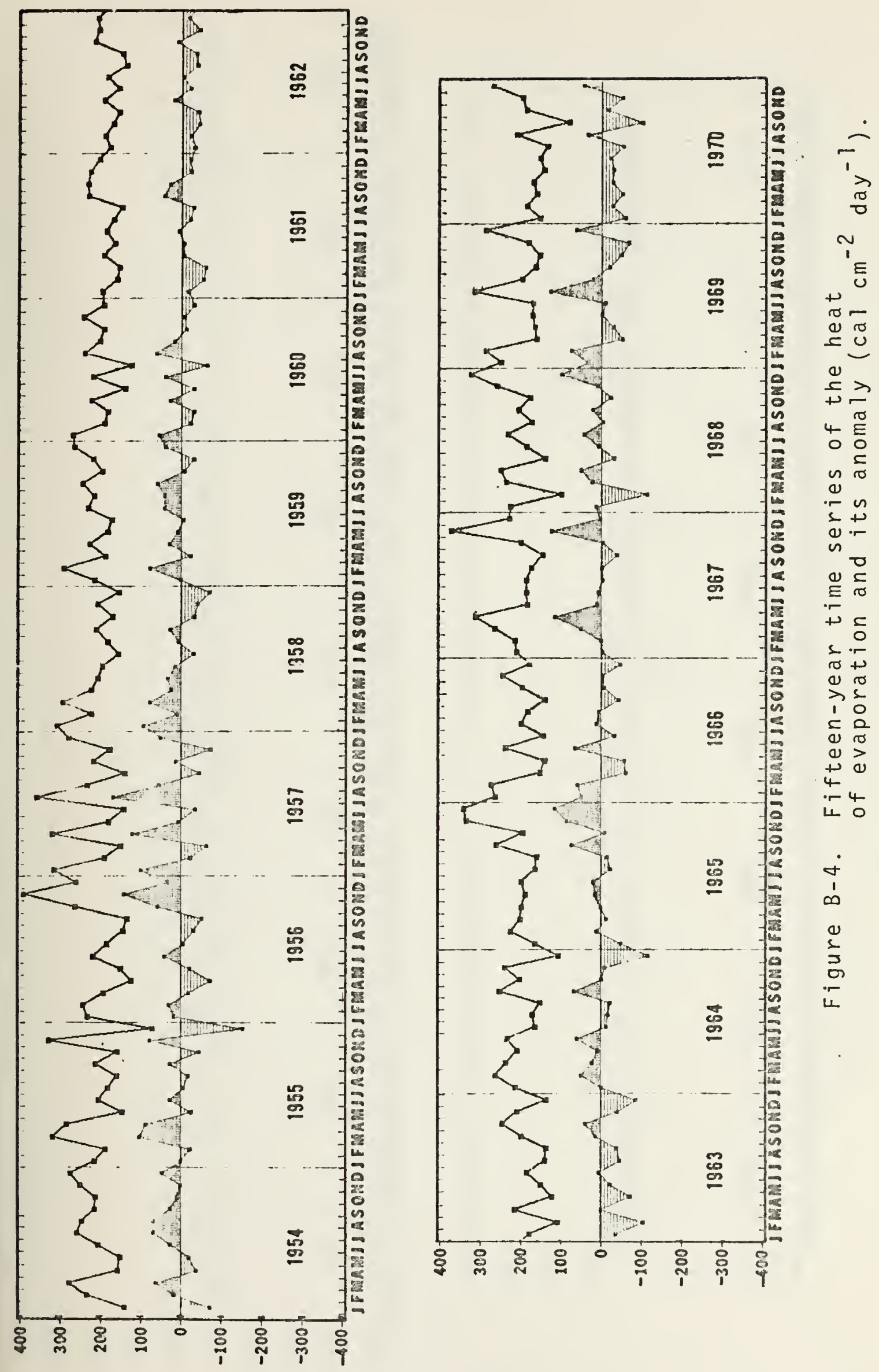





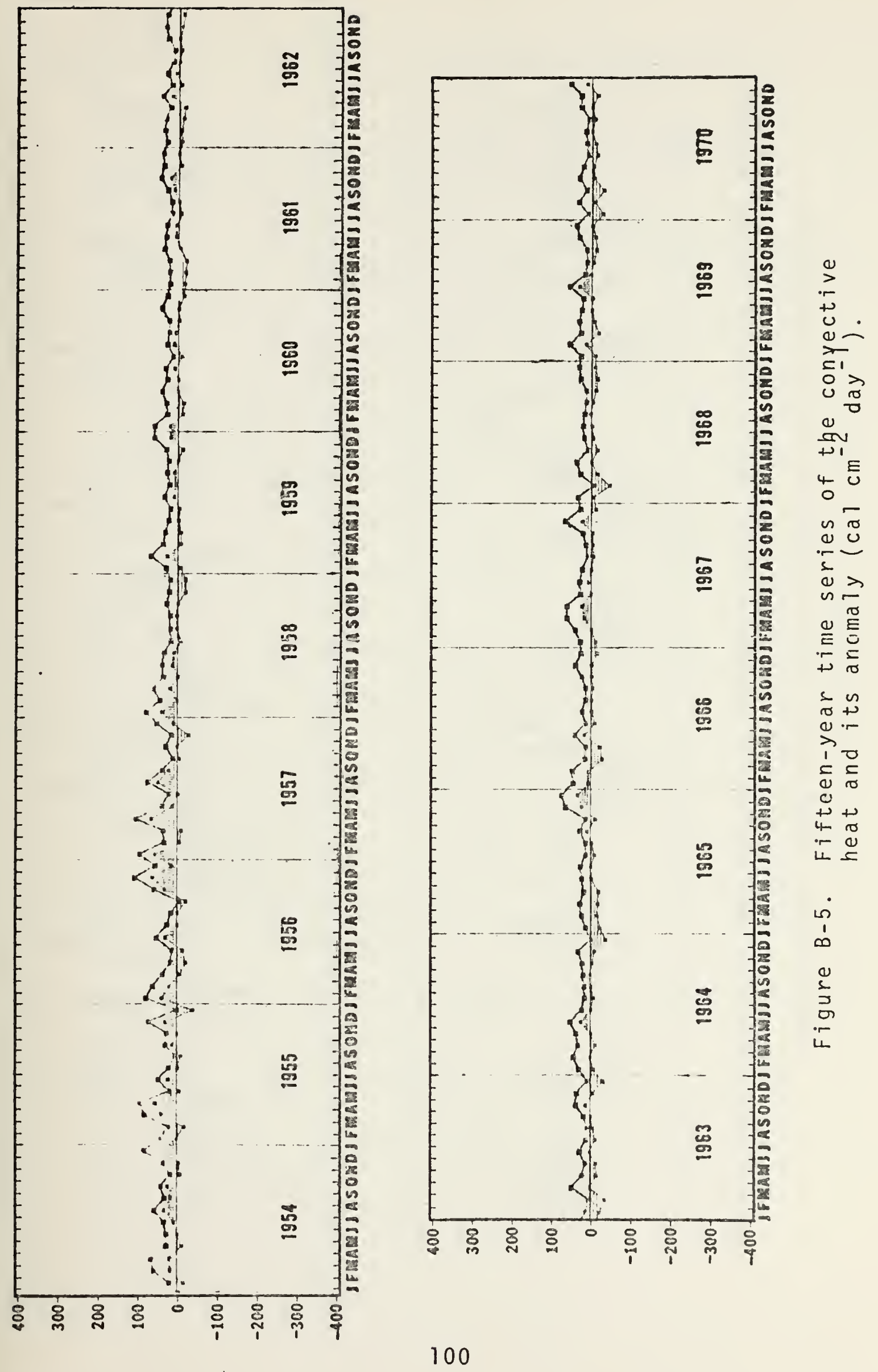




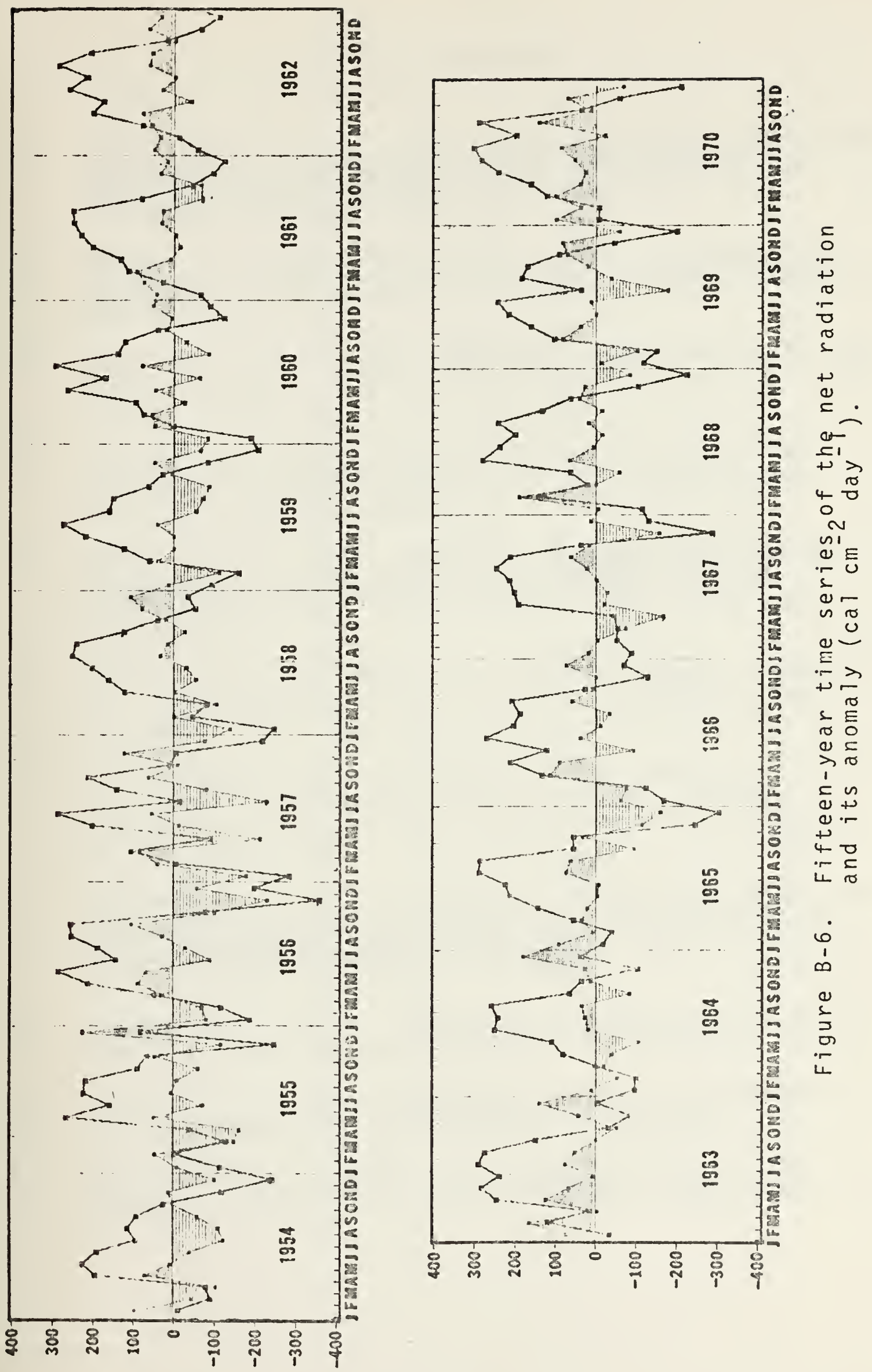



\section{LIST OF REFERENCES}

1. Beland, C.L., 1971: Sea surface and related subsurface temperature anomalies at several positions in the Northwest Pacific Ocean. Master's Thesis, Naval Postgraduate School, Monterey.

2. Bendat, J.S. and Piersol, A.G., 1971: Random Data: Analysis and Measurement Procedures. Wiley Interscience, New York.

3. Bernstein, R.L., 1974: Mesoscale ocean eddies in the North Pacific: Westward Propagation. Science, v. 183 $(4120): 71-72$.

4. Clark, N.E., 1972: Specification of Sea Surface Temperature Anomaly Patterns in the Eastern North Pacific. J. Phys. Oceanogr. V. 2(3): 391-404.

5. Dorman, C.E., 1974: Analysis of meteorological and oceanographic data from ocean station vessel $\mathrm{N}$ (30N 140W). Phd. Thesis, Oregon State University, Corvallis.

6. Elliot, W.P. and Reed, R.K., 1973: Oceanic rainfall off the Pacific Northwest Coast. J. Geophys. Res. v. $78(6): 941-948$.

7. Favorite, F. and D.R. McLain, 1973: Coherence in Transpacific Movements of Positive and Negative Anomalies of Sea-Surface Temperature 1953-60, Nature, v. 244, pp 139-143.

8. Hansen, D.E., 1973: A study of surface, $50^{\circ}$ meter and 200 meter temperature and salinity fluctuations at Ocean Weather November, 1968-1970. Master's Thesis, Naval Postgraduate School, Monterey.

9. Husby, D.M., 1968: Oceanographic observations North Pacific Ocean Station November. CG 373-18.

10. Husby, D.M., 1969: Oceanographic Observations North Pacific Ocean Station November. CG 373-26.

11. List, Robert J., 1951: Smithsonian Meteorological Tables. Smithsonian Miscel. Collect., Washington, D.C., 1951. 

12. Namias, J., 1970: Macroscale variations in sea-surface temperatures in the North Pacific. J. Geophys. Res. v. $75(3): 565-582$.

13. Namias, J. and R.M. Born, 1970: Temporal coherence in North Pacific sea-surface temperature patterns. J. Geophys. Res., v. 75(30): 5952-5955.

14. Namias, J., 1971: The 1968-69 winter as an outgrowth of sea and air coupling during antecedent seasons. J. Phys. Oceanogr. v. 1(2): 65-81.

15. National 0ceanographic Data Center, 1972: Ocean Weather Station November Data, Washington, D.C.

16. Robinson, M.K., 1971: Atlas of monthly mean sea surfacesubsurface temperature and depth of the top of the thermocline North Pacific Ocean. Fleet Numerical Weather Central.

17. Roden, G.I., 1970: Aspects of the Mid-Pacific Transition Zone. J. Geophys. Res., v. 75(6): 1097-1109.

18. Roden, G.I., 1971: Aspects of the transition zone in the Northeastern Pacific. J.Geophys. Res., v. 76(15): $3462-3475$.

19. Roden, G.I., 1972: Temperature and salinity fronts at the boundaries of the subarctic-subtropical transition zone in the Western Pacific. J. Geophys. Res., v. $77(36): 7175-7187$.

20. Secke1, G.R., 1968: A time sequence oceanographic investigation in the North Pacific trade wind zone. Trans. Amer. Geophys. Union, v. 49:377-387.

21. Secke1, G.R. and Marion Y.Y. Yong: 1970: Harmonic functions for sea-surface temperatures and salinities, Koko Head, Oahu, 1956-69, and sea-surface temperatures, Christmas Island, 1954-69. Fishery Bulletin, v. 69(1): 1970 .

22. Seckel, G.R., 1970: The trade wind zone oceanography pilot study part VIII: sea-level meteorological properties and heat exchange processes July 1963 to June 1965. U.S. Fish and Wildlife Service, Special Scientific Report-Fisheries No. 612, U.S.D. of I. 

23. Tucker, G.B., 1961: Precipitation over the North Atlantic Ocean. Quart. J. Roy. Meteor. Soc., v. $87: 147-158$.

24. Tully, J.P., 1964: Oceanographic regions and assessment of temperature structure in the seasonal zone of the North Pacific Ocean. J. Fish. Res. Bd. of Canada, v. $21(5): 941-970$.

25. U.S. Dept. of Commerce, 1961: Climatological and oceanographic atlas for mariners, North Pacific Ocean. U.S. Department of the Navy, Office of Climatology and oceanographic Analysis Division.

26. White, W.B., 1974: SST anomaly development and changes in the general circulation in the upper ocean. NORPAX Highlight, pp. 3-6.

27. Wickett, W.P., and J.A. Thomson, 1971: Transport computations for the North Pacific Ocean, 1970. Fish. Res. Bd. Canada, Tech. Rep. No. 238.

28. Wickett, W.P., and J.A. Thomson, 1971: Transport computations for the North Pacific Ocean, 1969. Fish. Res. Bd. Canada, Tech. Rep. No. 239.

29. Wyrtki, K., 1965: The average heat balance of the North Pacific Ocean and its relation to ocean circulation. J.Geophys. Res., v. 70(18): 4547-4559. 

No. Copies

2

Cameron Station

Alexandria, VA 22314

2. Library (Code 0212)

Naval Postgraduate School

Monterey, CA 93940

3. Dr. R. H. Bourke, Code 58Bf

Department of 0 ceanography

Naval Postgraduate School

Monterey, CA 93940

4. Department of Oceanography, Code 58

Naval Postgraduate School

Monterey, CA 93940

5. Oceanographer of the Navy

Hoffman Bidg. No. 2

200 Stovall Street

Alexandria, VA 22332

6. Office of Naval Research

Code 480

Arlington, VA 22217

7. Dr. Robert E. Stevenson

Scientific Liaison Office, ONR

Scripps Institution of Oceanography

La Jolla, CA 92037

8. Library, Code 3330

Naval Oceanographic Office

Washington, D.C. 20373

9. SIO Library

University of California, San Diego

P.0. Box 2367

La Jolla, CA 92037

10. Department of Oceanography Library University of Washington

Seattle, WA 98105 

11. Department of Oceanography Library

Oregon State University

Corvallis, oregon 97331

12. Commanding officer

Fleet Numerical Weather Central

Monterey, CA 93940

13. Commanding officer

Environmental Prediction Research Facility

Monterey, CA 93940

14. Department of the Navy

Commander Oceanographer System Pacific

Box 1390

FPO San Francisco 96610

15. Lieutenant Larry M. Thorne, USN

Box 11

Dutton, Montana 59433

16. Dr. G. H. Jung, Code $54 \mathrm{Jg}$

Department of Oceanography

Naval Postgraduate School

Monterey, CA 93940

17. Mr. Kevin Rabe

Environmental Prediction Research Facility Naval Postgraduate School

Monterey, CA 93940

18. Lieutenant Donnel E. Hansen, USN

USS FULTON (AS11)

FPO New York 09501

19. Dr. C. E. Dorman

Department of Geology

San Diego State University

San Diego, CA 92115

20. Dr. C. Paulson

School of Oceanography

Oregon State University

Corvallis, Oregon 97331

21. Mr. G. R. Seckel

National Marine Fisheries Service Monterey, CA 93940 

No. Copies

22. Lieutenant Commander N. Camp, USN Department of Oceanography Naval Postgraduate School

Monterey, CA 93940

23. Dr. S. Tabata

Fisheries Research Board of Canada Pacific Oceanographic Group

Nanaimo, British Columbia

24. Dr. K. Kenyon

NORPAC

Scripps Institution of Oceanography

University of California

La Jolla, CA 92037

25. Dr. K. Wyrtki

University of Hawaji

Honolulu, HI 96822

26. Dr. Michael Laurs

National Marine Fisheries Service

La Jolla, CA 92037 





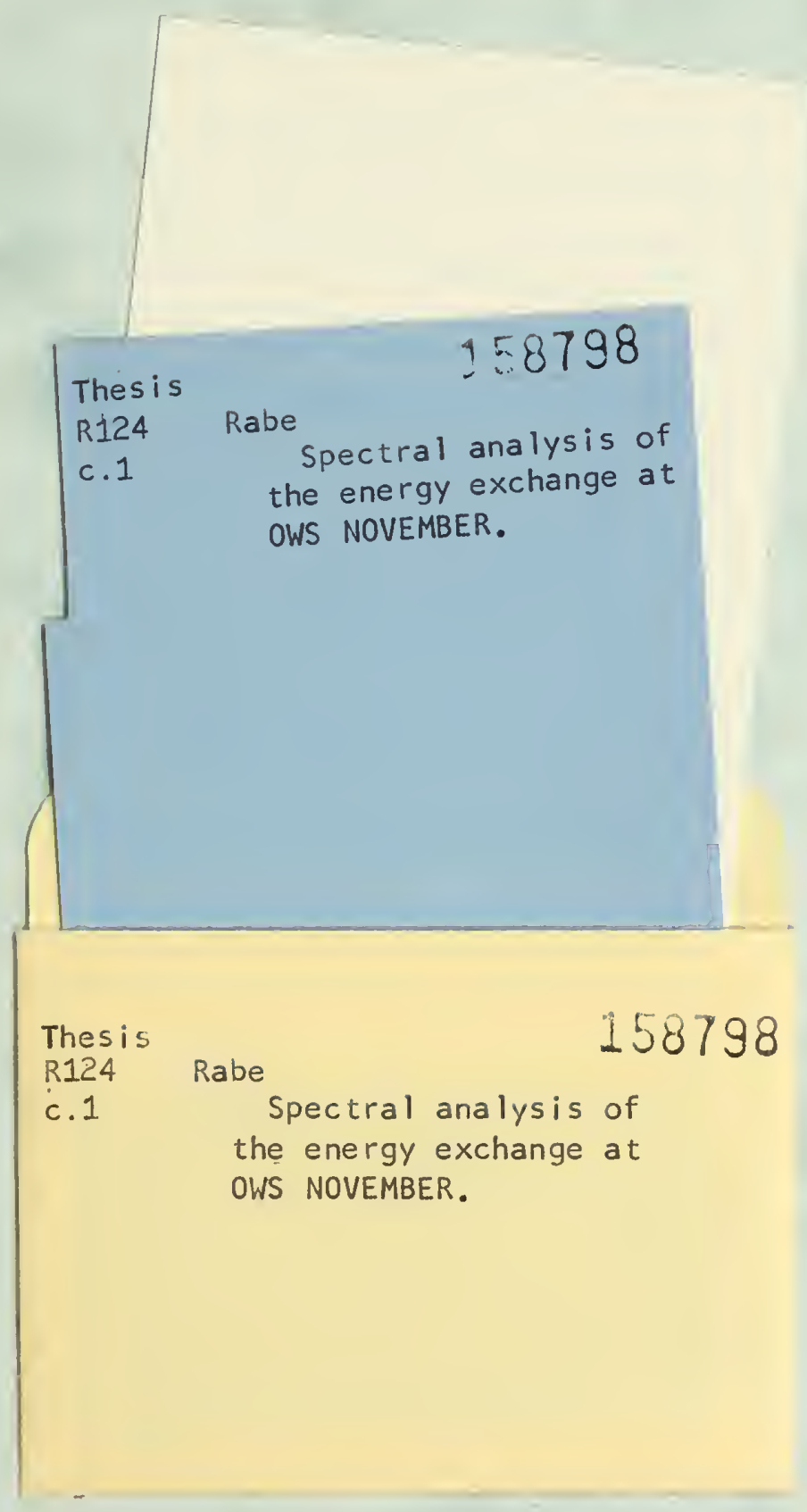




\section{thesR 124}

Spectral analysis of the energy exchange

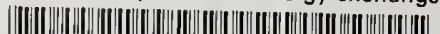



32768002052334 DUDLEY KNOX LIBRARY 